\title{
A STUDY OF THE RELATIONSHIPS OF THREE FACTORS ON ERRORS IN INSPECTION
}

R. S. Leete, Jr

W. E. Lever

April 1977

\section{UNION CARBIDE}

\section{OAK RIDGE Y-12 PLANT OAK RIDGE, TENNESSEE}

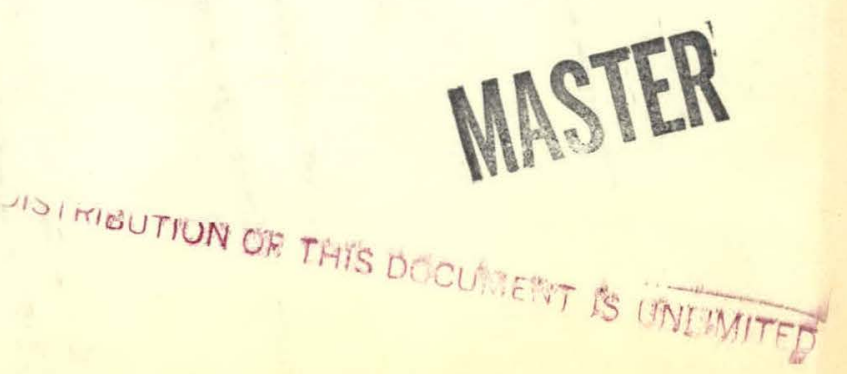




\section{DISCLAIMER}

This report was prepared as an account of work sponsored by an agency of the United States Government. Neither the United States Government nor any agency Thereof, nor any of their employees, makes any warranty, express or implied, or assumes any legal liability or responsibility for the accuracy, completeness, or usefulness of any information, apparatus, product, or process disclosed, or represents that its use would not infringe privately owned rights. Reference herein to any specific commercial product, process, or service by trade name, trademark, manufacturer, or otherwise does not necessarily constitute or imply its endorsement, recommendation, or favoring by the United States Government or any agency thereof. The views and opinions of authors expressed herein do not necessarily state or reflect those of the United States Government or any agency thereof. 


\section{DISCLAIMER}

Portions of this document may be illegible in electronic image products. Images are produced from the best available original document. 
This report was prepared as an account of work sponsored by the United States Government. Neither the United States nor the Energy Research and Development Administration, nor any of their employees, nor any of their contractors, subcontractors, or their employees, makes any warranty, express or implied, or assumes any legal liability or responsibility for the accuracy, completeness or usefulness of any information, apparatus, product or process disclosed, or represents that its use would not infringe privately owned rights.

Printed in the United States of America. Available from National Technical Information Service

U.S. Depdr Lment of Commerce

5285 Pur L Ruyd Ruad, Springfleld, Virginia 22161

Price: Printed Copy $\$ 5.00$; Microfiche $\$ 3.00$ 
Date of Issue: April 21, 1977

Report Number: Y-2075

Distribution Category: UC-32

\title{
A STUDY OF THE RELATIONSHIPS OF THREE FACTORS ON ERRORS IN INSPECTION
}

\author{
R. S. Leete, Jr \\ W. E. Lever
}

Statistical Services Department

Y-12 Technical Division

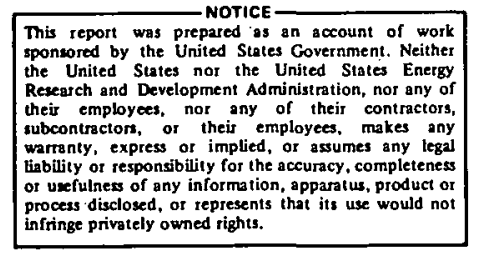

Oak Ridge Y-12 Plant

P. O. Box Y, Oak Ridge, Tennessee 37830

Prepared for the US Energy Research and Development Administration

Under US Government Contract W-7405-eng-26

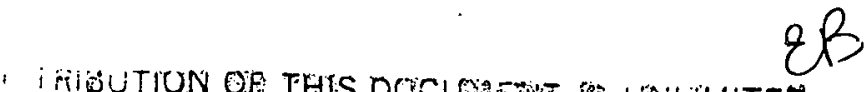

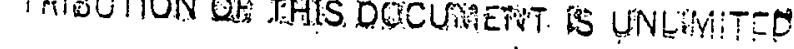




\begin{abstract}
A study was pertormed to show the relationships of three factors on the two errors that can be made in deciding whether a feature is in tolerance. Graphs and tables show the likelihood of inspection errors for many combinations of feature tolerance, processing capability, and measuring capability. Examples of applications have been included.
\end{abstract}


CONTENTS

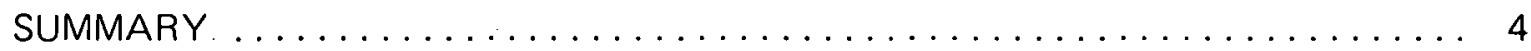

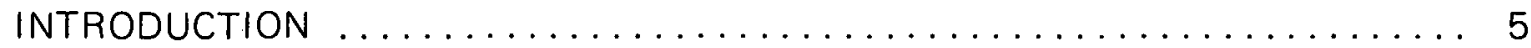

RELATIONSHIPS OF THREE FACTORS ON INSPECTION ERRORS $\ldots \ldots \ldots \ldots 7$

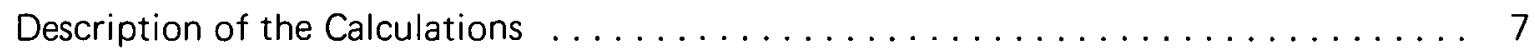

Definitions and Assumptions ............................ 7

Remarks .................................... 8

Example .................................. 8

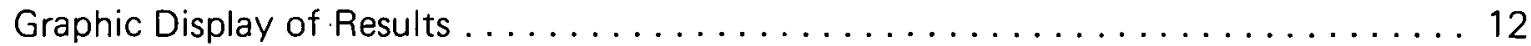

Tables............................................ 12

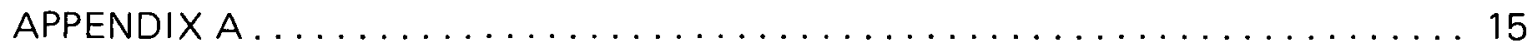

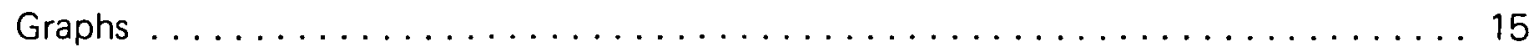

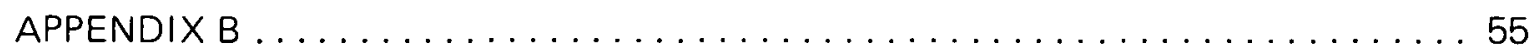

Tabular Information .................................... 55

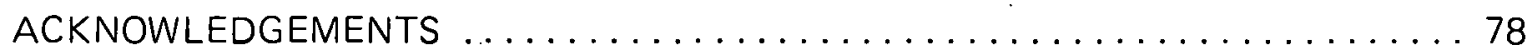




\section{SUMMARY}

Gaging errors can occur in any process of fabrication and inspection of product. There are two types of errors: (1) accepting product that should be rejected, and (2) rejecting product that should be accepted. Costs of these errors depend on how frequently they occur. The frequency of these errors (ie, their probability of occurring) is a function of three factors: (1) specification limits (tolerance) of the feature being processed, (2) variability of the fabrication process, and (3) variability of the inspection process.

With some basic assumptions, this report shows the likelihood of each type of gaging error for many combinations of these three factors. Thus, for example, with knnwlerige of the tolerance for a feature and an estimate of the variation of the fabricating process, a gage designer can objectively assess how critical his gaging repeatability is in terms of errors of inspection. "This assessment should prove more cost effective than any rule of thumb such as "gaging repeatability should be $10 \%$ of the feature tolerance". 


\section{INTRODUCTION}

Inspection is largely a decision-making process. The inspector measures a feature and decides whether the feature is in tolerance. Consider a process that is operating such that $95 \%$ of the features are truly in tolerance and $5 \%$ are truly out of tolerance. This situation might be represented in this manner:

\begin{tabular}{|c|c|c|c|}
\hline Inspector's & \multicolumn{2}{|c|}{ True Condition of Feature } & \multirow[b]{2}{*}{ Total } \\
\hline Decision & In Tolerance & Out of Tolerance & \\
\hline Accept & 0.95 & 0 & 0.95 \\
\hline Reject & 0 & 0.05 & 0.05 \\
\hline Total & 0.95 & 0.05 & 1.00 \\
\hline
\end{tabular}

This, of course, is the ideal situation. In this case, the inspector always makes the right decision. A more realistic situation might be this:

Inspector's

Decision

Accept

Reject

Total
True Condition of Feature

\begin{tabular}{lcc}
\hline In Tolerance & Out of Tolerance & Total \\
\cline { 2 - 2 } 0.92 & 0.01 & 0.93 \\
$\frac{0.03}{0.95}$ & $\frac{0.04}{0.05}$ & $\frac{0.07}{1.00}$
\end{tabular}

This time, errors are made. Here, $1 \%$ of the time the inspector accepts a part that is out of tolerance, and $3 \%$ of the time the inspector rejects a part that is in tolerance.

How realistic is this situation? How likely are these errors? Intuitively, the likelihood of these errors depends on three factors:

1. The specification limits (tolerance) of the feature being processed. As these limits get wider, fewer errors are made since features have lessening chances of being either bad or rejected.

2. Variability of the fabrication process. As this variability is reduced, the effect is the same as when tolerance limits get wider.

3. Variability of the inspection process. As this variability is reduced, the inspector can more reliably separale youd product fiom bad. 
This study, conducted at the Oak Ridge Y-12 Plant, (a) shows the likelihood of each type of gaging error for many combinations of these three factors. Graphs and tables display the two probabilities of interest:

The probability that a feature is out of tolerance and accepted.

The probability that a feature is in tolerance and rejected.

Knowledge of these probabilities allows objective assessments of how critical gaging repeatability is in terms of errors of inspection.

(a) Operated by the Union Carbide Corporation's Nuclear Division for the US Energy Research and Development Administration. 


\section{RELATIONSHIPS OF THREE FACTORS ON INSPECTION ERRORS}

\section{DESCRIPTION OF THE CALCULATIONS}

\section{Definitions and Assumptions}

\section{Fabrication Process -}

1. Fabricated features follow a normal (bell-shaped) distribution.

2. The long-term average of the features is split tolerance.

3. The variability is expressed in terms of $\pm K$, where $K=2$ times the standard deviation of the fabrication process. This value expresses the fabrication repeatability over time, giving limits expected to be met about $95 \%$ of the time. It is referred to in the graphs and tables as the "process capability".

\section{Gaging Process -}

1. Repeated measurements of the same feature follow a normal distribution.

2. The long-term average of these ineasurements is the true (but unknown) value of the feature being measured.

3. The variability is expressed in terms of $\pm M$, where $M=2$ times the standard deviation of the measurement process. This value expresses the measurement repeatability over time, giving limits within which repeated measurements should fall about $95 \%$ of the time. It is referred to in the graphs and tables as the "measurement capability".

Tolerances - Feature tolerances are bilateral. They are of the form $\pm T$, where $T$ is the allowable departure from "split tolerance", the nominal value of the feature.

\section{Cautions about Assumptions -}

1. In practice, the assumption of normal distributions is generally sound. The most common distributions that are not normal arise generally on features not bilaterally toleranced. Examples would be: flatness, straightness, perpendicularity, or, in general, tolerances on variability. Also included are true-position tolerances of location.

Hole-diameter features are one known example of bilaterally toleranced features that may not be normally distributed. Drilled-hole diameters often tend to have skewed populations since many factors could make the hole larger than the drilling tool diameter; but few, if any, smaller. Knowledge of the processes involved can temper the usefulness of this study. 
2. Estimates of fabrication process variability may not be obviously available. In practice, the usual process estimates come from measurements of product, but these measurements include variability of the inspection process. It is usually necessary to take repeated measurements of fabricated product to determine estimates of fabricating variability.

\section{Remarks}

In general, both types of gaging errors have controls to some extent, although the controls have associated costs. Production areas may elect to have product reinspected where it is believed that inspection errors have occurred. Both the $Y-12$ reinspection program and the ERDA verification inspection program provide additional protection against out-oftolerance features being incorrectly accepted.

\section{Example}

Suppose a diameter requirement is shown on a drawing as \pm 1.2 mils. The feature must be certified from the average of eight equally spaced measurements. The machining area feels confident that $95 \%$ of the parts it produces will have a diameter that meets \pm 0.9 m।l. How critical is gaging repeatability in terms of inspection errors?

Gage A could be used to check this feature. Gage B is also a candidate. Studies have shown that an inspector can use Gage $A$ with a repeatability (95\% confidence) of \pm 0.4 mil, but Gage $B$ can be used with a repeatability of \pm 0.6 mil. To compare these gages, either graphs or tables could be used, but tables are recommended since no interpolation is necessary. The situation described here can be found in Table 1.

The tables are constructed so that tigures of interest can be easily displayed in a small table. Considering first Gage $A$, the probabilities are tabulated as follows:

\begin{tabular}{|c|c|c|c|}
\hline & Gage A Su & & \\
\hline & True Co & n of Fearure & \\
\hline $\begin{array}{l}\text { Inspector's } \\
\text { Decisivili }\end{array}$ & $\begin{array}{c}\text { in Tolerance } \\
\text { (good) }\end{array}$ & $\begin{array}{c}\text { Out of Tolerance } \\
\text { (bad) }\end{array}$ & Total \\
\hline Acrept & 0.9830 & 0.0022 & 0.9852 \\
\hline Reject & 0.0093 & 0.0055 & 0.0148 \\
\hline Total & $0.99^{\prime} 23$ & $0.00 / 1$ & 1.0000 \\
\hline
\end{tabular}

A similar table is constructed for Gage B: 
Table 1

INSPECTION DECISION PROBABILITIES

\begin{tabular}{|c|c|c|c|c|c|c|c|}
\hline & & & & & sposition & the Produ & \\
\hline & & & ability & & & & \\
\hline & Tolerance & Process & Measurement & Good & Bad & Good & Bad \\
\hline & 1.2 & 0.7 & 0.35 & 0.9976 & 0.0002 & 0.0018 & 0.0004 \\
\hline & 1.2 & 0.7 & 0.40 & 0.9969 & 0.0002 & 0.0025 & 0.0004 \\
\hline & 1.2 & 0.7 & 0.45 & 0.9959 & 0.0002 & 0.0035 & 0.0004 \\
\hline & 1.2 & 0.7 & 0.50 & 0.9945 & 0.0002 & 0.0049 & 0.0004 \\
\hline & 1.2 & 0.7 & 0.55 & 0.9928 & 0.0002 & 0.0066 & 0.0004 \\
\hline & 1.2 & 0.7 & 0.60 & 0.9905 & 0.0002 & 0.0089 & 0.0004 \\
\hline & 1.2 & 0.7 & 0.65 & 0.9878 & 0.0002 & 0.0116 & 0.0004 \\
\hline & 1.2 & 0.7 & 0.70 & 0.9844 & 0.0002 & 0.0150 & 0.0004 \\
\hline & 1.2 & 0.8 & 0.05 & 0.9971 & 0.0002 & 0.0002 & 0.0025 \\
\hline & 1.2 & 0.8 & 0.10 & 0.9967 & 0.0004 & 0.0006 & 0.0023 \\
\hline & 1.2 & 0.8 & 0.15 & 0.9963 & 0.0005 & 0.0010 & 0.0022 \\
\hline & 1.2 & 0.8 & 0.20 & 0.9958 & 0.0006 & 0.0015 & 0.0021 \\
\hline & 1.2 & 0.8 & 0.25 & 0.9951 & 0.0007 & 0.0022 & 0.0020 \\
\hline i & 1.2 & 0.8 & 0.30 & 0.9943 & 0.0007 & 0.0030 & 0.0020 \\
\hline & 1.2 & 0.8 & 0.35 & 0.9932 & 0.0008 & 0.0041 & 0.0019 \\
\hline & 1.2 & 0.8 & 0.40 & 0.9919 & 0.0008 & 0.0054 & 0.0019 \\
\hline & 1.2 & 0.8 & 0.45 & 0.9902 & 0.0009 & 0.0071 & 0.0018 \\
\hline & 1.2 & 0.8 & 0.50 & 0.9881 & 0.0009 & 0.0092 & 0.0018 \\
\hline & 1.2 & 0.8 & 0.55 & 0.9856 & 0.0010 & 0.0117 & 0.0017 \\
\hline & 1.2 & 0.8 & 0.60 & 0.9826 & 0.0010 & 0.0147 & 0.0017 \\
\hline & 1.2 & 0.8 & 0.65 & 0.9791 & 0.0010 & 0.0182 & 0.0017 \\
\hline & 1.2 & 0.8 & 0.70 & 0.9750 & 0.0010 & 0.0223 & 0.0017 \\
\hline & 1.2 & 0.9 & 0.05 & 0.9918 & 0.0005 & 0.0006 & 0.0072 \\
\hline & 1.2 & 0.9 & 0.10 & 0.9911 & 0.0008 & 0.0012 & 0.0068 \\
\hline & 1.2 & 0.9 & 0.15 & 0.9903 & 0.0012 & 0.0020 & 0.0065 \\
\hline & 1.2 & 0.9 & 0.20 & 0.9893 & 0.0014 & 0.0030 & 0.0062 \\
\hline & 1.2 & 0.9 & 0.25 & 0.9881 & 0.0017 & 0.0042 & 0.0060 \\
\hline & 1.2 & 0.9 & 0.30 & 0.9867 & 0.0019 & 0.0056 & 0.0058 \\
\hline & 1.2 & 0.9 & 0.35 & 0.9850 & 0.0020 & 0.0073 & 0.0056 \\
\hline Gage A - & $\rightarrow 1.2$ & 0.9 & 0.40 & 0.9830 & 0.0022 & 0.0093 & 0.0055 \\
\hline & 1.2 & 0.9 & 0.45 & 0.9806 & 0.0023 & 0.0117 & 0.0054 \\
\hline & 1.2 & 0.9 & 0.50 & 0.9778 & 0.0024 & 0.0145 & 0.0052 \\
\hline & 1.2 & 0.8 & 0.55 & 0.9746 & 0.0025 & 0.0177 & 0.0052 \\
\hline Gage B - & $\rightarrow 1.2$ & 0.9 & 0.60 & 0.9709 & 0.0026 & 0.0214 & 0.0051 \\
\hline & 1.2 & 0.9 & 0.65 & 0.9667 & 0.0027 & 0.0256 & 0.0050 \\
\hline & 1.2 & 0.9 & 0.70 & 0.9620 & 0.0027 & 0.0304 & 0.0049 \\
\hline & 1.2 & 1.0 & 0.05 & 0.9826 & 0.0008 & 0.0010 & 0.0156 \\
\hline & 1.2 & 1.0 & 0.10 & 0.9815 & 0.0015 & 0.0021 & 0.0149 \\
\hline & 1.2 & 1.0 & 0.15 & 0.9802 & 0.0022 & 0.0034 & 0.0142 \\
\hline & 1.2 & 1.0 & 0.20 & 0.9787 & 0.0027 & 0.0049 & 0.0137 \\
\hline & 1.2 & 1.0 & $0.2 b$ & $0 . y / 6 y$ & 0.0032 & 0.0067 & U. Uं132 \\
\hline & 1.2 & 1.0 & 0.30 & 0.9749 & 0.0036 & 0.0087 & 0.0128 \\
\hline & 1.2 & 1.0 & 0.35 & 0.9726 & 0.0039 & 0.0110 & 0.0125 \\
\hline & 1.2 & 1.0 & 0.40 & 0.9699 & 0.0042 & 0.0137 & 0.0122 \\
\hline & 1.2 & 1.0 & 0.45 & 0.9669 & 0.0045 & 0.0167 & 0.0119 \\
\hline & 1.2 & 1.0 & 0.50 & 0.9634 & 0.0048 & 0.0202 & 0.0116 \\
\hline & 1.2 & 1.0 & 0.55 & 0.9596 & 0.0050 & 0.0241 & 0.0114 \\
\hline & 1.2 & 1.0 & 0.60 & 0.9552 & 0.0052 & 0.0284 & 0.0112 \\
\hline & 1.2 & 1.0 & 0.65 & 0.9505 & 0.0053 & 0.0331 & 0.0111 \\
\hline & $i .2$ & 1.0 & 0.70 & 0.9452 & 0.0055 & 0.0384 & 0.0109 \\
\hline
\end{tabular}




\section{Gage B Summary}

\begin{tabular}{c} 
Inspector's \\
Decision \\
\hline
\end{tabular}

Accept

Reject

Total

\section{True Condition of Fealure}

\begin{tabular}{ccc}
$\begin{array}{c}\text { In Tolerance } \\
\text { (good) }\end{array}$ & $\begin{array}{c}\text { Out of Tolerance } \\
\text { (bad) }\end{array}$ & Total \\
\cline { 2 - 2 } 0.9709 & 0.0026 & 0.9735 \\
$\frac{0.0214}{0.9923}$ & $\underline{0.0051}$ & \\
0.0077 & & 1.00265 \\
\hline
\end{tabular}

Which gage should be used? Gross differences do not seem to be in the two tables; hnwever. with tables and cost figures, an economic decision can be made.

Suppose these figures are available:

For the gages:

$\begin{array}{lrrr} & \text { Gage A } & \text { Fage R } \\ \text { Initial Cost (\$) } & 1000 & 400 \\ \text { Time Required to Gage a Featurc (min) } & 10 & 8 \\ \text { Number of Gages Required } & 3 & 3\end{array}$

Other information:

$\begin{array}{lr}\text { Cost of Reworking a Rejected Viameter }(\$) & 20 \\ \text { Cost of Deviation for a Rejecled Diamotor }(\$) & 50 \\ \text { Cost of Accepting an Out-of-Tolerance Diameter }(\$) & 200 \\ \text { Cost of Inspection }(\$ / h r) & 10 \\ \text { Number of Parts Required } & 1000\end{array}$

The probabilities and costs can be used in a cost analysis. Specific costs can be estimated and the total cost of using the gages can be studied. Consider four cost components: (1) purchasing the required gages, (2) inspecting the production requirement, (3) resolving the rejected features that are in tolerance, and (4) accepting features that are out of tolerance.

Probabilities are used to estimate the last two components. Consider Gage A for example. Suppose that half the diameters rejected are reworked and the other half are deviated. The summary table for Gage A shows that the probability of an incorrect rejection is 0.0093 . So, in a run of 1000 parts, an expected 9.3 good parts should be rejected. Half of the parts are reworked and the other half deviated. The associated costs are: 
$\begin{array}{lr}\text { Cost of Rework }=[0.5 \times 9.3] \text { at } \$ 20 / \text { part }(\$) & 93 \\ \text { Cost of Deviation }=[0.5 \times 9.3] \text { at } \$ 50 / \text { part }(\$) & \frac{232}{325}\end{array}$

Similarly, for the cost of accepting features that are out of tolerance, the table shows that the probability of an incorrect acceptance is 0.0022 . So, in a run of 1000 parts, an expected 2.2 parts should be incorrectly accepted, with an associated cost of $\$ 200$ each, for an expected cost of $\$ 440$.

A comparable study for Gage B would lead to the following results:

\begin{tabular}{lrr} 
& \multicolumn{2}{c}{ Cost Analysis } \\
& Gage A & Gage B \\
Purchasing the Three Gages & $\$ 3000$ & $\$ 1200$ \\
Inspecting 1000 Parts, at \$10/hr & 1667 & 1333 \\
Resolving Erroneous Rejects & 325 & 749 \\
Accepting Out-of-Tolerance Features & 440 & 520 \\
Total & $\mathbb{\$ 5 4 3 2}$ & $\$ 3802$
\end{tabular}

In this case, Gage B is more economical.

It may not always be the case that a gage with worse repeatability is more economical. In some cases, the cost of accepting a bad feature might be tremendously expensive; in others, this cost may be unknown. Suppose that was the case for the previous example:

Let $\mathrm{C}$ be that cost of accepting a had feature which makes the total cost of the two gages identical. Then from the cost table:

$$
\$ 3000+\$ 1667+\$ 325+[2.2 \text { parts at } C]=\$ 1200+\$ 1333+\$ 749+[2.6 \text { parts at } C] \text {. }
$$

Solving:

$$
\begin{aligned}
2: 2 \mathrm{C}+\$ 4992 & =2.6 \mathrm{C}+\$ 3282, \text { or } \\
0.4 \mathrm{C} & =\$ 1710, \text { or } \\
\mathrm{C} & =\$ 4275 .
\end{aligned}
$$

Gage $B$ is more economical as long as the cost of accepting a bad feature is less than $\$ 4275$. At that cost, the two gages are equally cost effective; beyond that figure, Gage $A$ is the ecorioritical choice.

Thus, where practical, these probabilities can give the inspection engineer or gage designer a basis for making a reasonable decisiun concerning gage selection. 


\section{GRAPHIC DISPLAY OF RESULTS}

A series of graphs (Appendix A) display the calculations of this study. The ranges of values covered in these graphs are:

Tolerance
Process Capability
Measurement Capability

from \pm 0.2 to \pm 2.0 in steps of 0.1
from \pm 0.2 to \pm 2.0 in steps of 0.1
from \pm 0.05 to \pm 0.70 in steps of 0.05

For each tolerance value, two graphs are presented. The first graph is concerned with good parts (relative to the one feature of interest); the second graph deals with bad part3. A description of the graphs can be summarized:

Left-Side Scale:

Right-Side Scale: (1)
Good Parts

\begin{tabular}{l} 
Good Parts \\
\hline Percent of parts produced that \\
are bolh in tolerance and \\
rejected.
\end{tabular}

Percent of parts produced that are in tolerance.
Bad Parts

Percent of parts produced that are both out of tolerance and accepted.

Percent of parts produced that are out of tolerance.

(1) Only the dashed line is read on this scale.

\section{TABLES}

Some of the musl frequently observed ranges of values are tabulated (Appendix B). The ranges of values covered in these tables are:

$\begin{array}{ll}\text { Tolerance } & \text { from } \pm 0.2 \text { to } \pm 1.5 \text { in steps of } 0.1 \\ \text { Process Capability } & \text { frnm half the Tolerance to the Tolerance }+0.5 \text { in stcps of } 0.1 \\ \text { Measurement Capability } & \text { from } \pm 0.05 \text { to } \pm 0.70 \text { in steps of } 0.05 .\end{array}$

In the example described in the next paragraph, use of the tables is illustrated. Although these tables explicitly cover only the range of values shown above, a means is provided for obtaining the probabilities for many more combinations of tolerance, process capability. and measurement capability. The last two columns of the tables show the ratio of the process capability to the tolerance and the ratio of the measurement capability to the process capability. For combinations of tolerance, process capability, and measurement capability that fall outside the range of values in the tables, these two ratios should be calculated for the specific case. Combinations that have identical ratios have identical probabilities in the body of the table. 
As an example, consider a tolerance of \pm 3.0 , a process capability of \pm 2.4 , and measurement capability of \pm 0.8 . Since these values are not tabled, two ratios are calculated:

$\frac{\text { Process Capability/Tolerance }}{0.8000} \quad \frac{\text { Measurement Capability/Process Capability }}{0.3333}$

In the tables, these ratios are identical to ratios found for a tolerance of \pm 1.5 , a process capability of \pm 1.2 , and a measurement capability of \pm 0.4 . The probabilities for the values not tabulated are identical to those for this set of values. 
THIS PAGE

\section{WAS INTENTIONALLY LEFT BLANK}


APPENDIX A

GRAPHS 
THIS PAGE

\section{WAS INTENTIONALLY \\ LEFT BLANK}




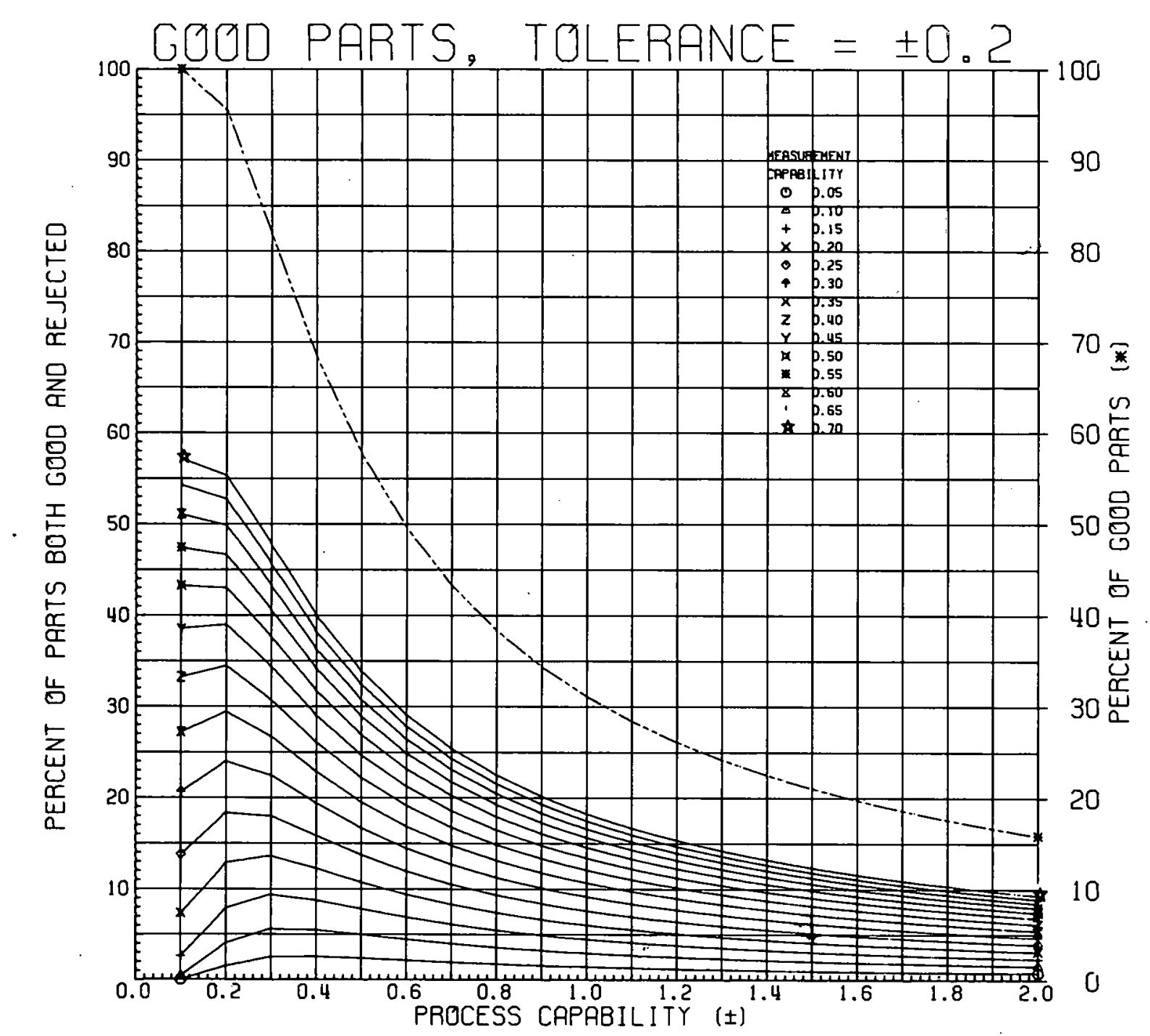

Figure A-1. GOOD PARTS. (Tolerance $= \pm 0.2$; Note: The Asterisk on the Right-Hand Scale on this and all Subsequent Graphs Indicates that only the Dashed Line is Read for these Data) 


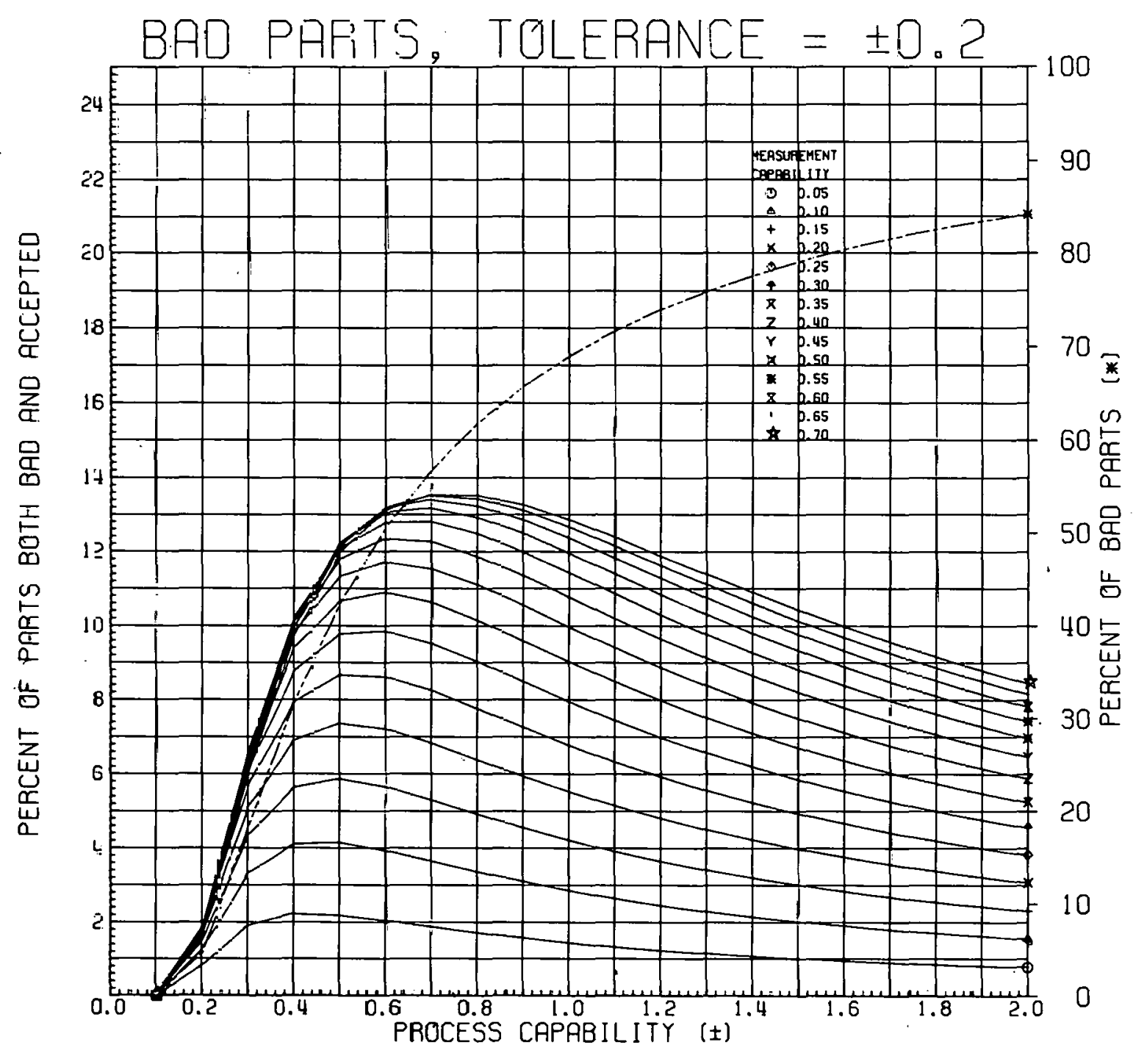

Figu $=E$ A-2. BAD PARTS. (Tolerance $=\doteq 0.2$ ) 


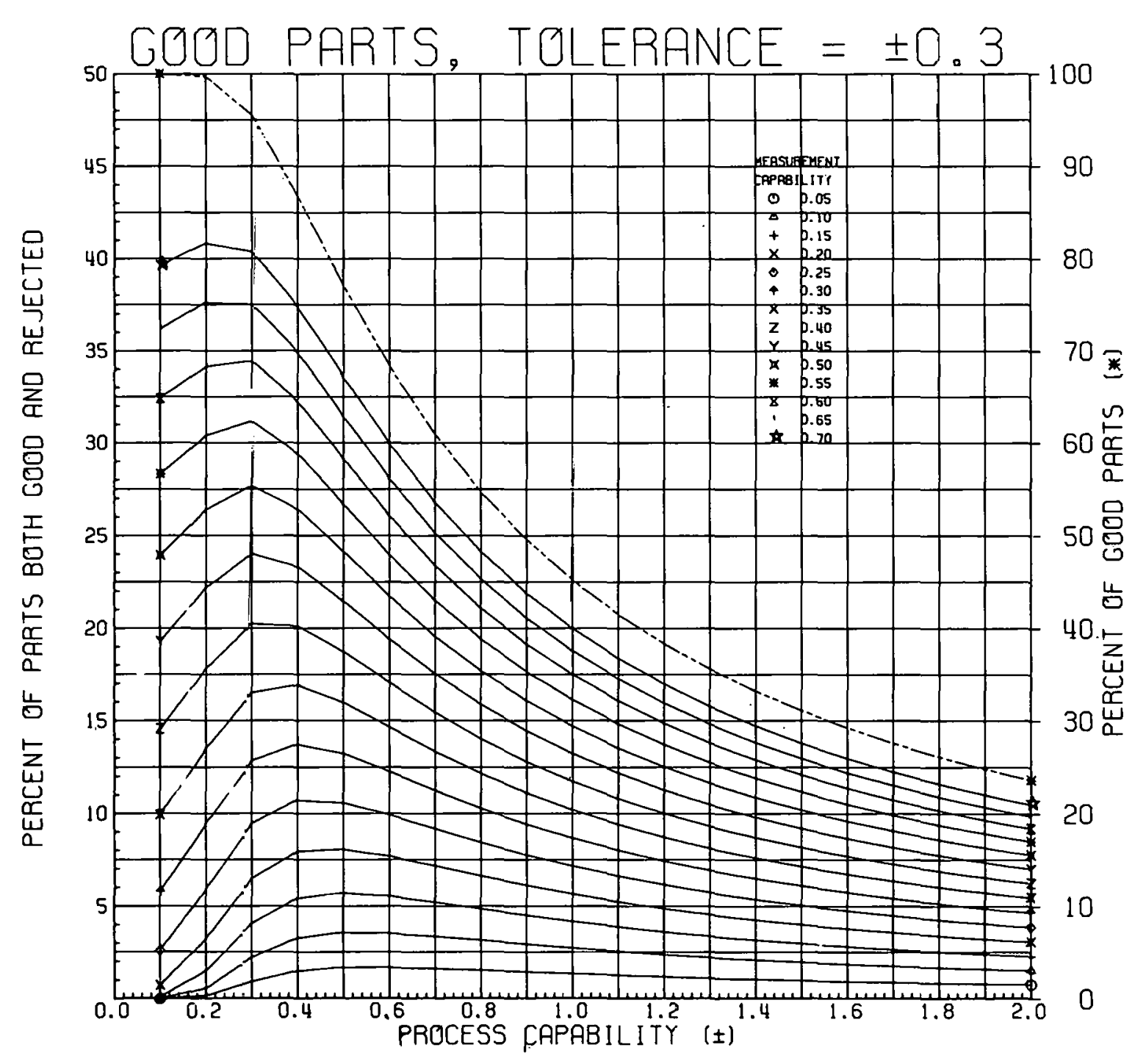

Figure A.3. GOOD PARTS. (Tolerance $= \pm 0.3$ ) 


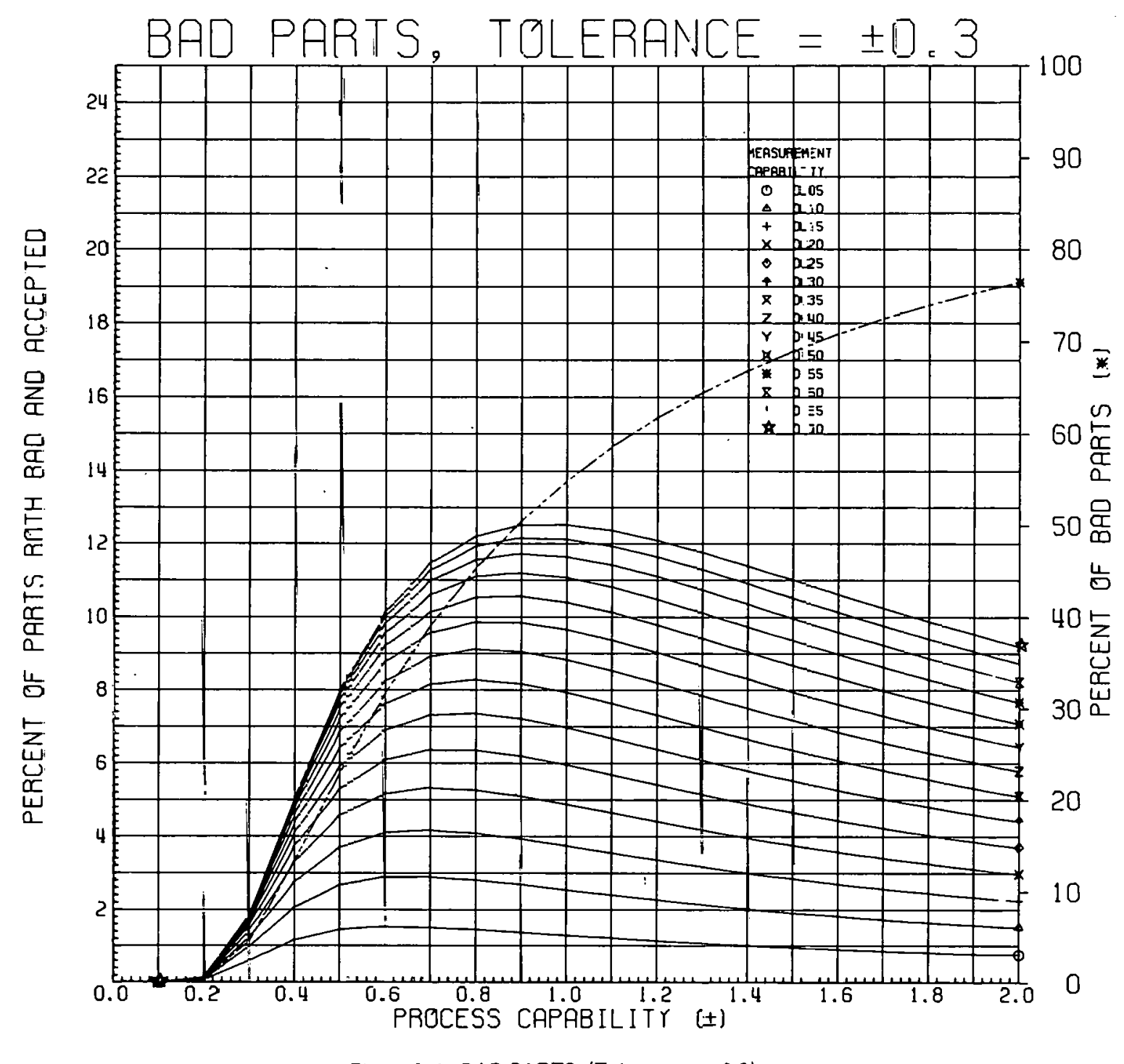

Figure 7-4. BAD PARTS. (Tolerance $= \pm 0.3)$ 


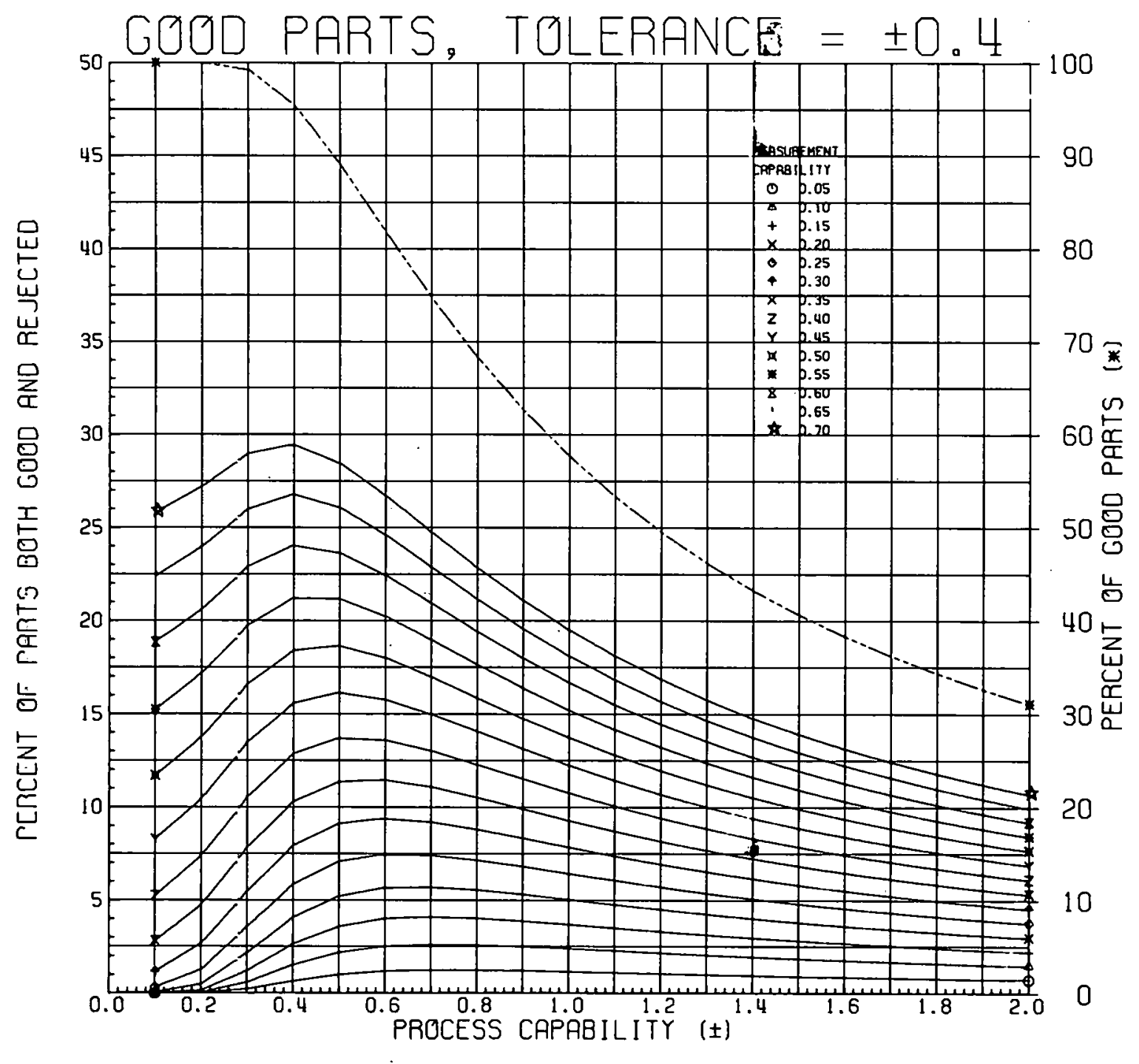

Figure A-5. GOOD PARTS. (Tolerance $= \pm 0.4$ ) 


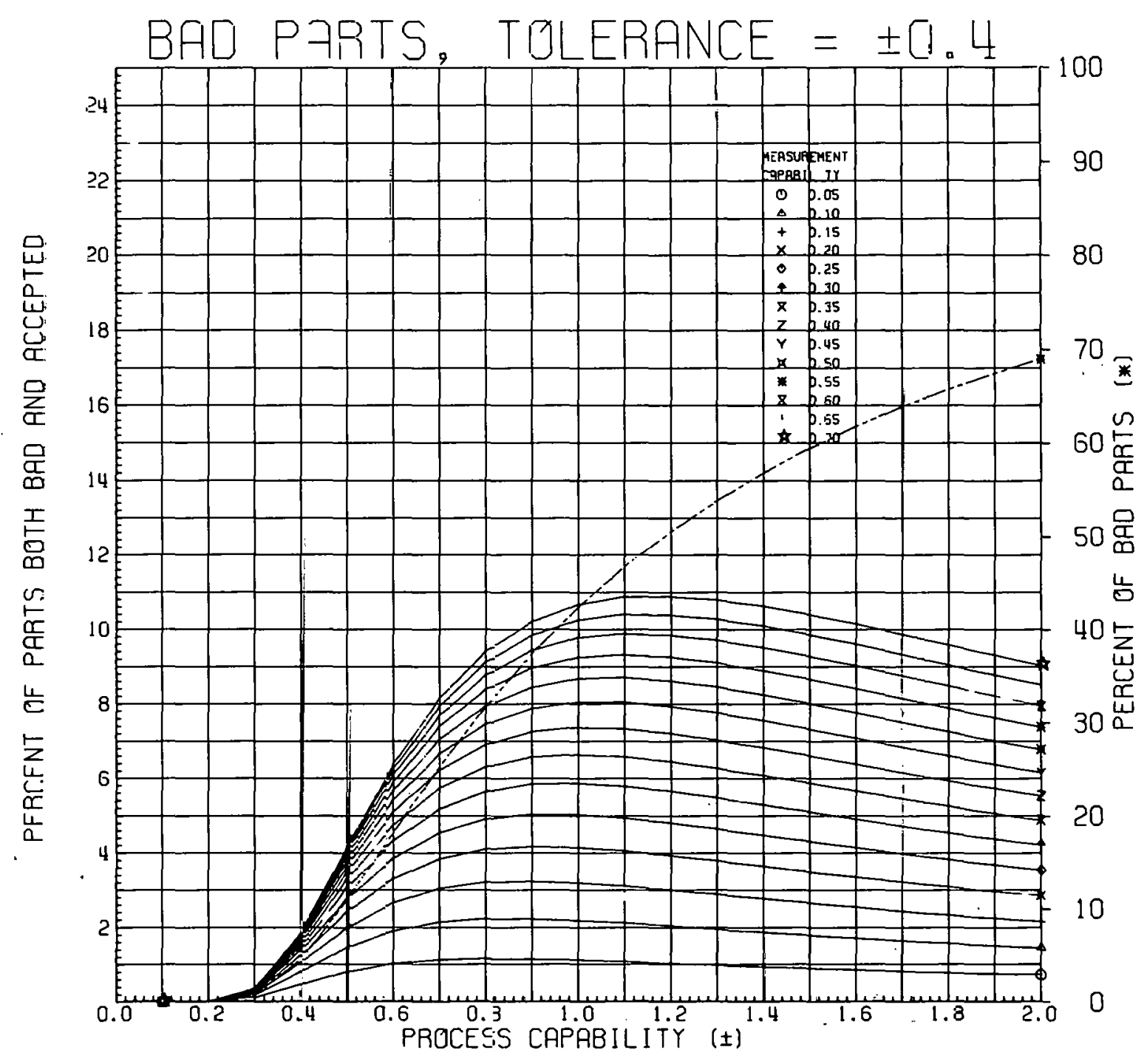

Figure A-6. BAD PARTS. (Tolerance $= \pm 0.4$ ) 


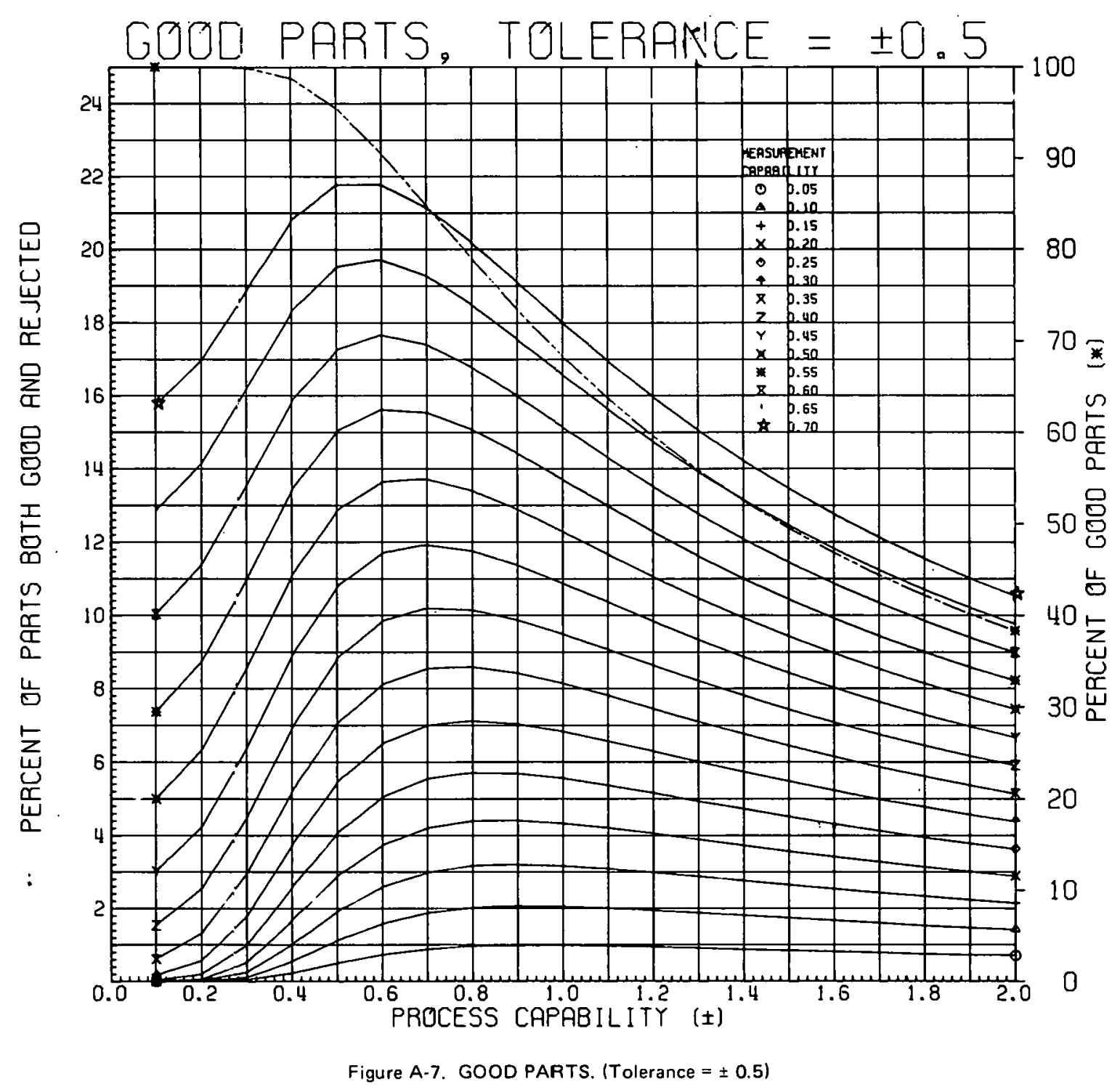




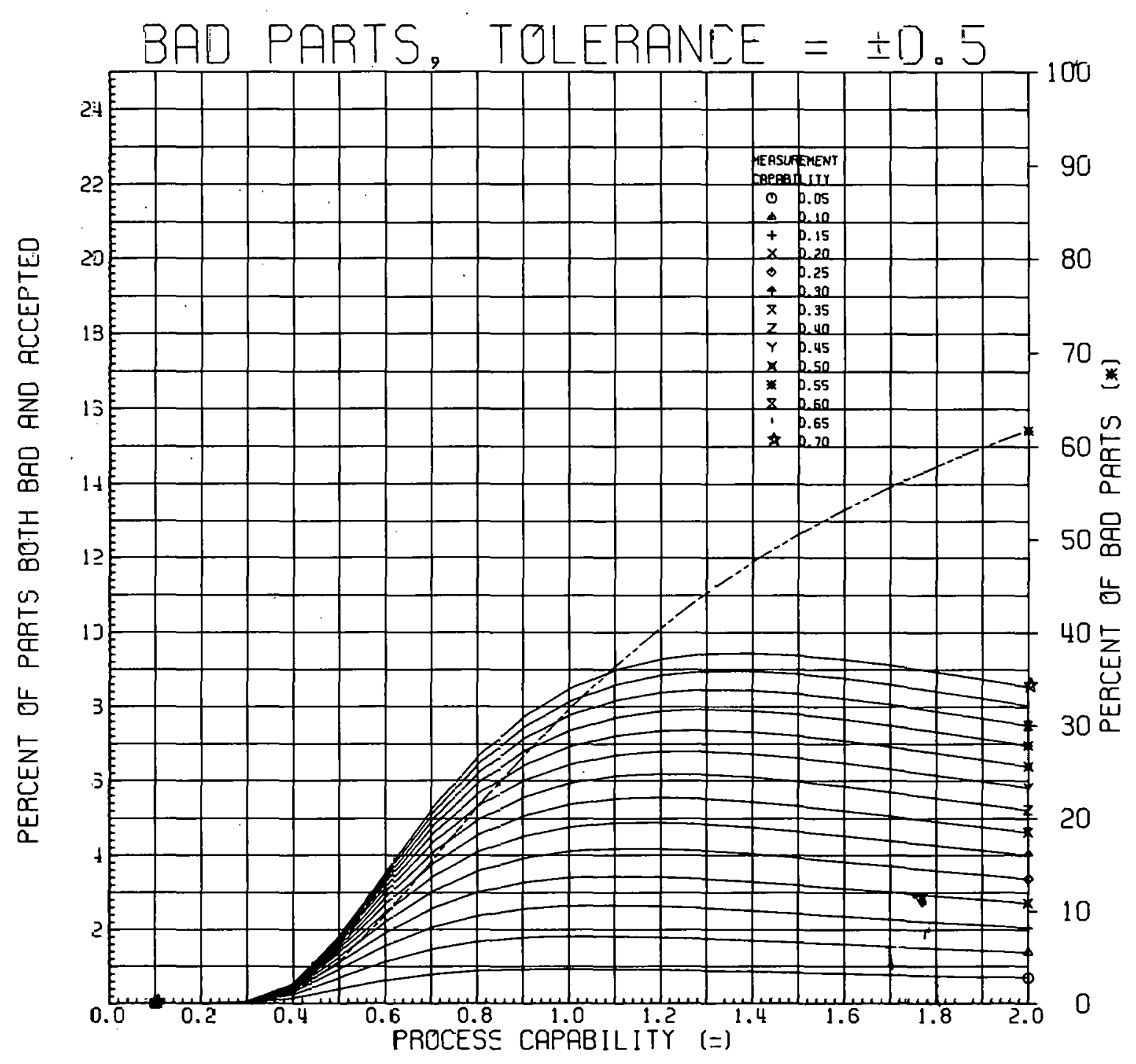

Figure A-8. BAD PARTS. (Tolerance $= \pm 0.5$ ) 


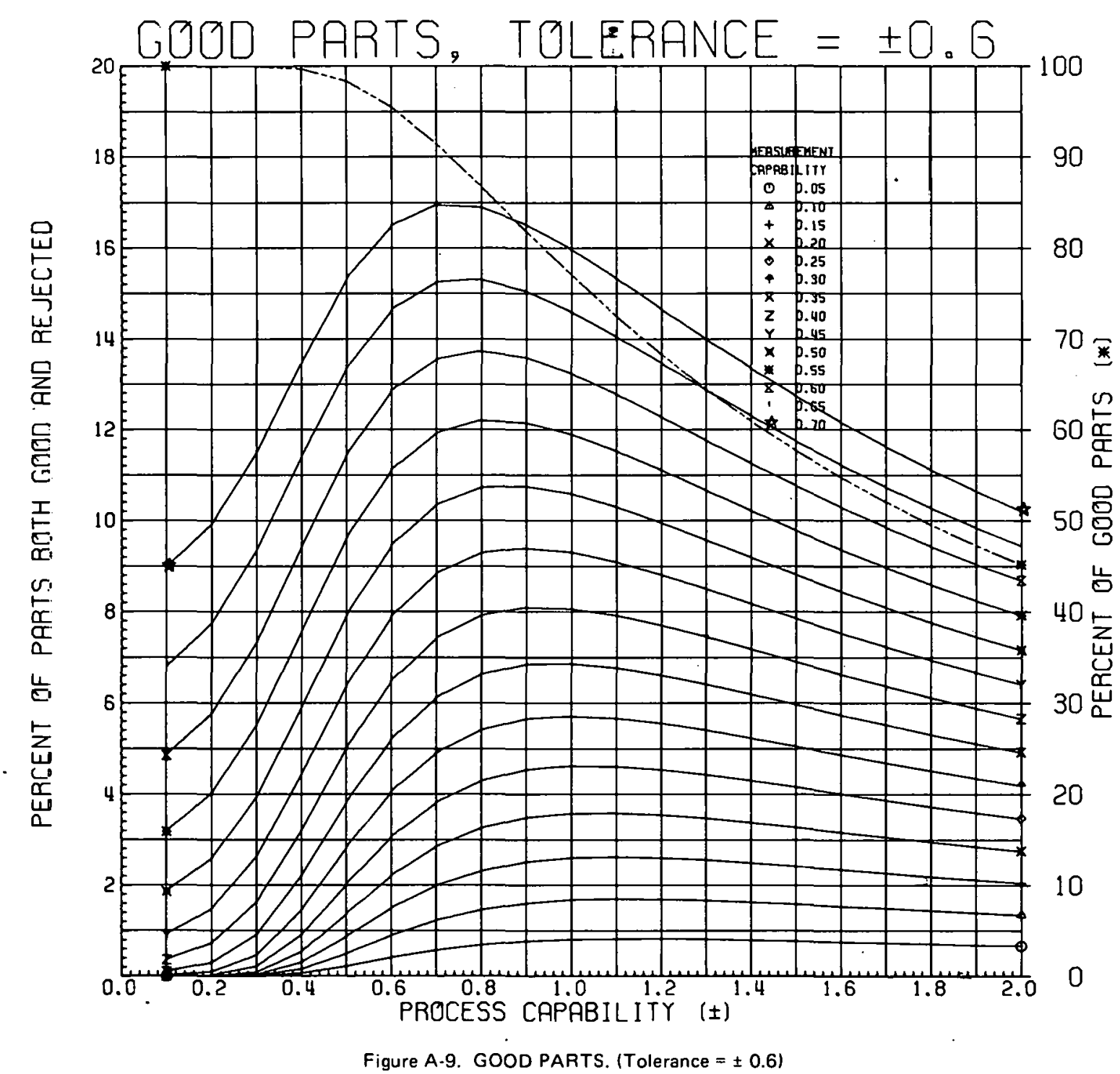




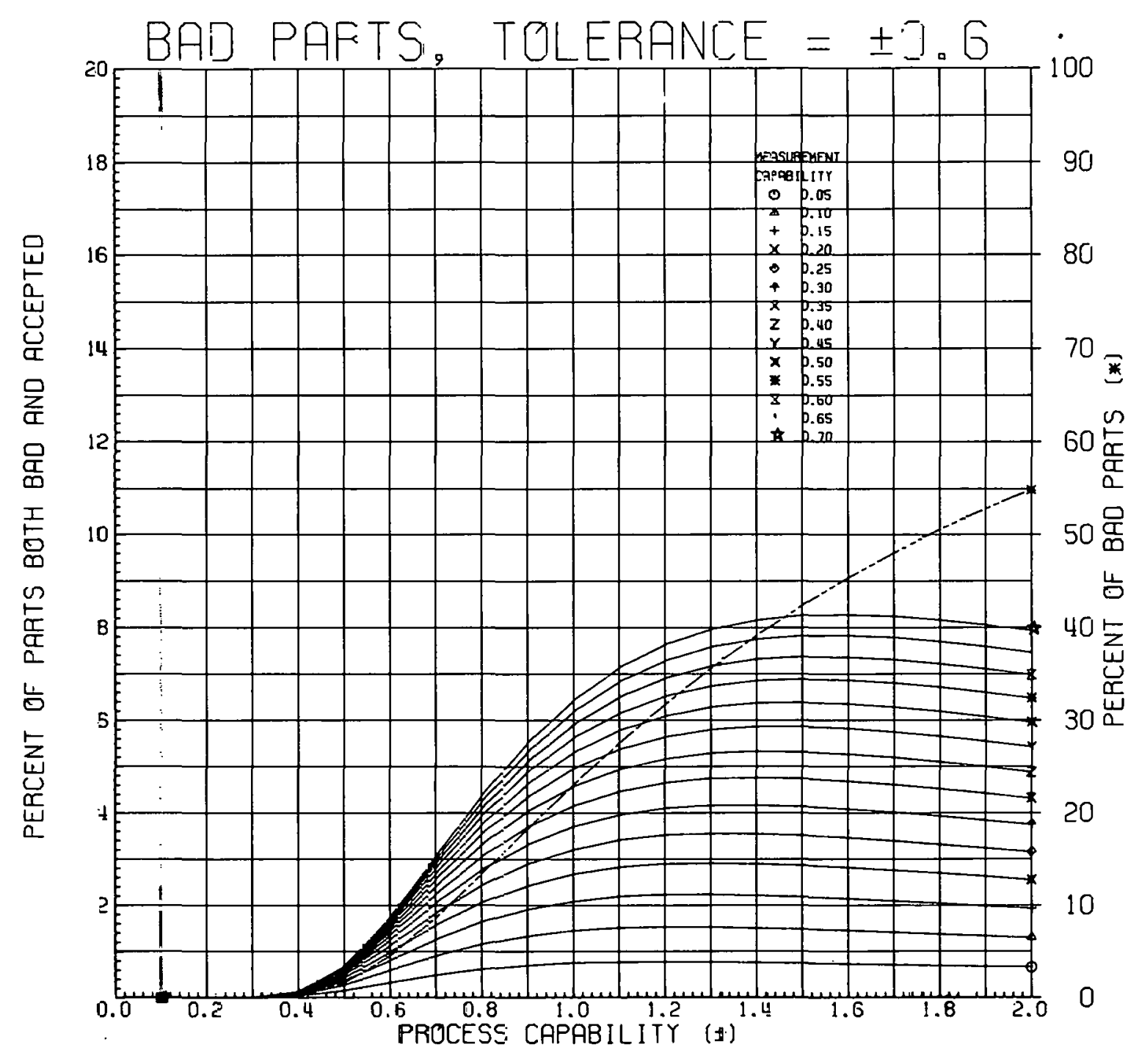

F:gure A.10. BA $)$ PARTS. (Tolerance $=:=0.6$; 


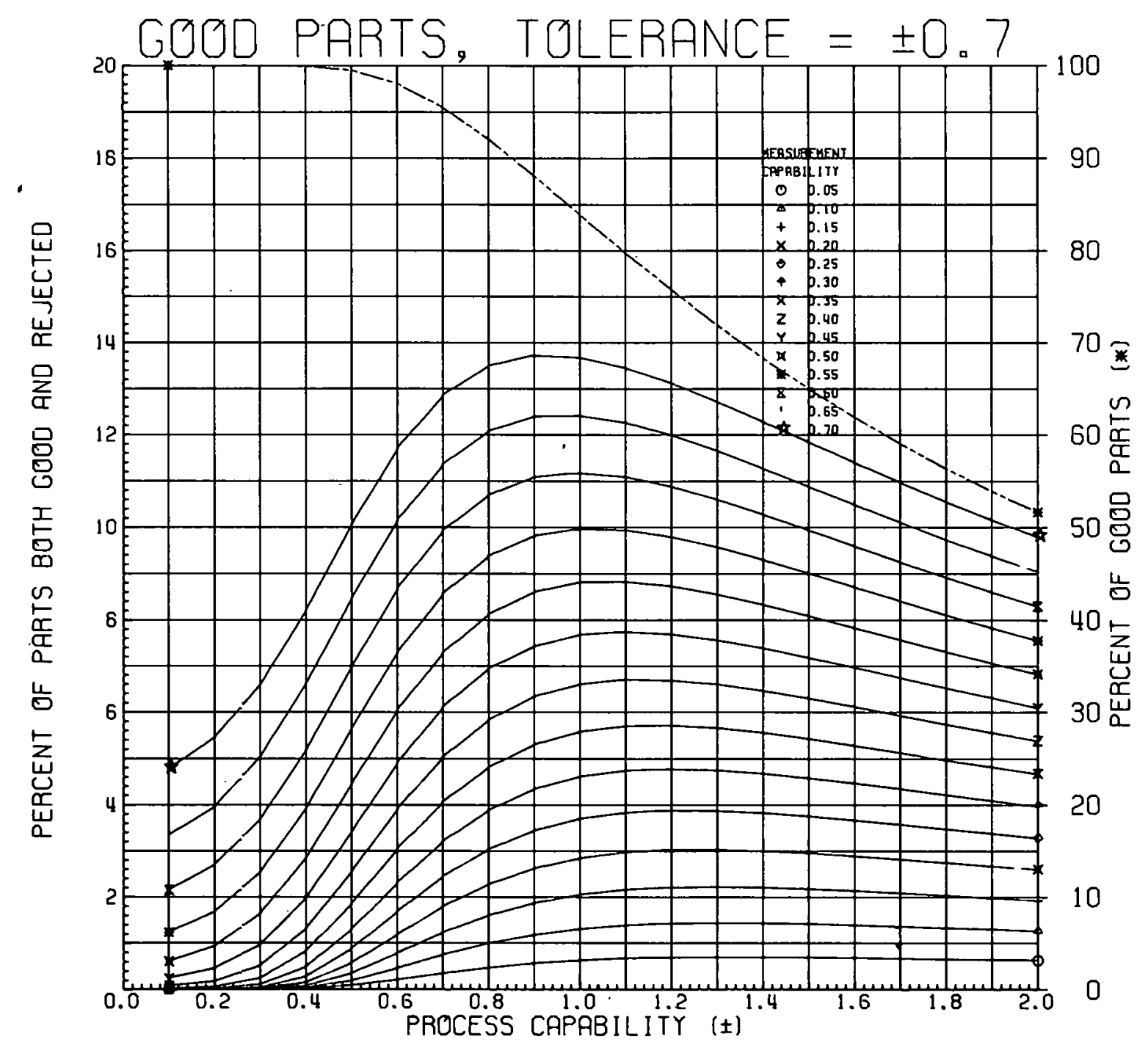

Figure A-11. GOOD PARTS. (Tolerance $= \pm 0.7$ ) 


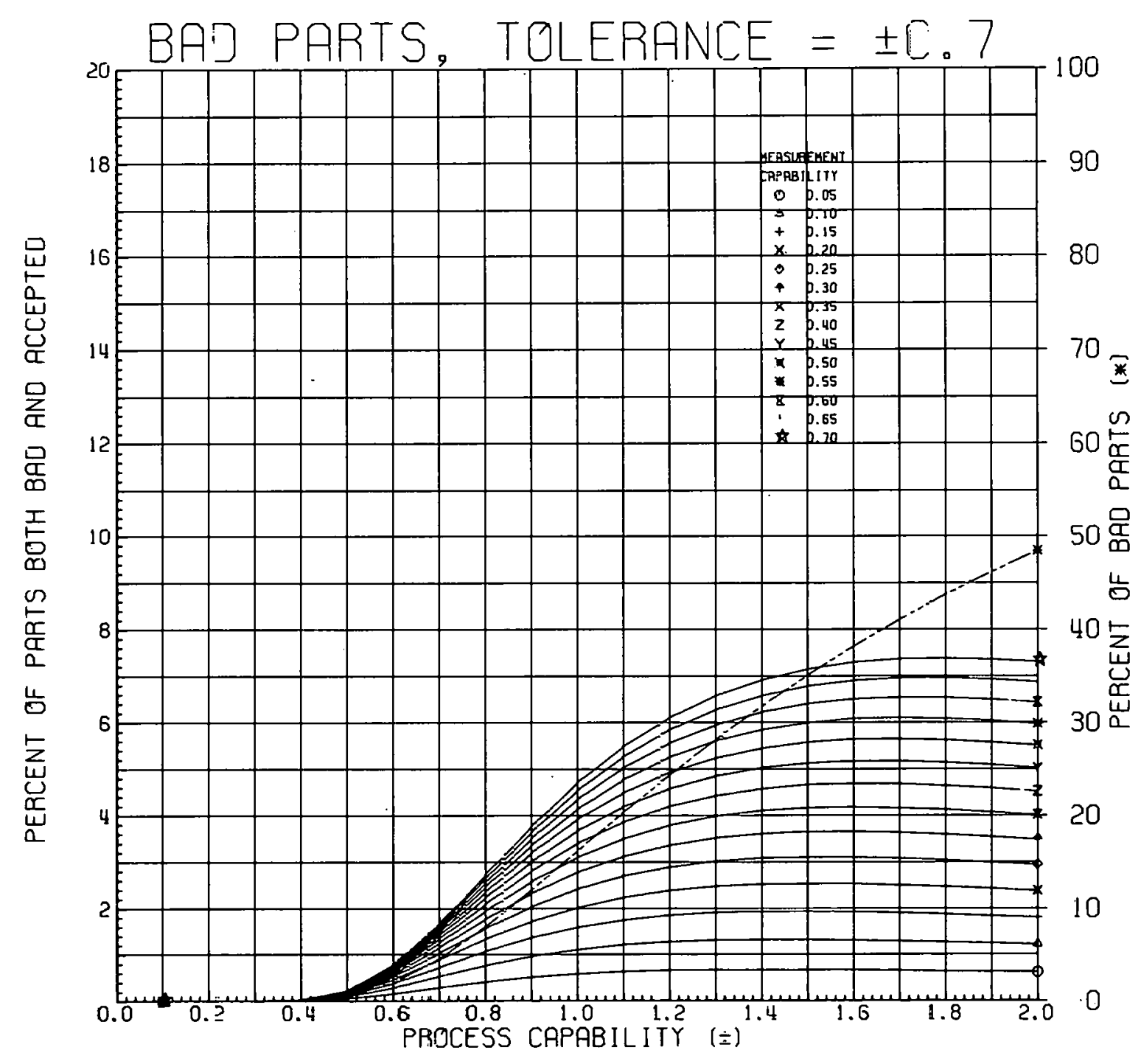

Figure A-12. BAD PARTS. (Toderance $= \pm 0.7$ ) 


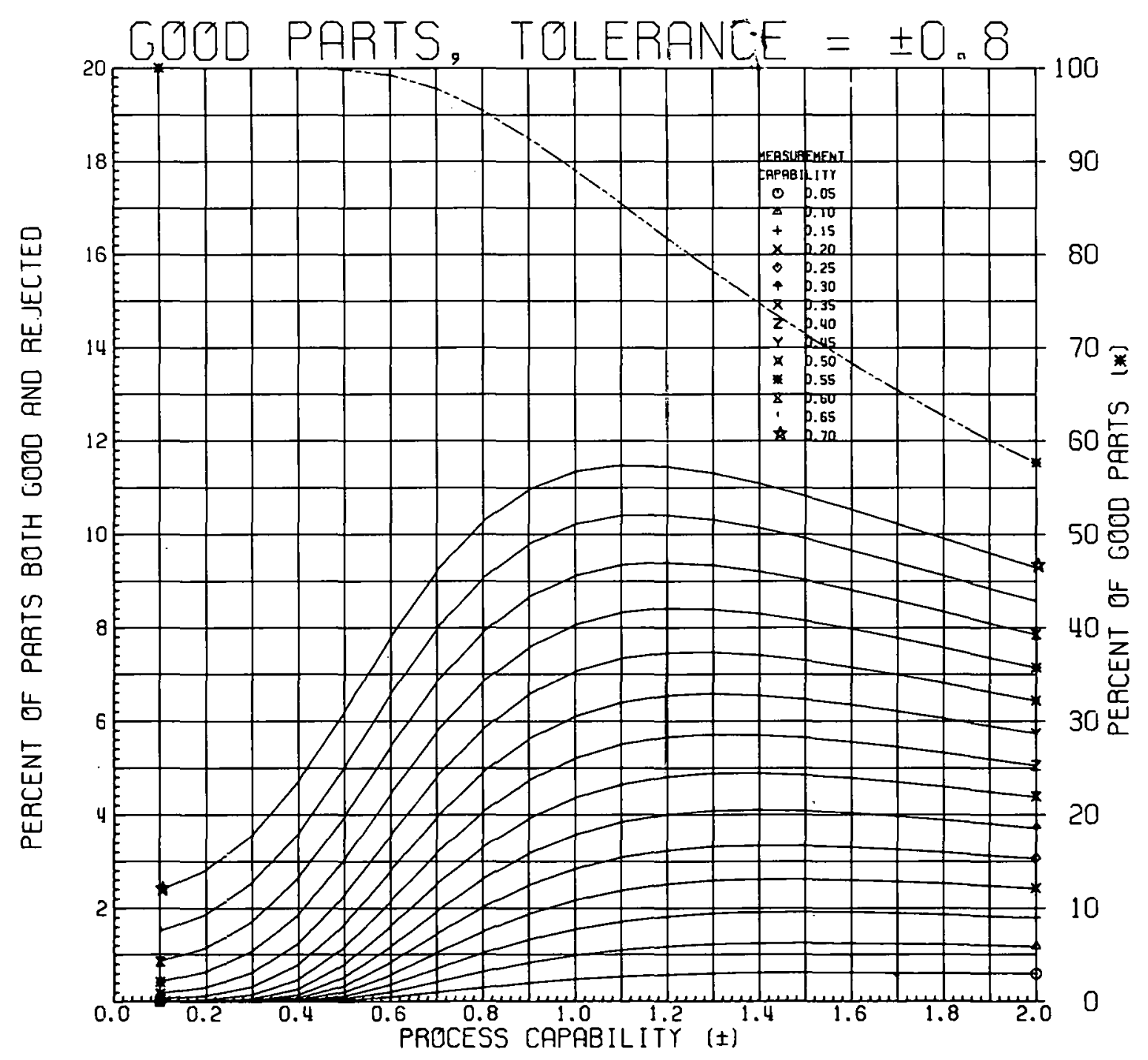

Figure A-13. GOOD PARTS. (Tolerance $= \pm 0.8$ ) 


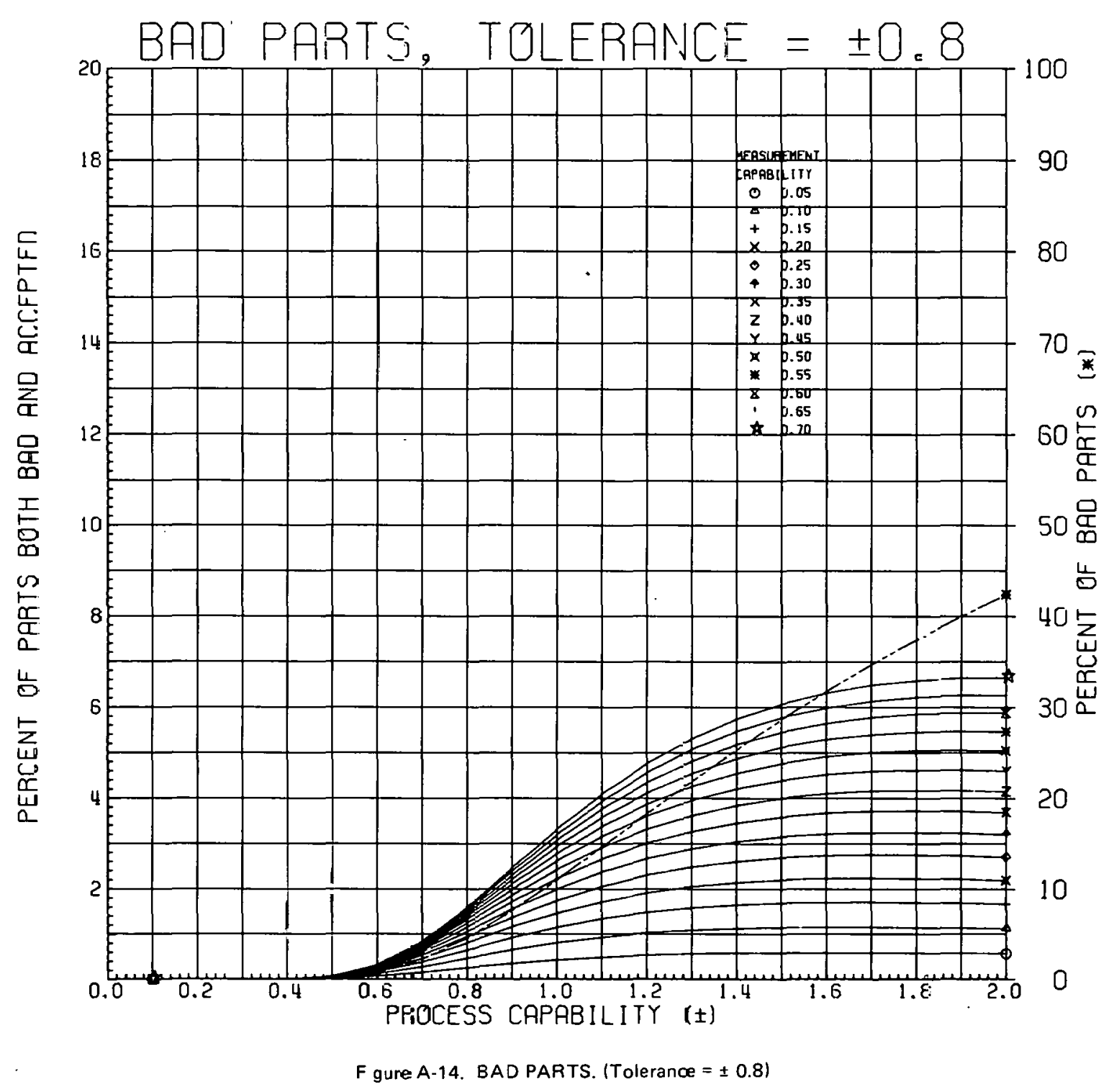




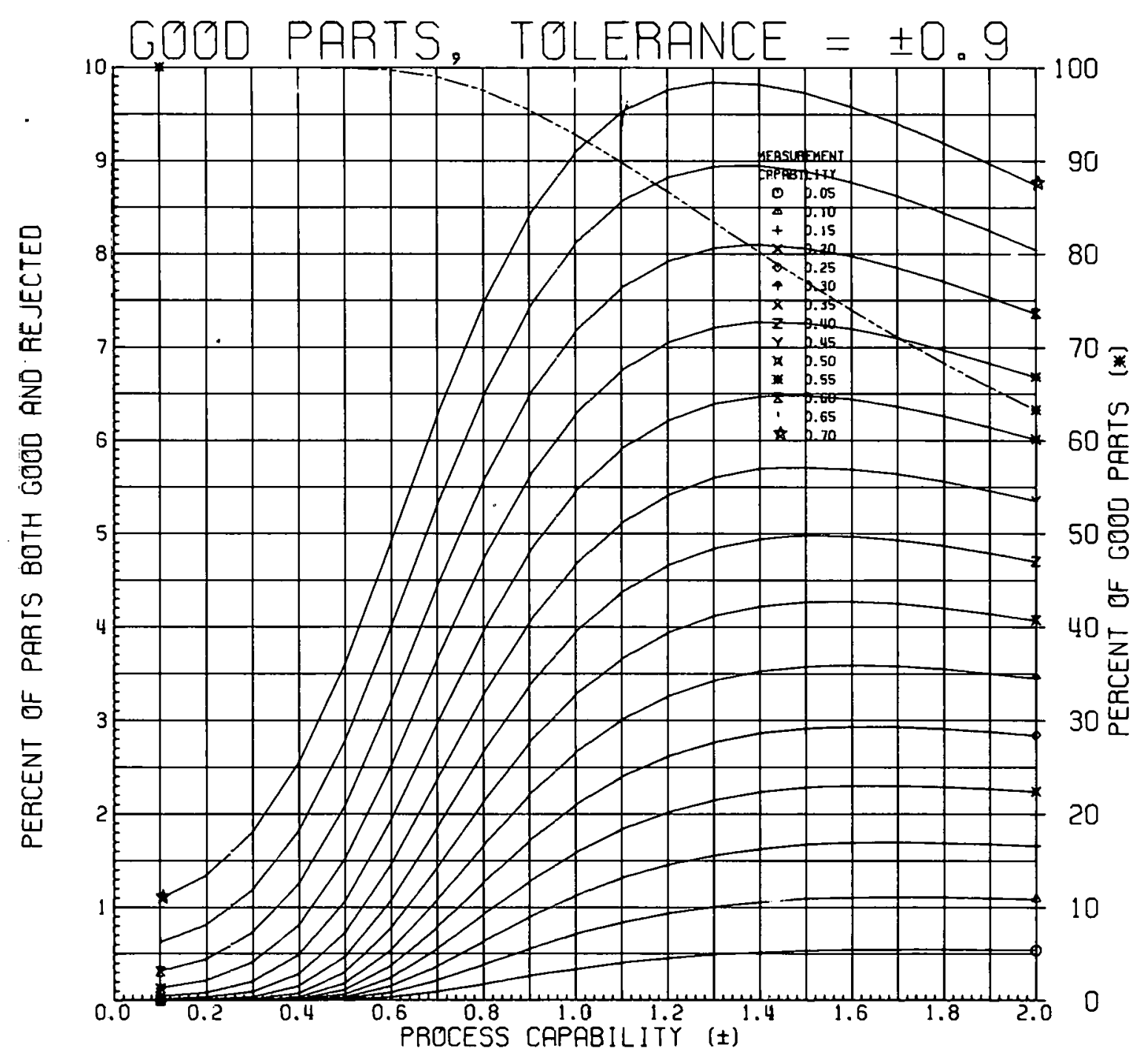

Figure A-15. GOOD PARTS. (Tolerance $= \pm 0.9$ ) 


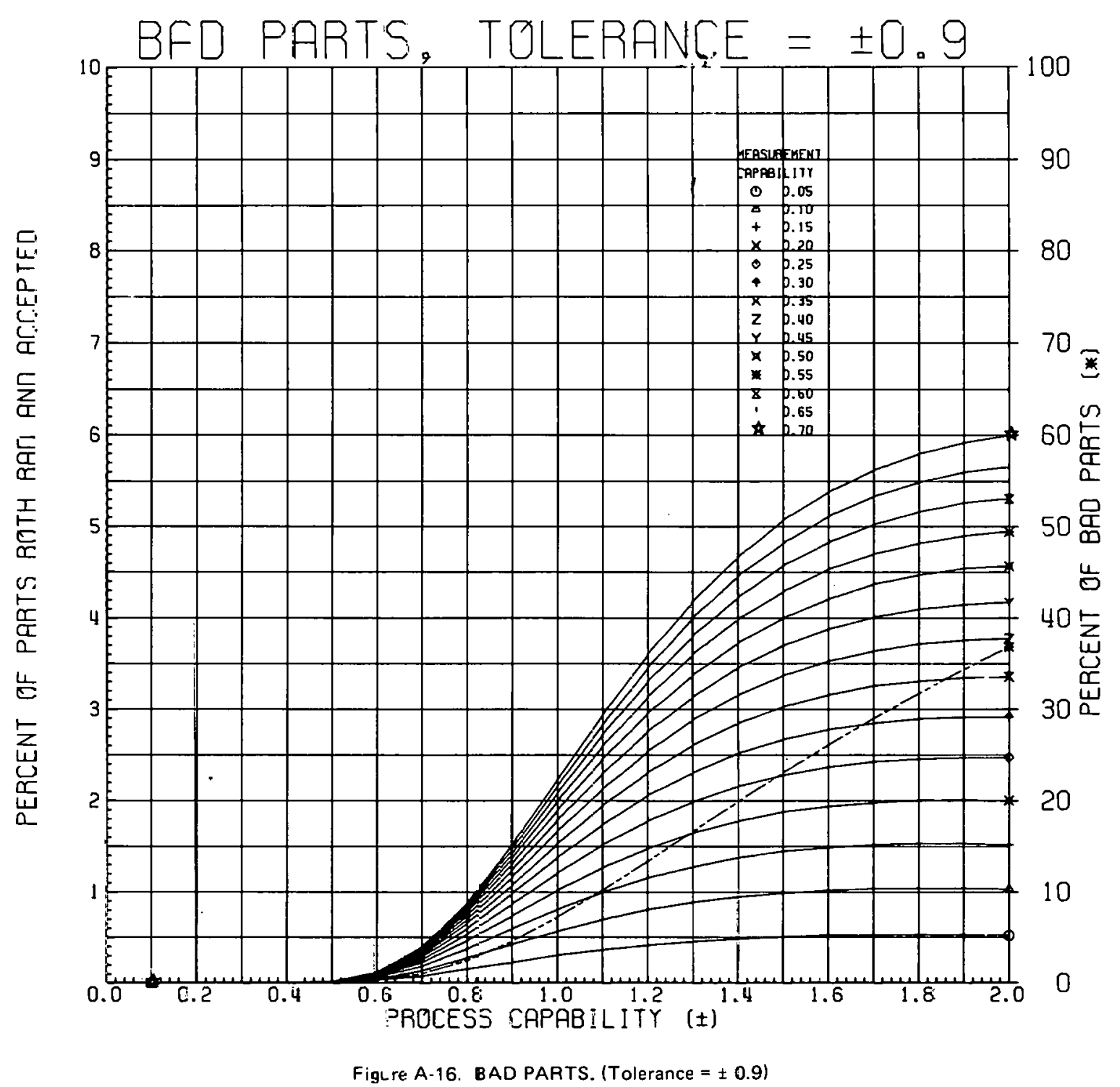

FigLre A-16. BAD PARTS. (Tolerance $= \pm 0.9)$ 


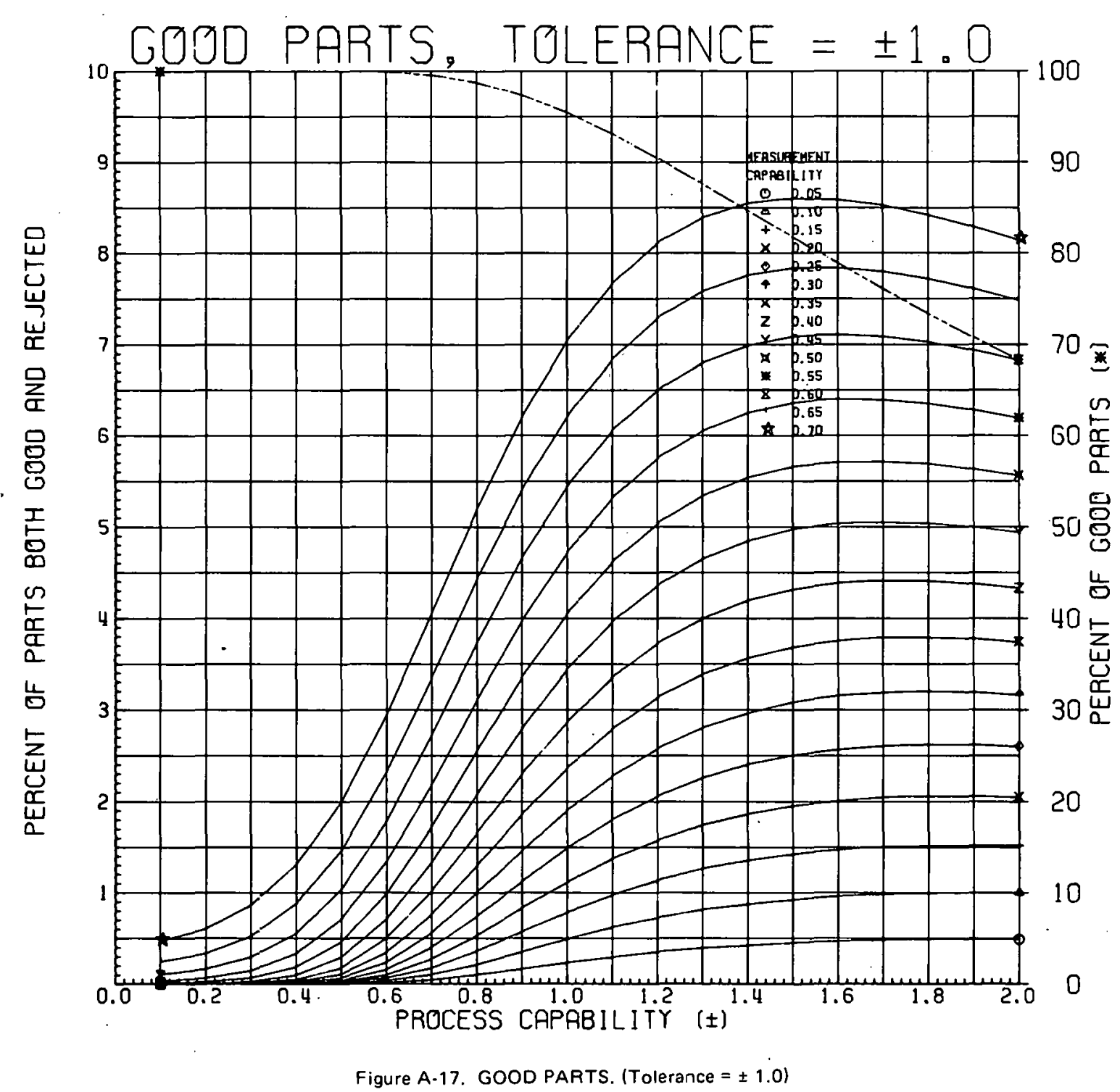




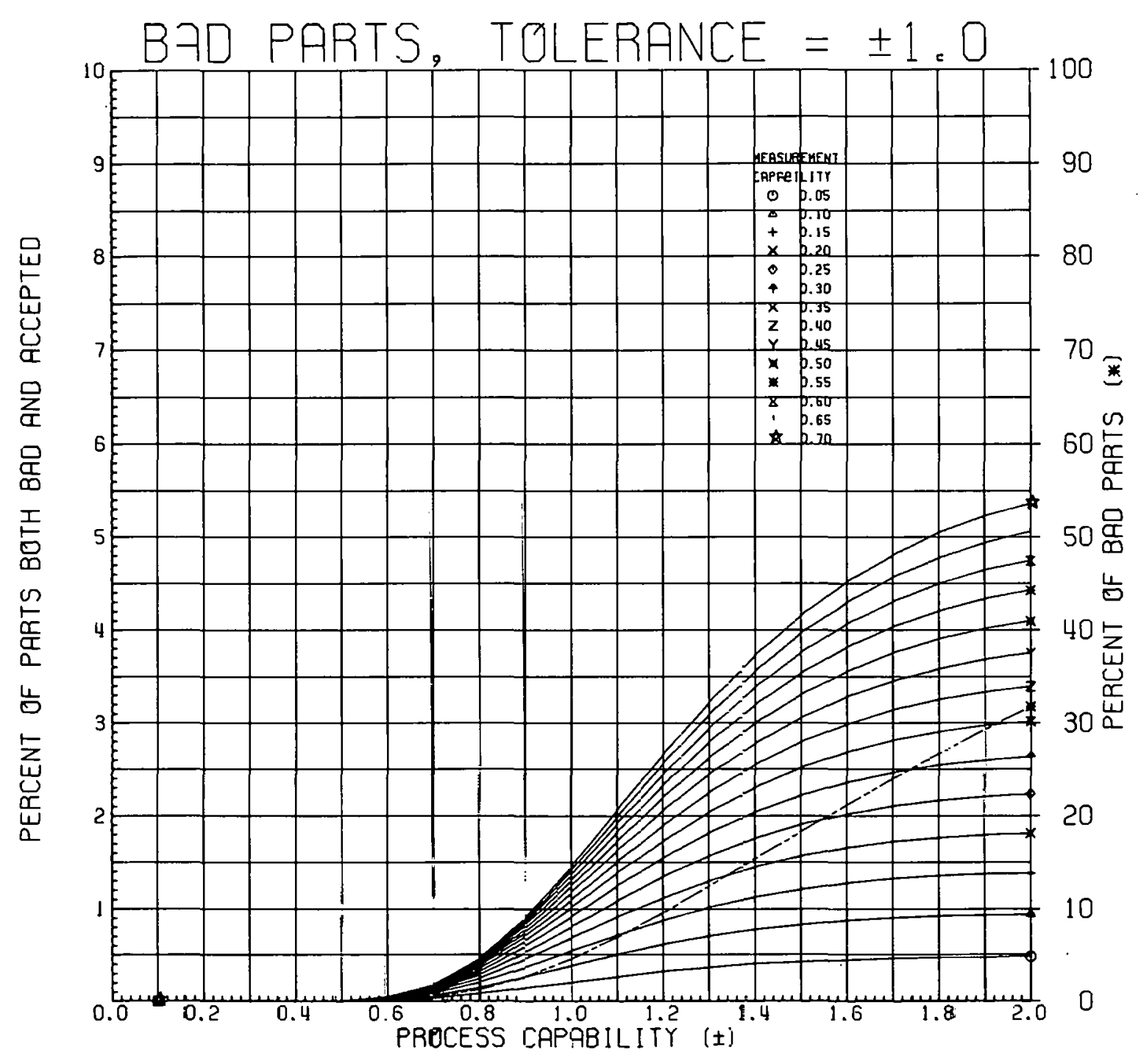

Fịcure f.-18. BAD PAFTS. (Tolerance $= \pm 1.0$ ) 


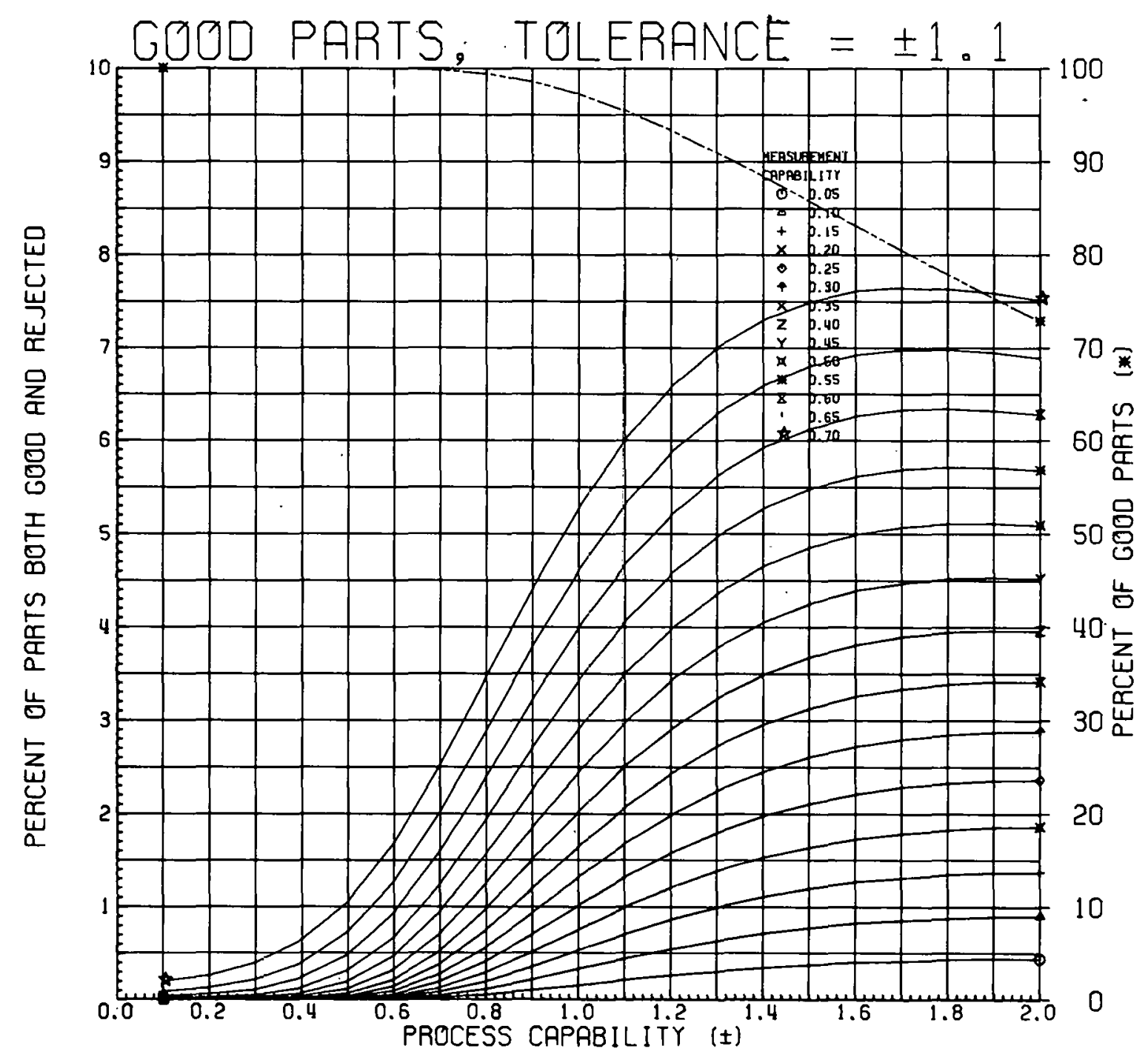

Figure A-19. GOOD PARTS. (Tolerance $= \pm 1.1$ ) 


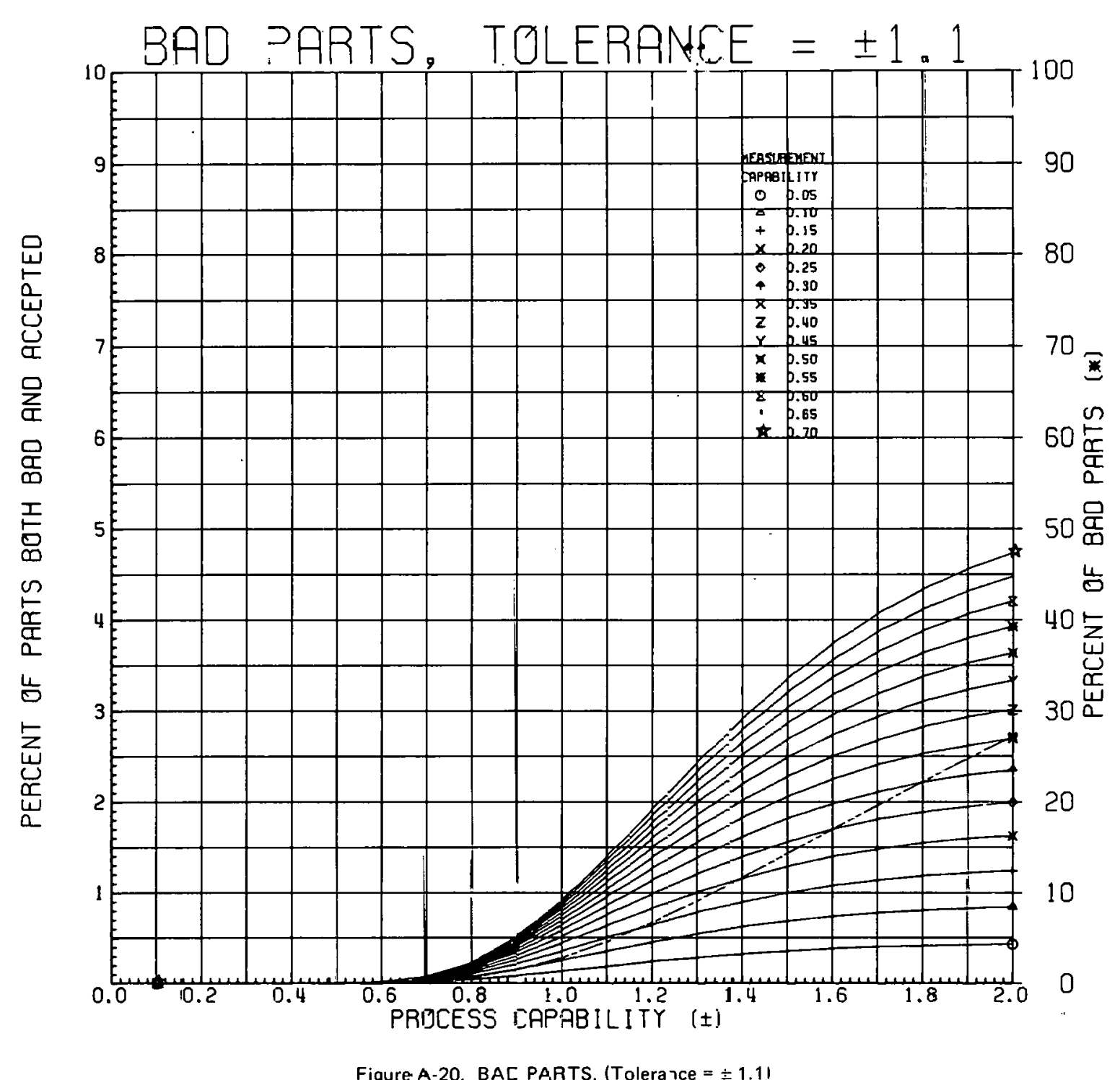

Figure A-20. BAL PARTS. (Tolera רce $=\doteqdot 1.1$ ) 


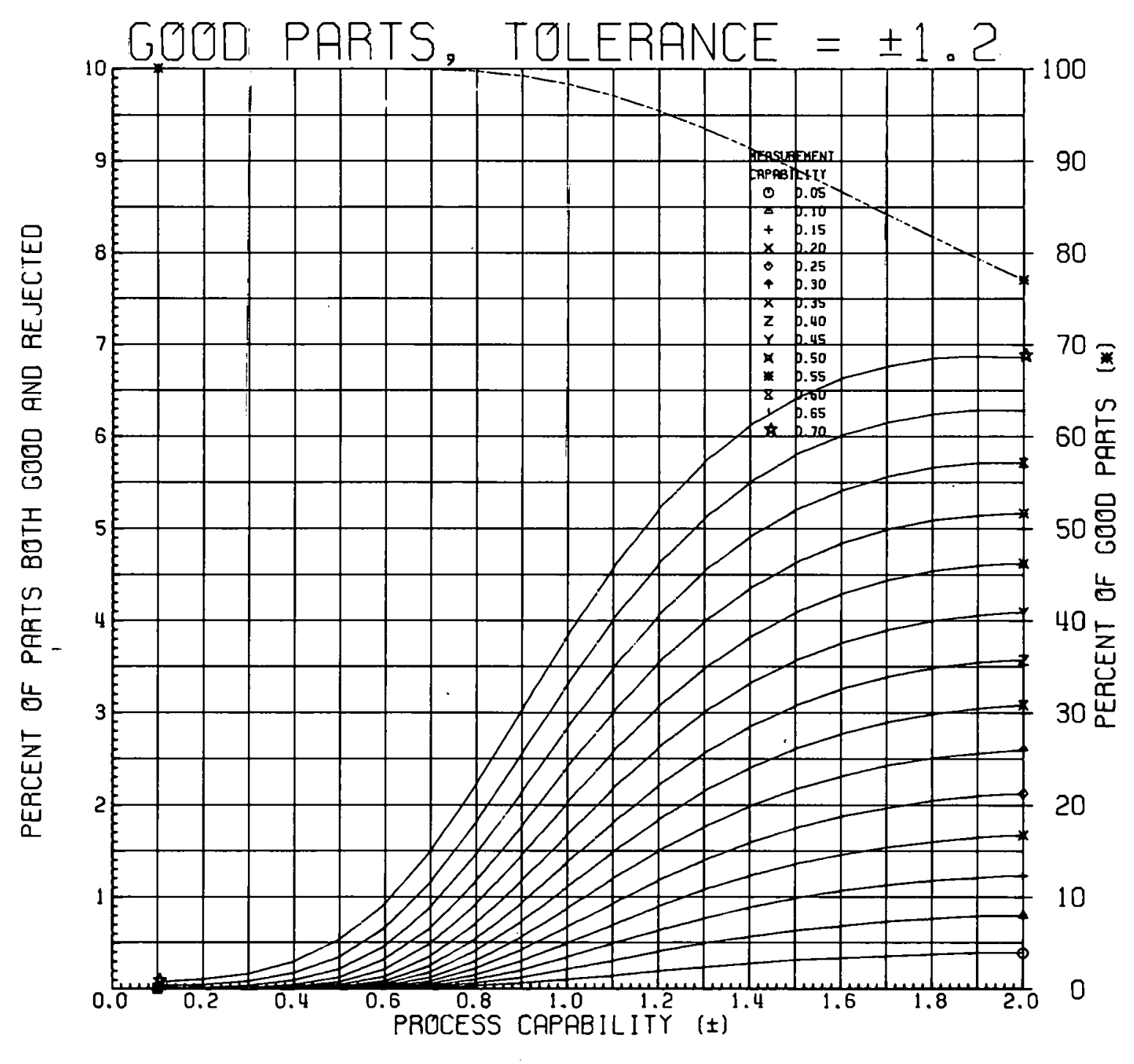

Figure A-21. GOOD PARTS. (Tolerance $= \pm 1.2$ r 


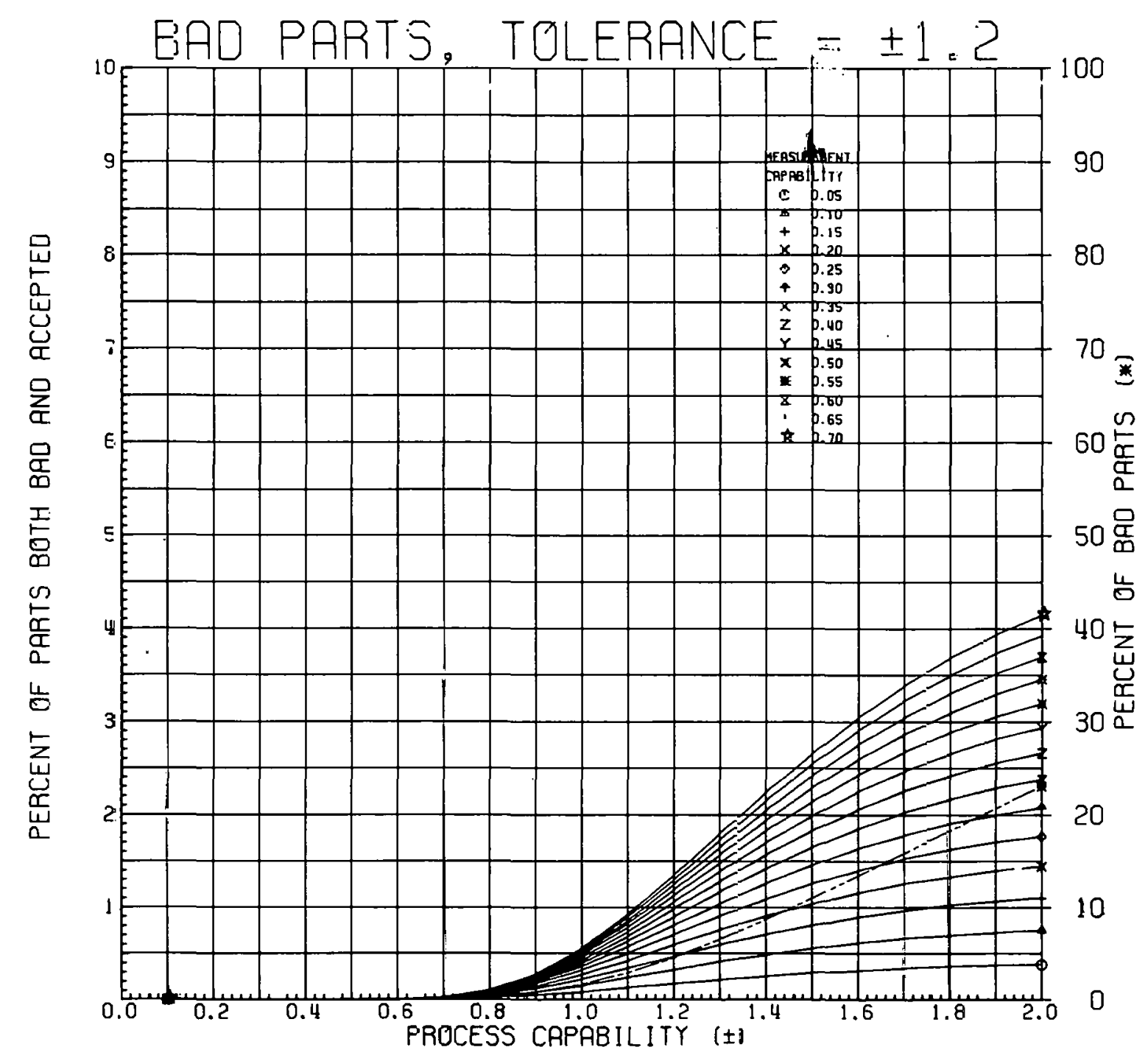

Figure A-22. BA[ PARTS. (Tolerance $=\$ 1.2)$ 


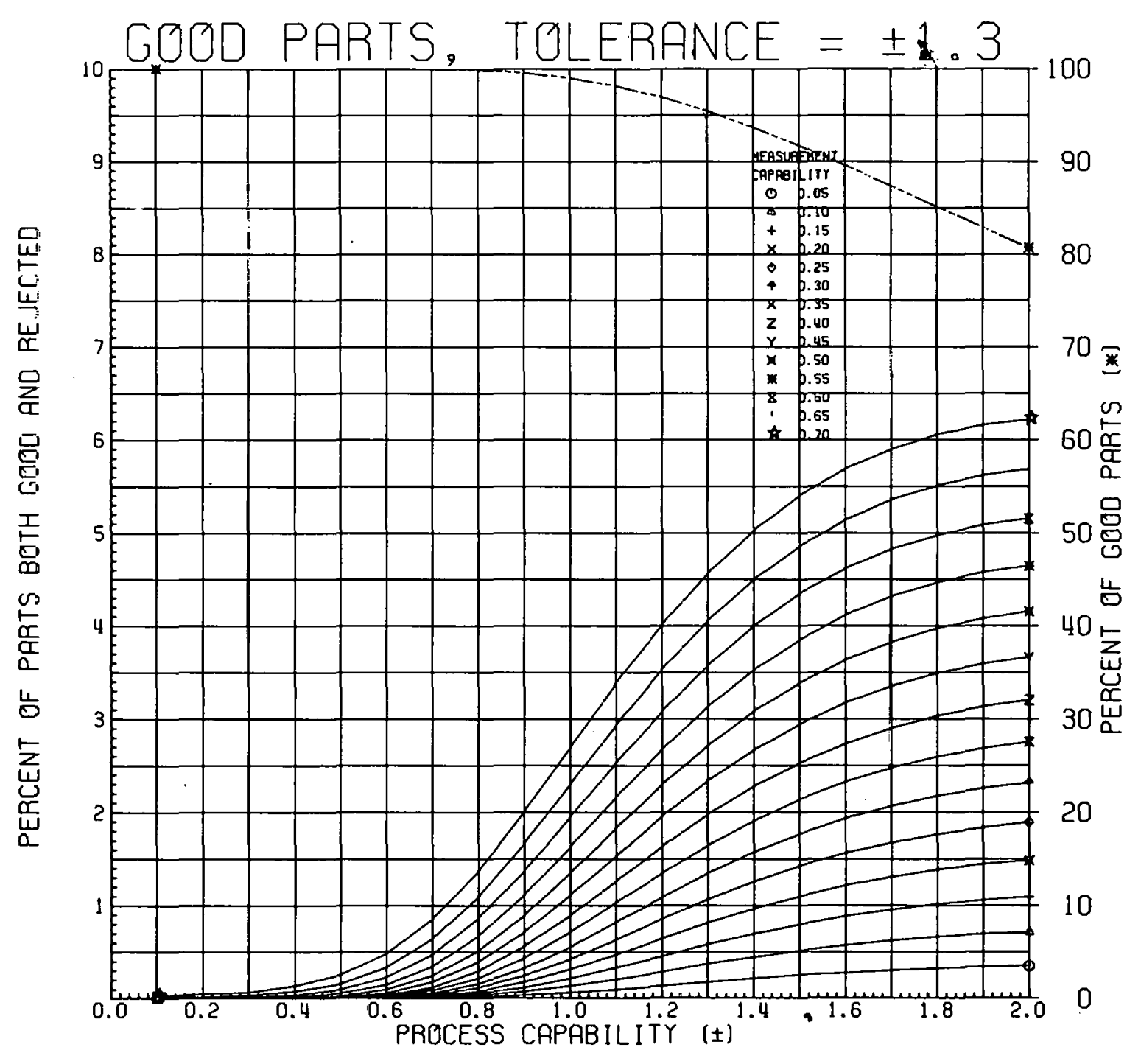

Figure A-23. GOOD PARTS. (Tolerance $= \pm 1.3$ ) 


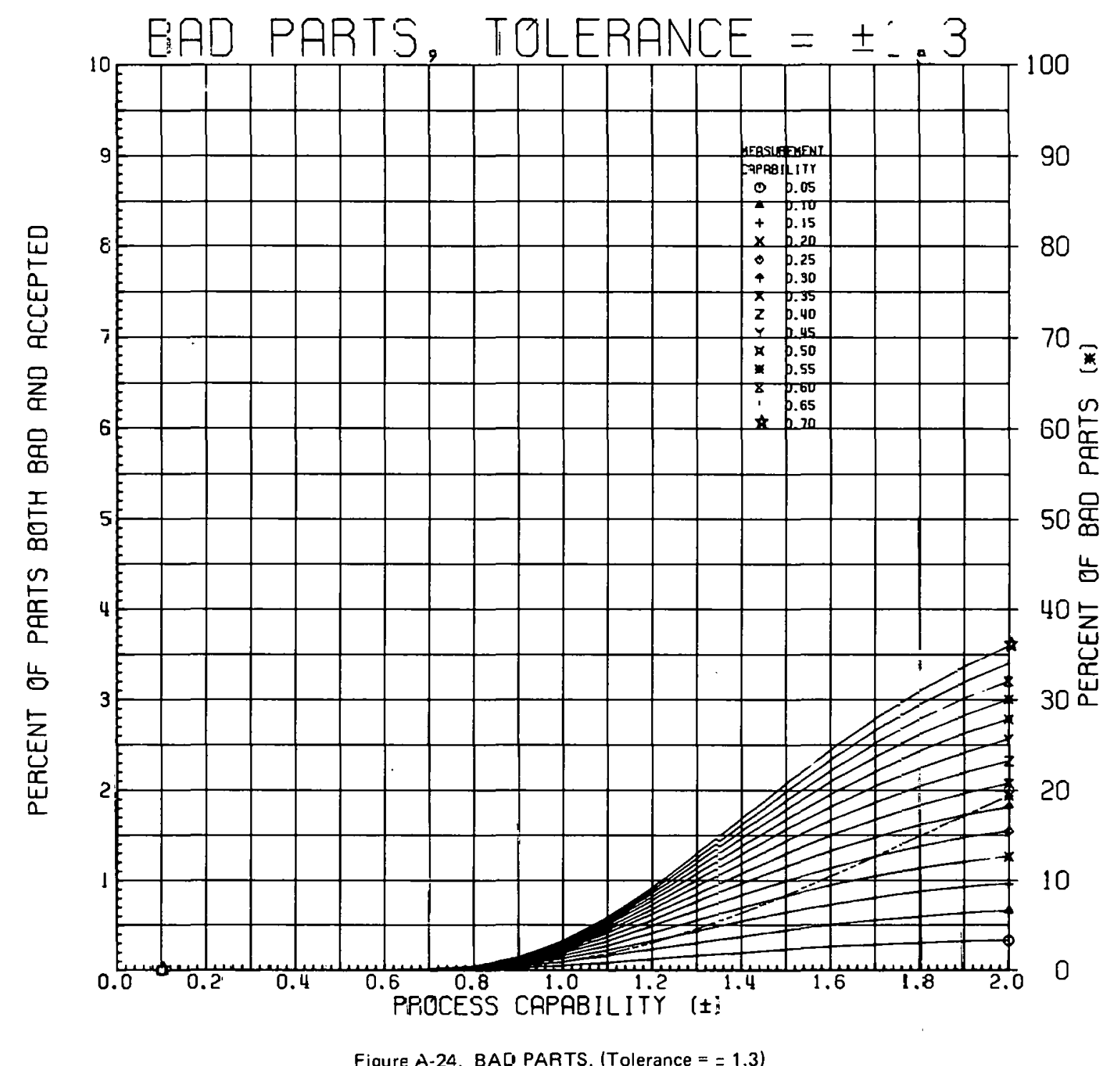

Figure A-24. BAD PARTS. (Tolerance $==1.3)$ 


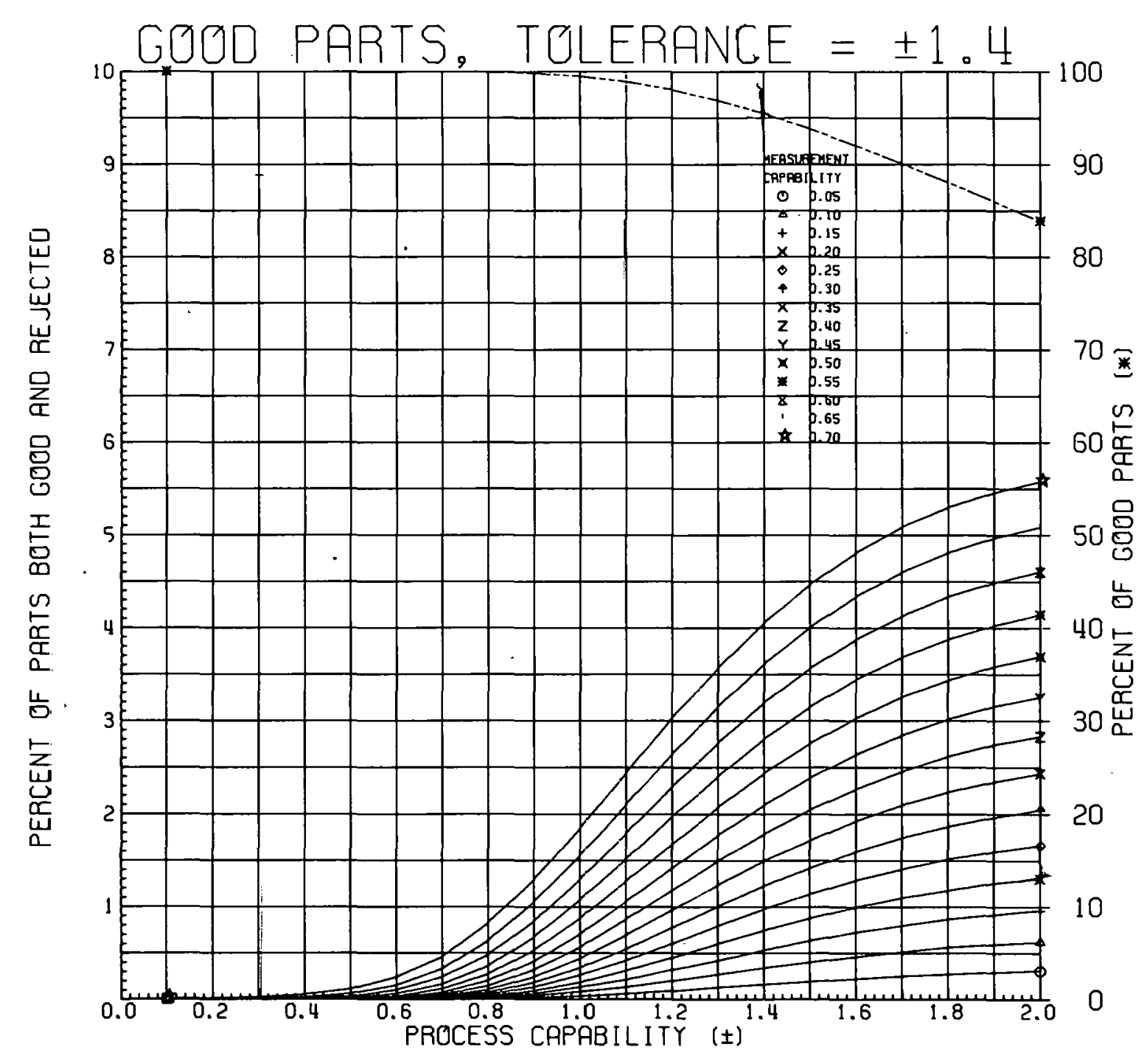

Figure A.25. GOOD PARTS. (Tolerance $= \pm 1.4)$ 


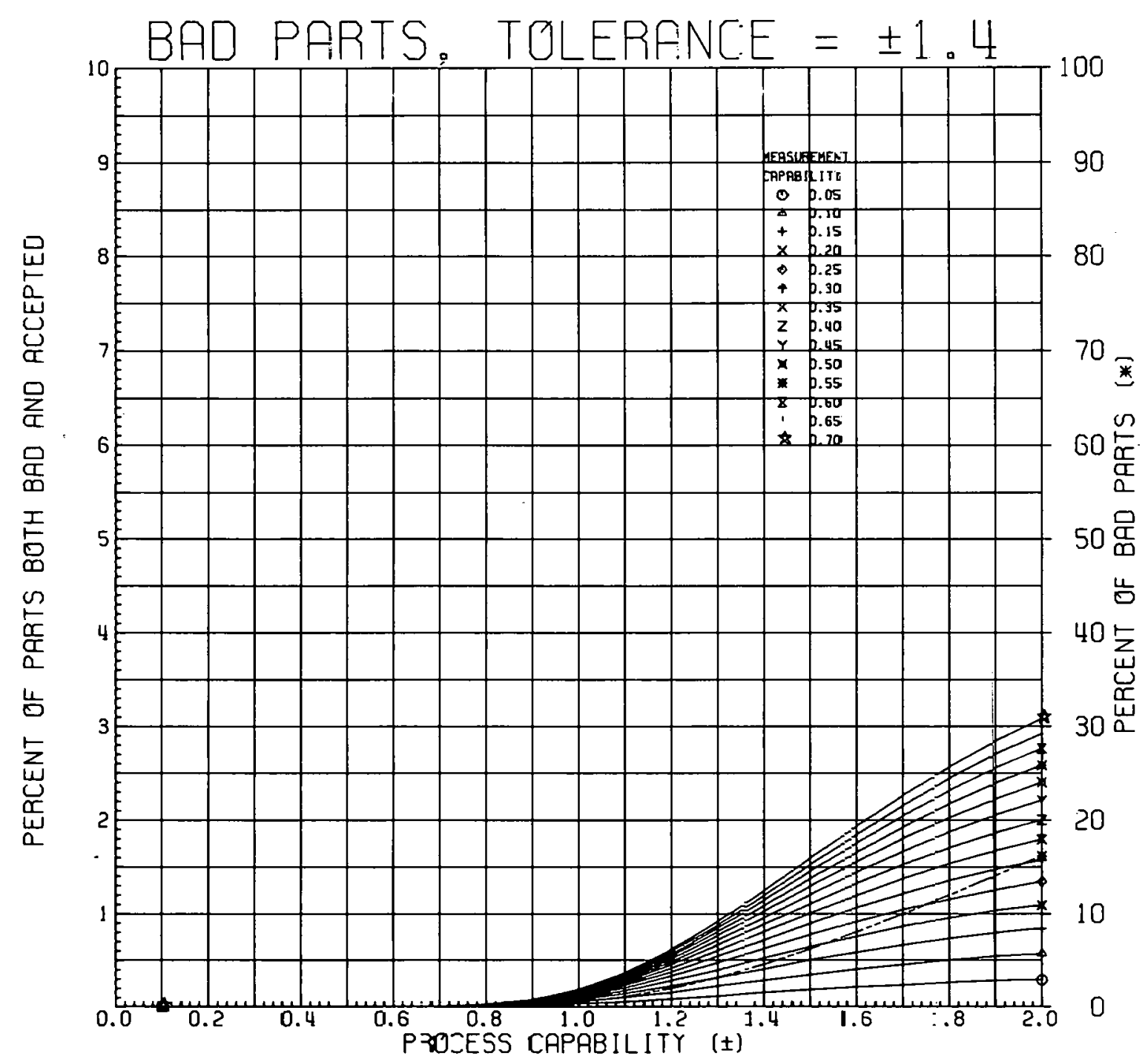

Fijure A-26. BAD PARTS. (Tolerance $==1.4$ ) 


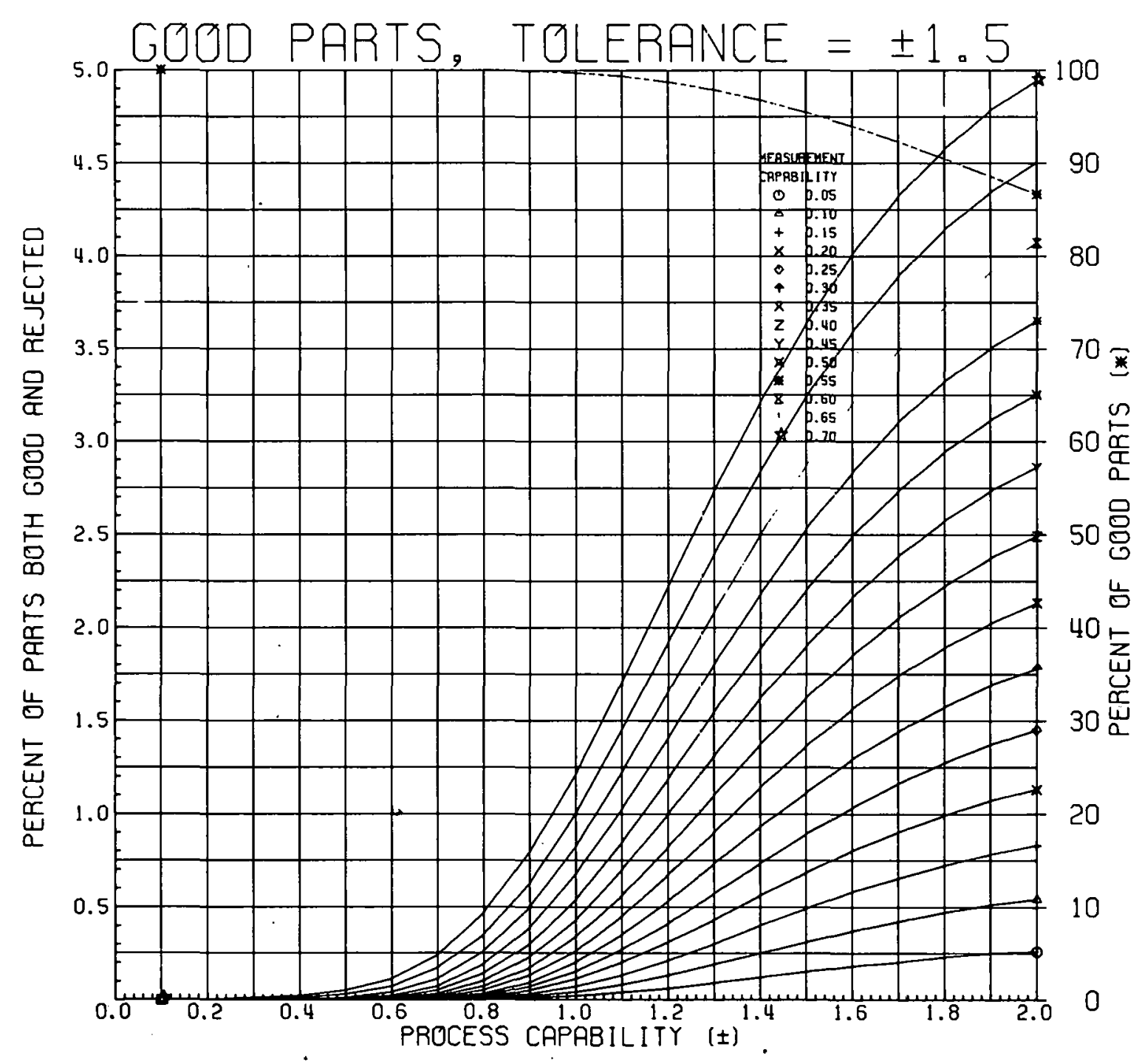

Figure A-27. GOOD PARTS. (Tolerance $= \pm 1.5$ ) 
EAD PARTS, TOLERANCE $= \pm 1.5$

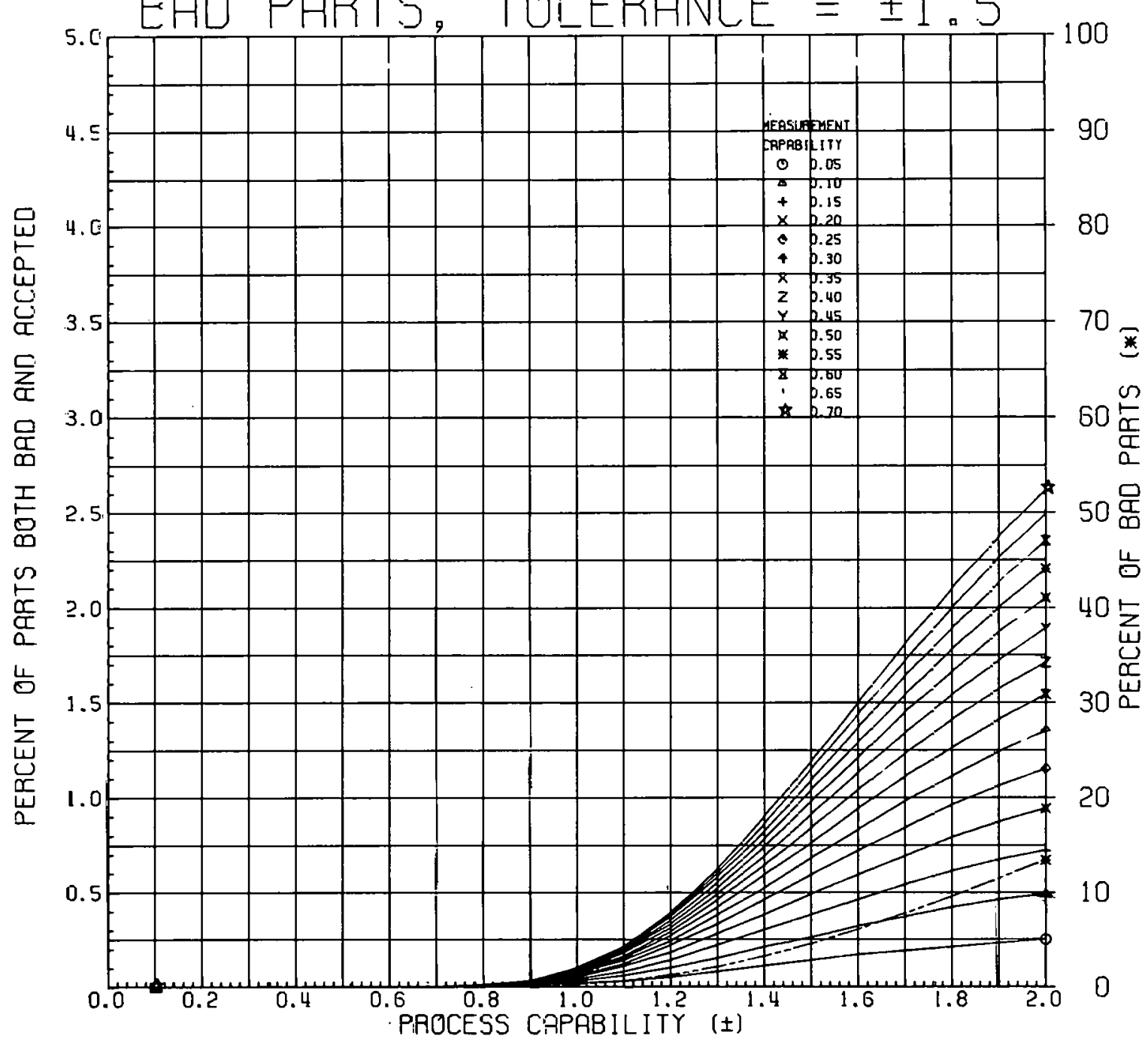

Figure A.28. BAD PARTS. (Tolerance $= \pm 1.5$ ) 


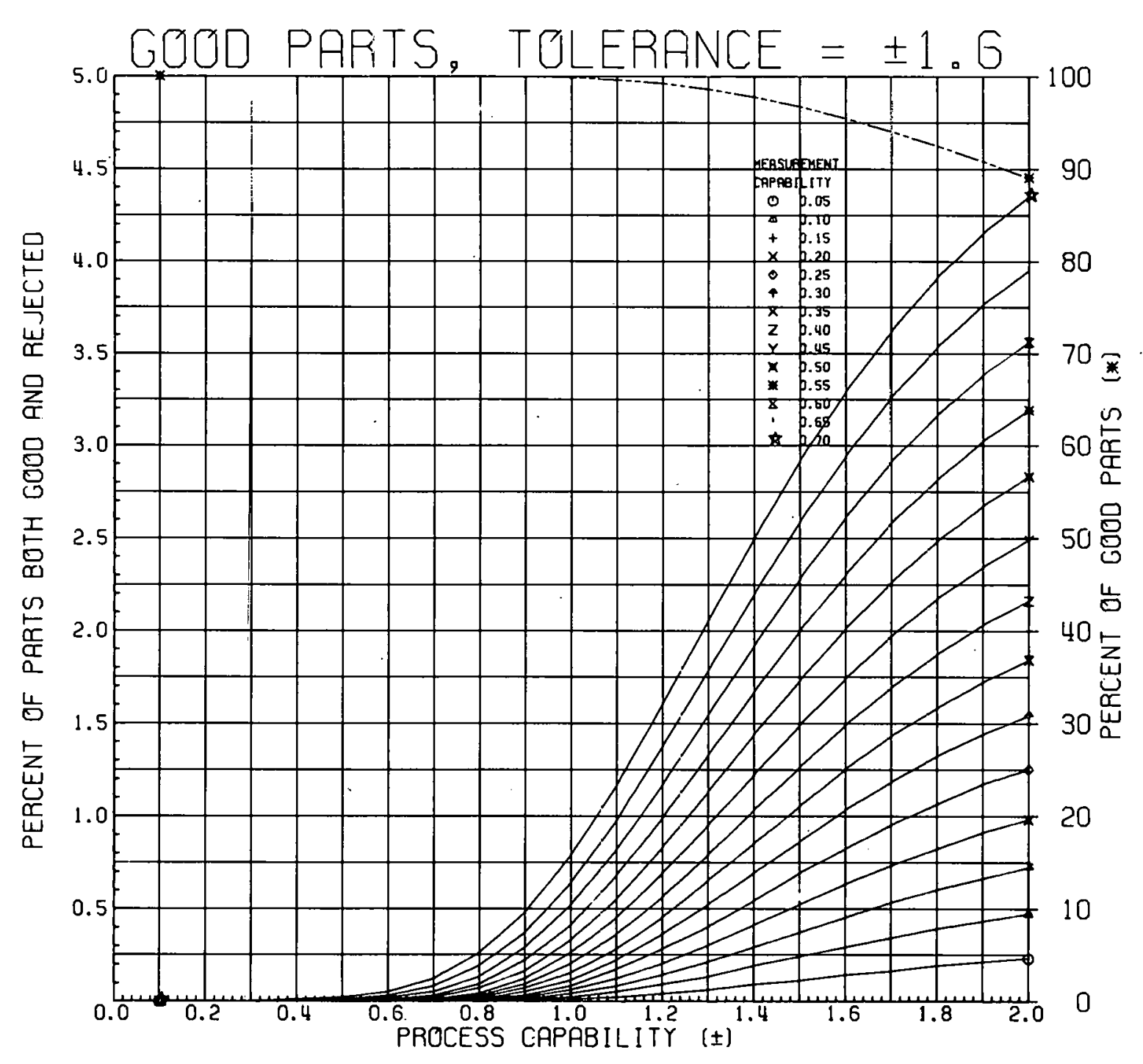

Figure A.29. GOOD PARTS. (Tolerance $= \pm 1.6)$ 


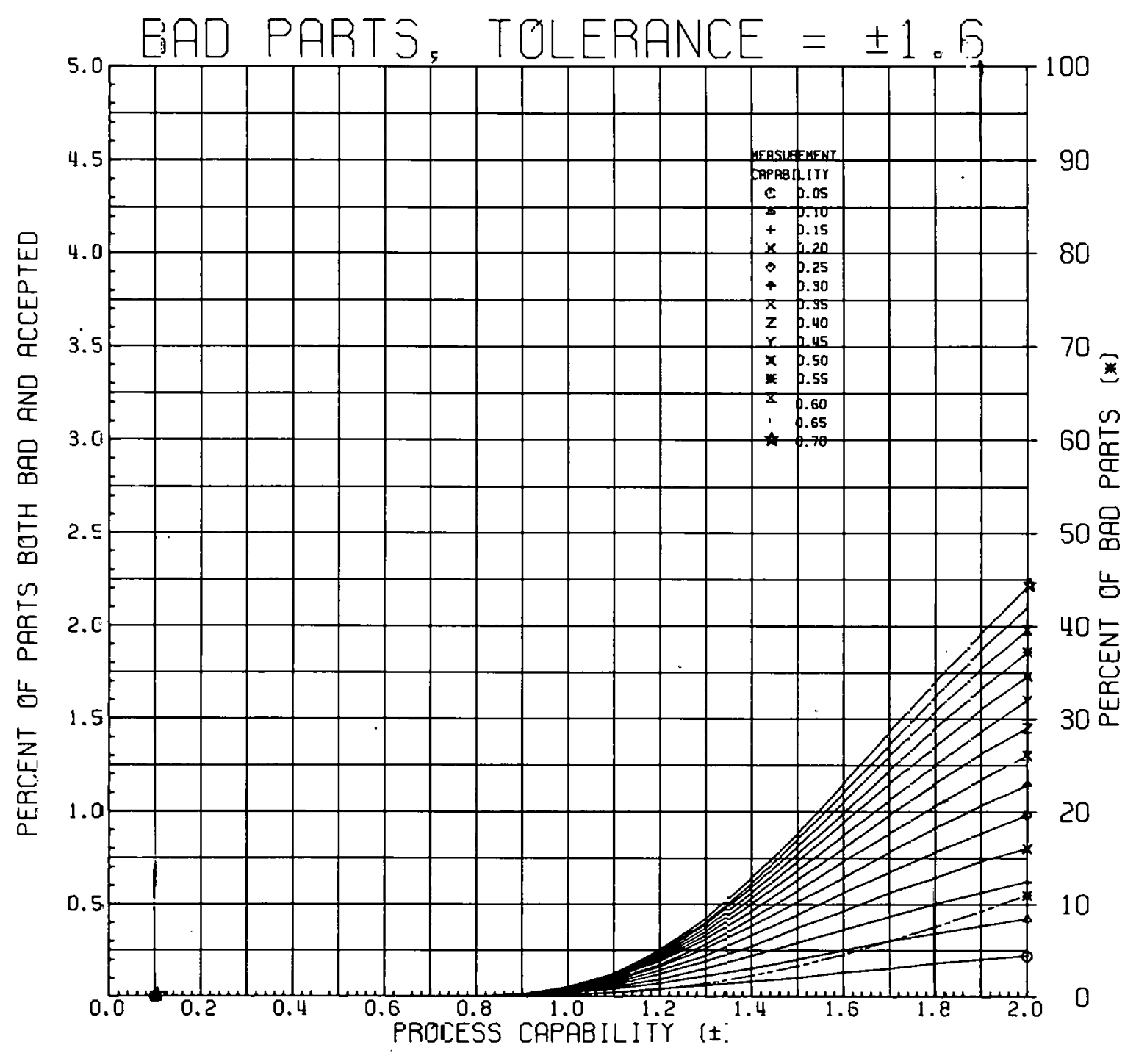

Figure $A-\approx 0$. BAD PARTS. $($ Tolerance $==1.6 \mathrm{i}$ 


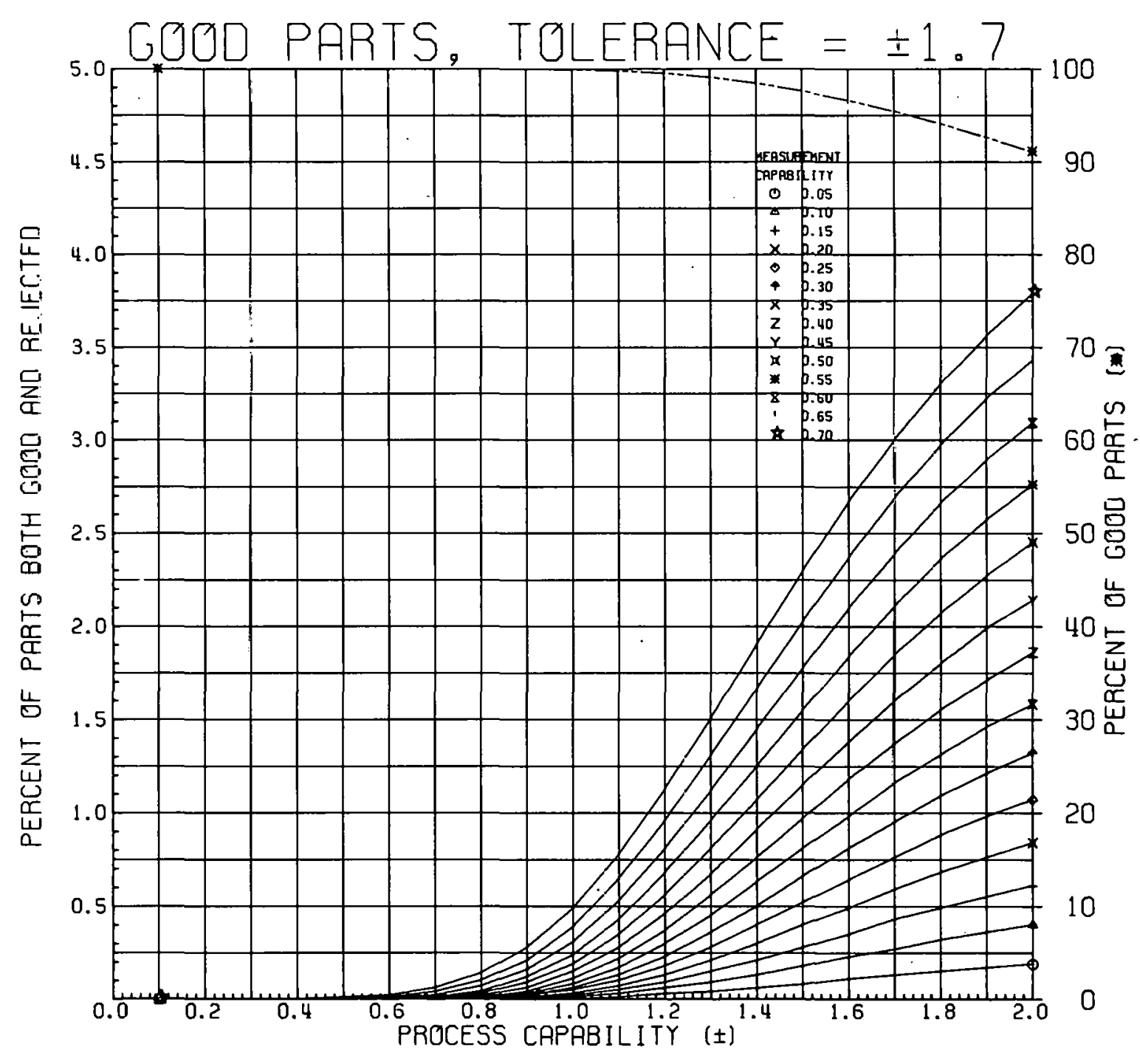

Figure A-31. GOOD PARTS. (Tolerance $= \pm 1.7$ ) 


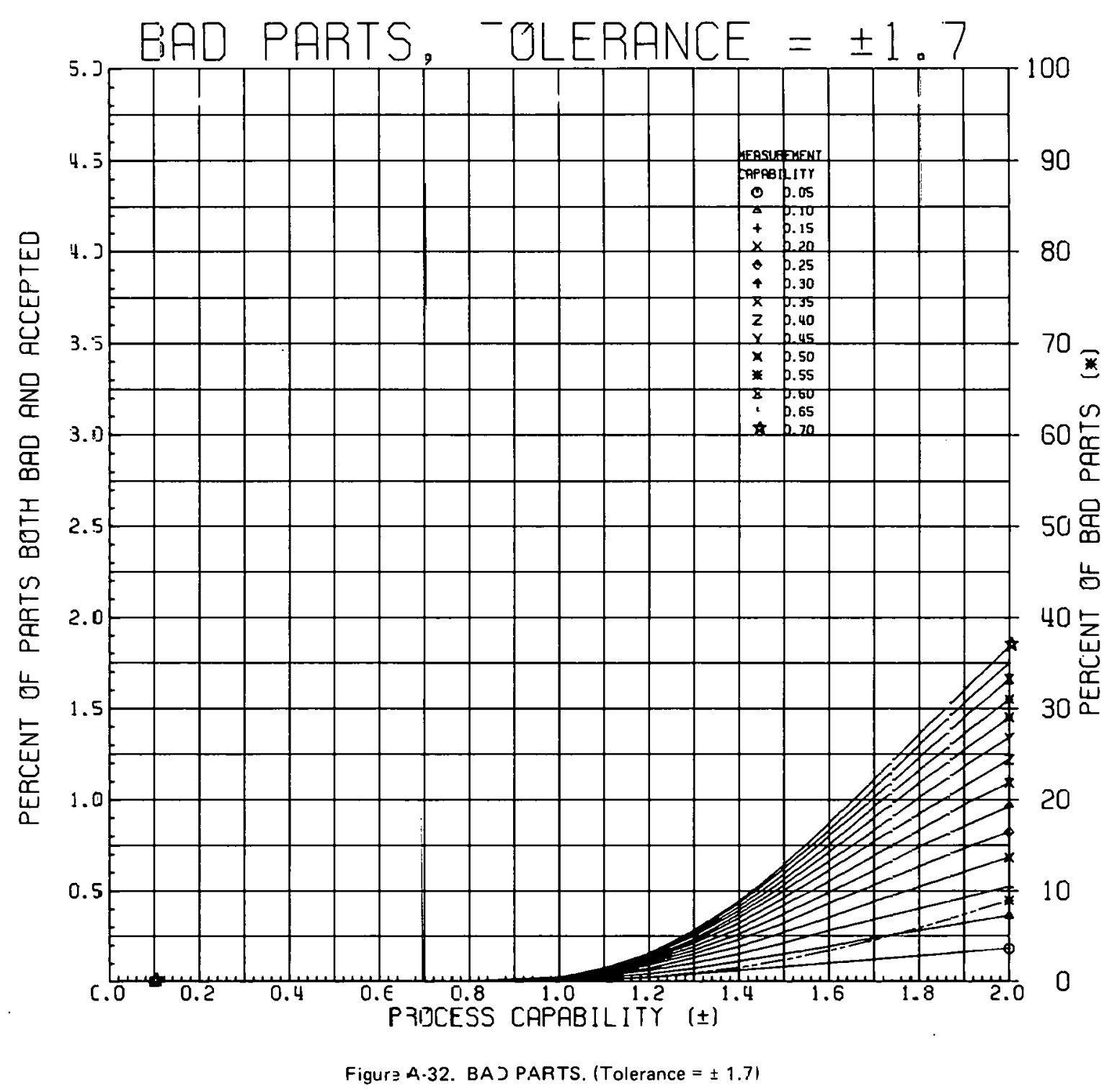

$\stackrel{\infty}{\infty}$

Figur 2 A-32. BA ) P.ARTS. (Tolerance $= \pm 1.7$ I 


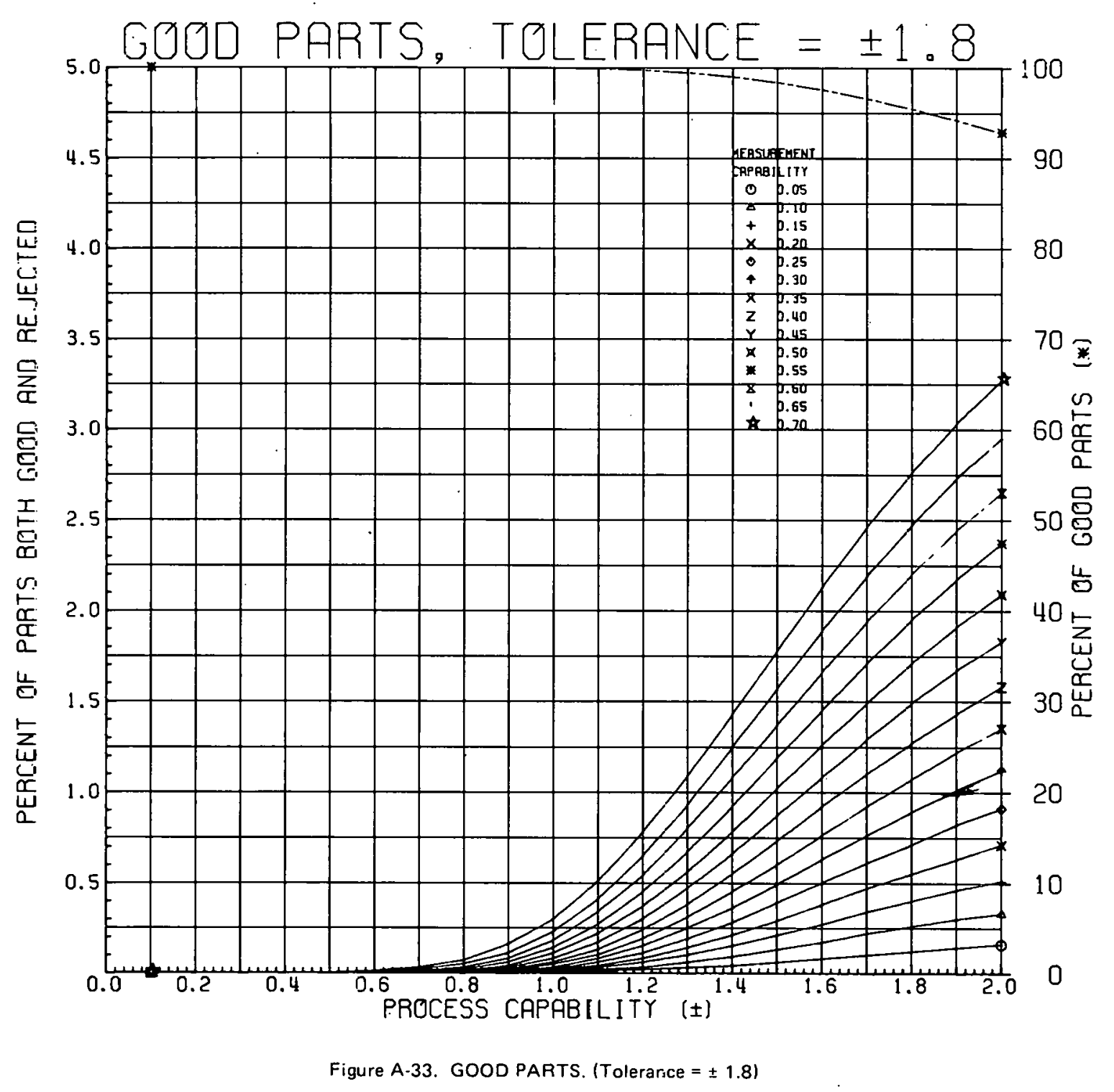




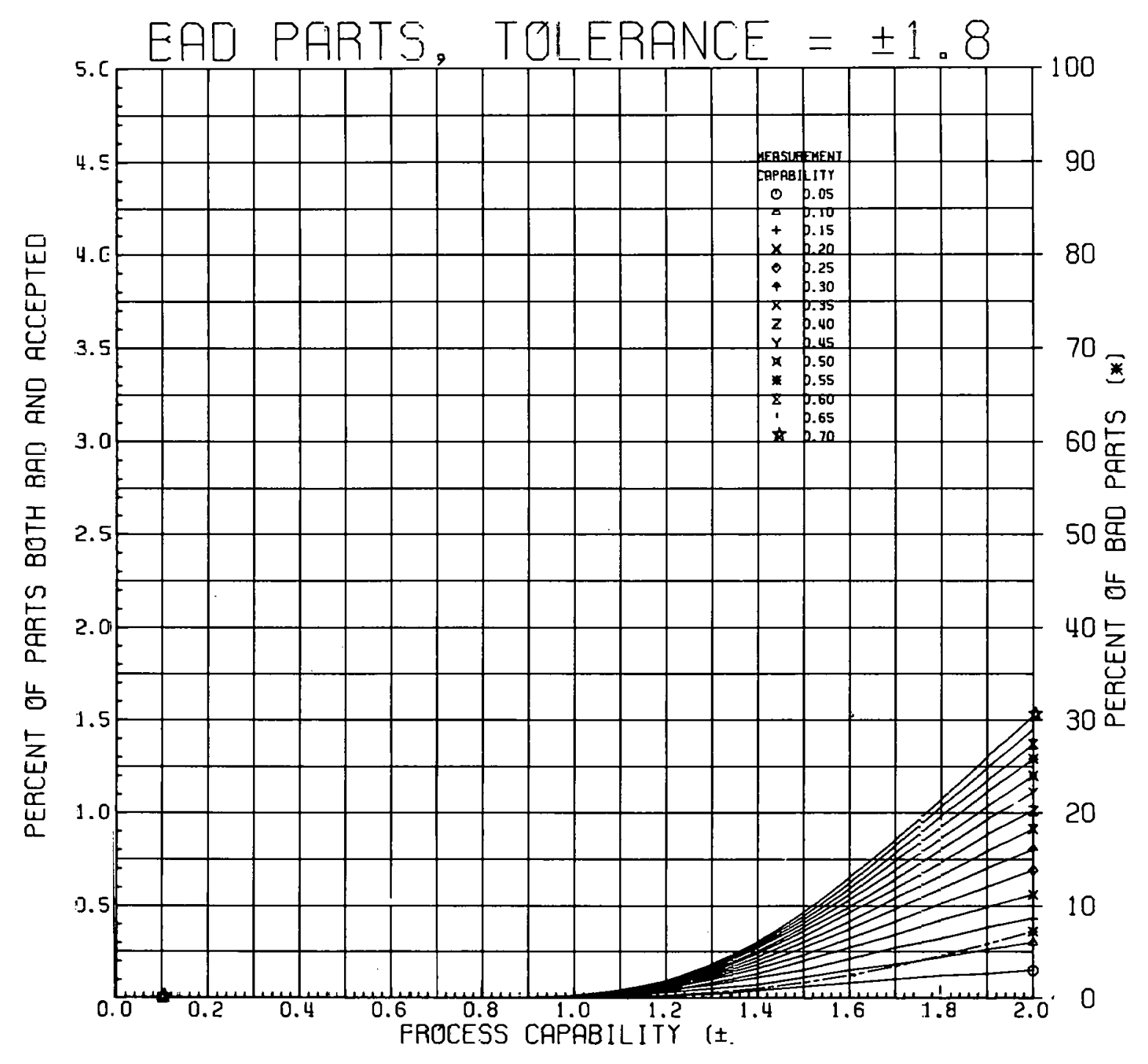

Figure A-34. BAD PARTS. (Tolerance $=\equiv 1.8$ ) 


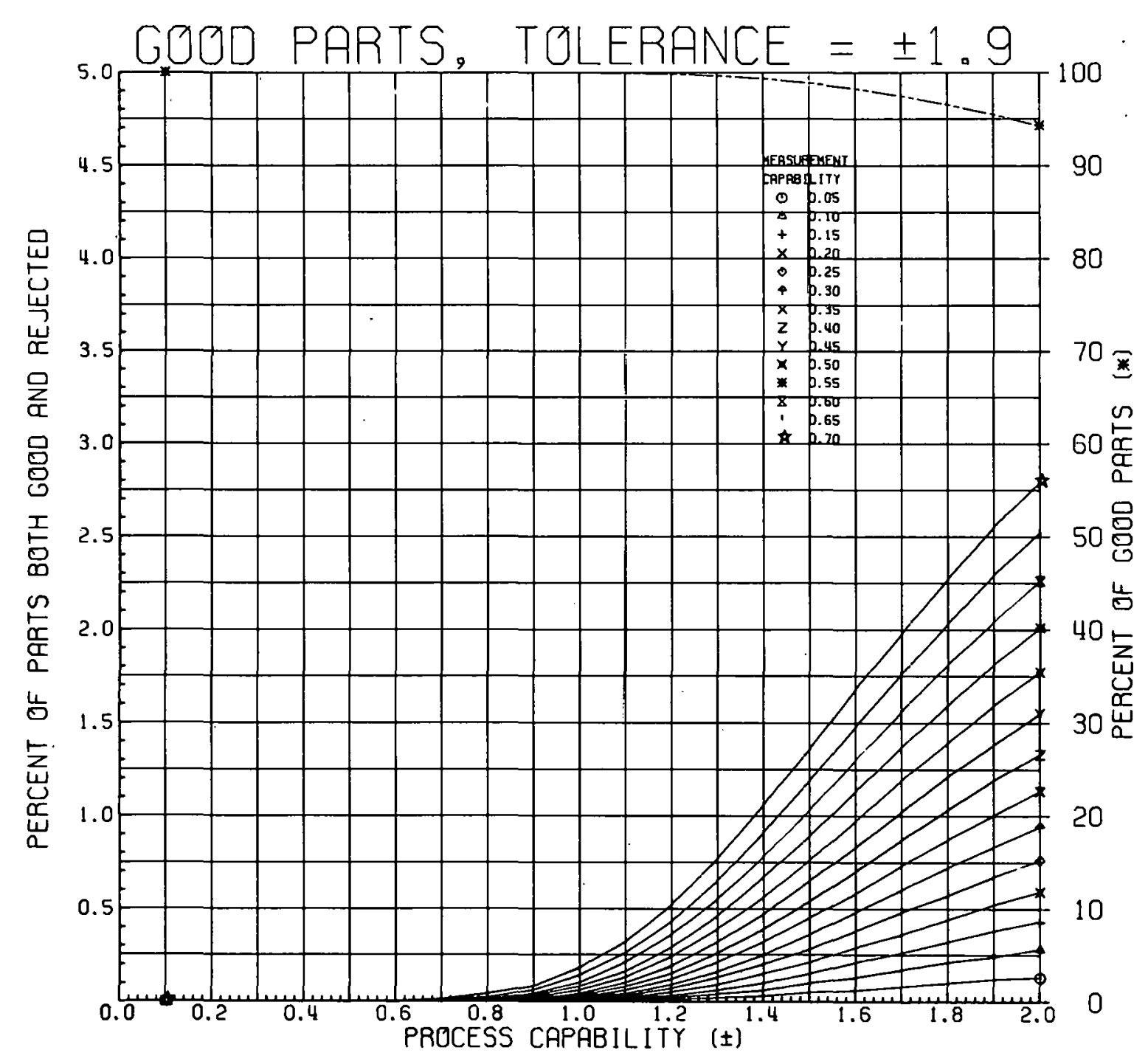

Figure A-35. GOOD PARTS. (Tolerance $= \pm 1.9$ ) 


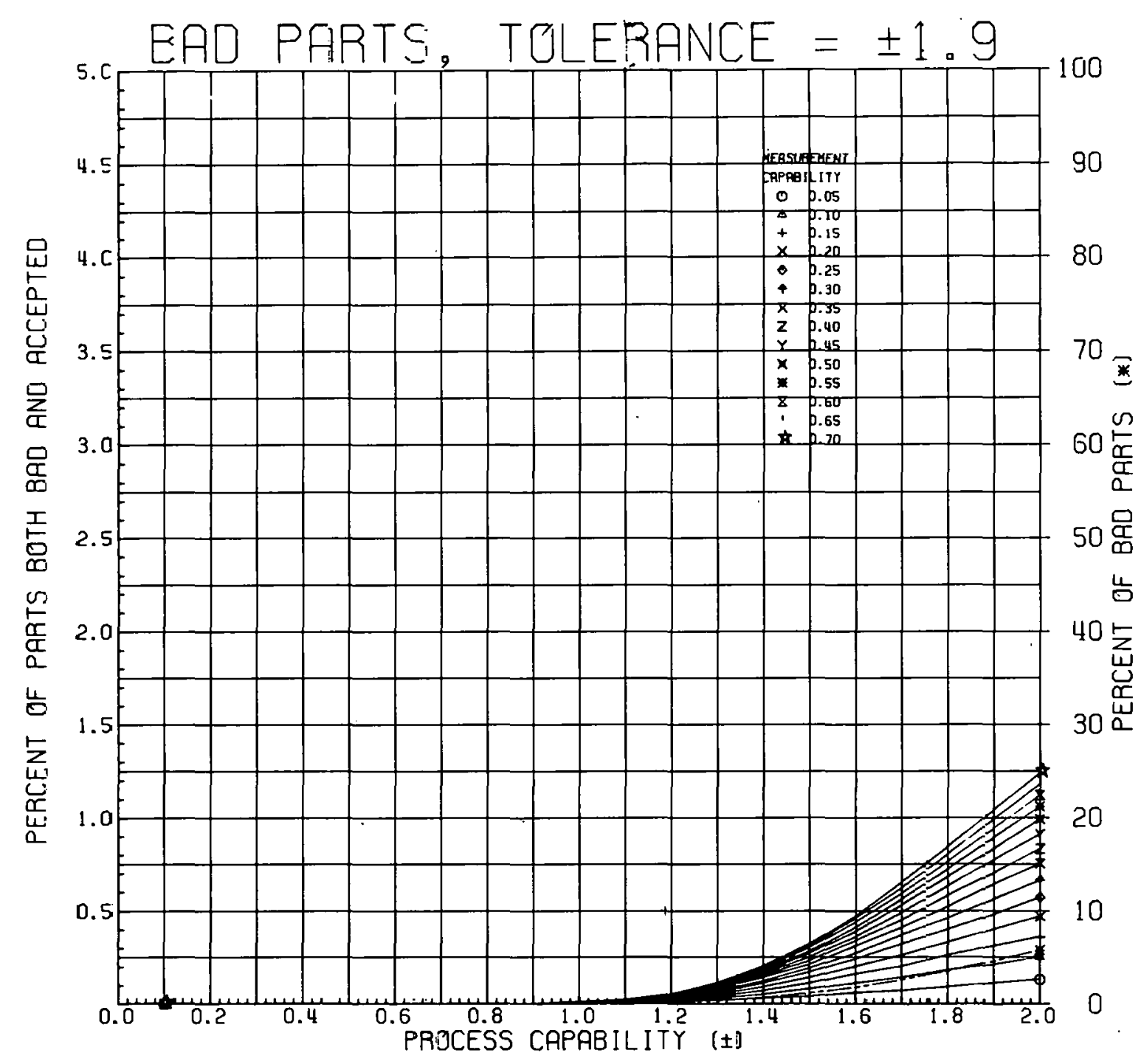

Figure A-36. BAD PARTS. (Tolerance $==1.9$ ) 


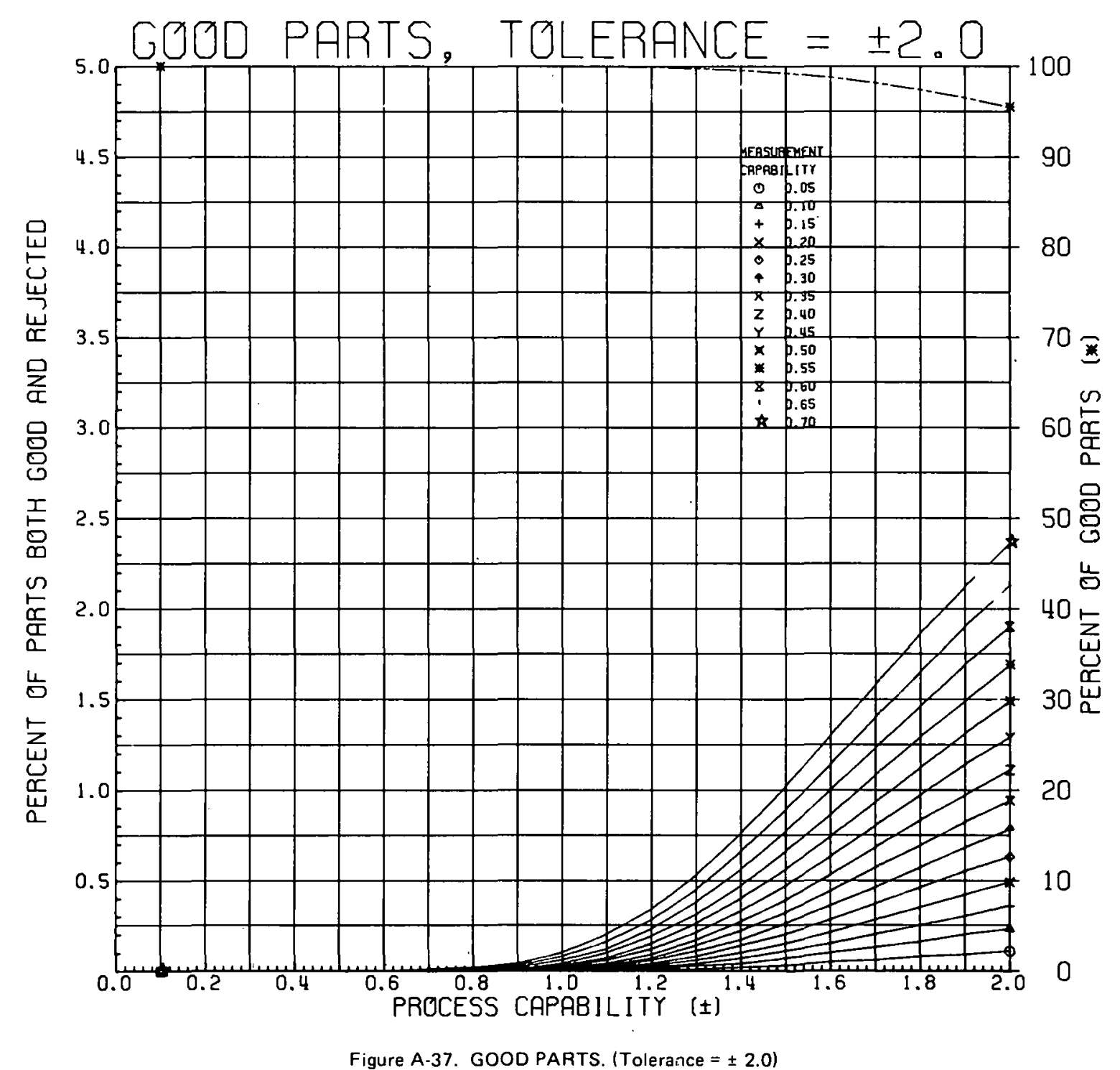




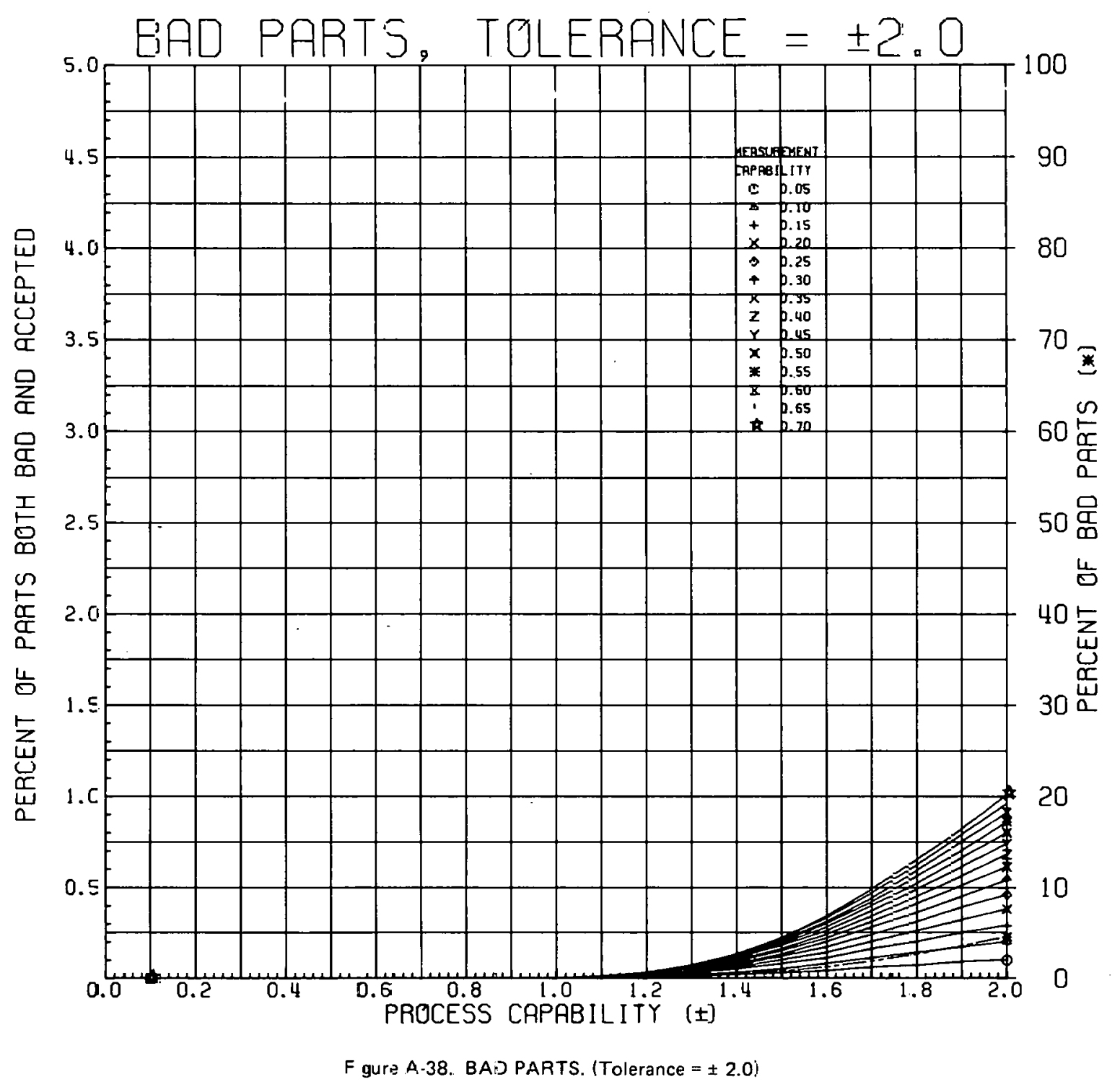


APPENDIX B

TABULAR INFORMATION 
THIS PAGE

WAS INTENTIONALLY

LEFT BLANK 


\begin{tabular}{|c|c|}
\hline 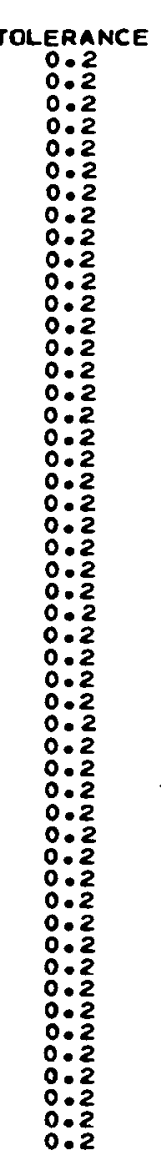 & 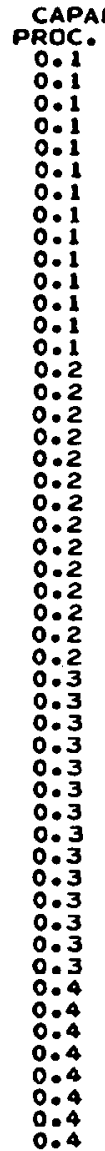 \\
\hline
\end{tabular}

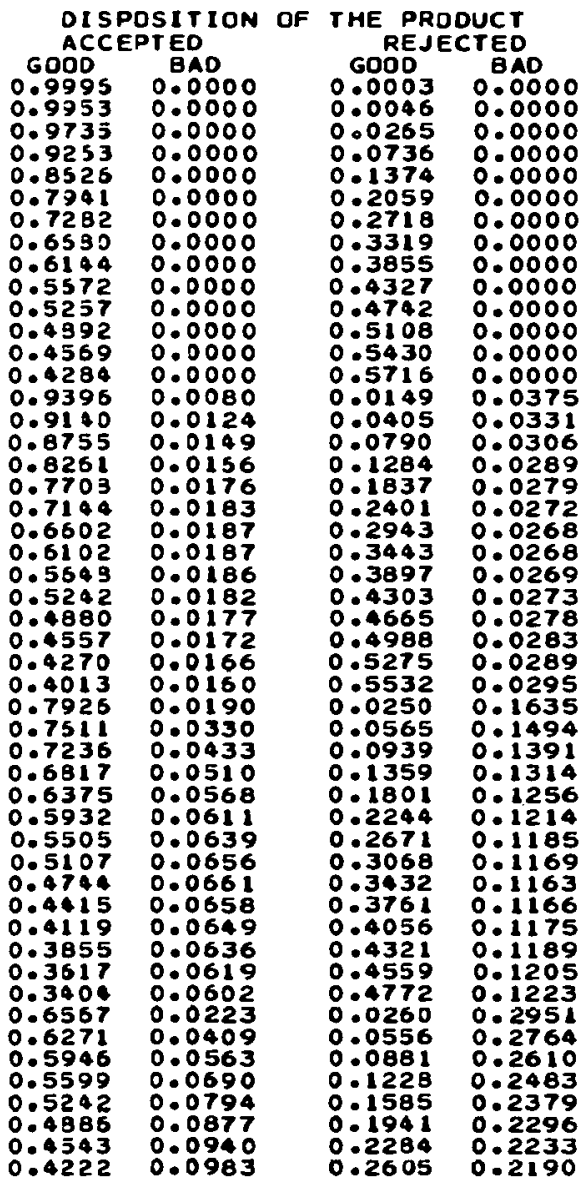

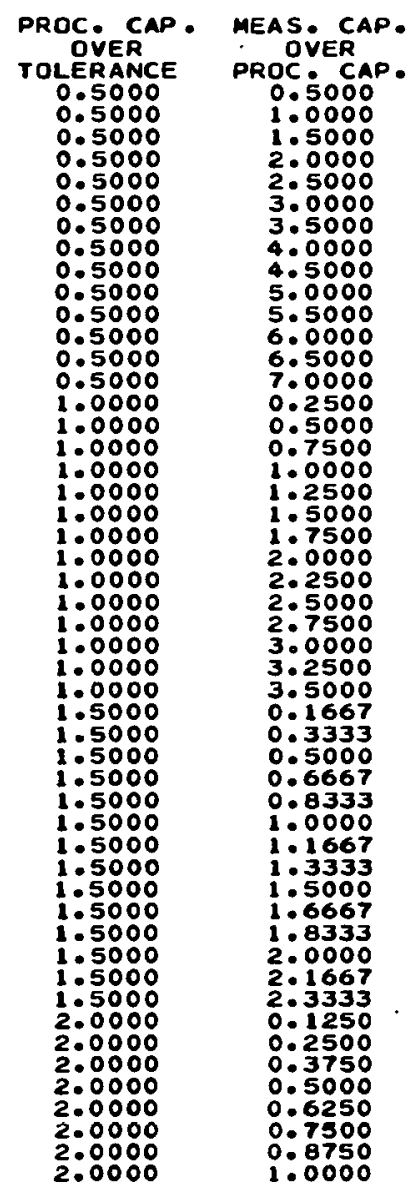

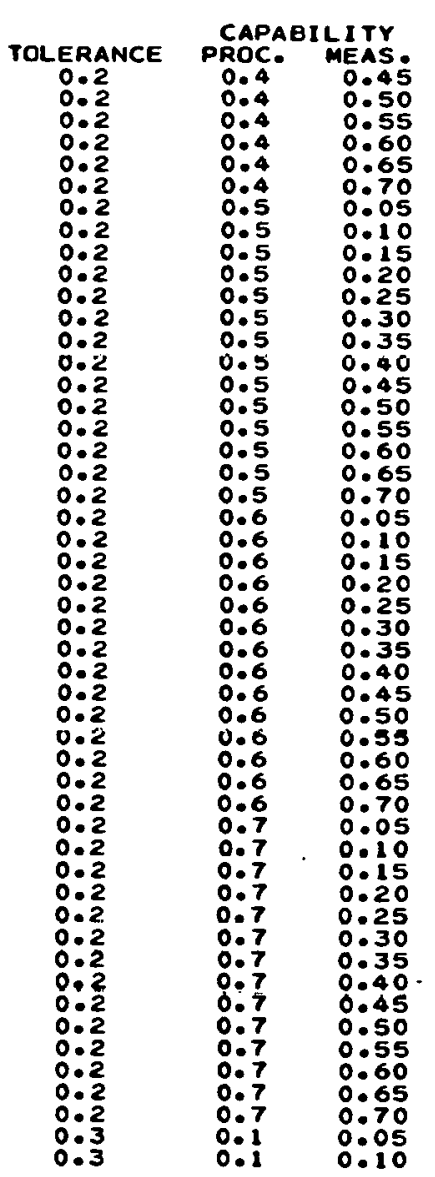

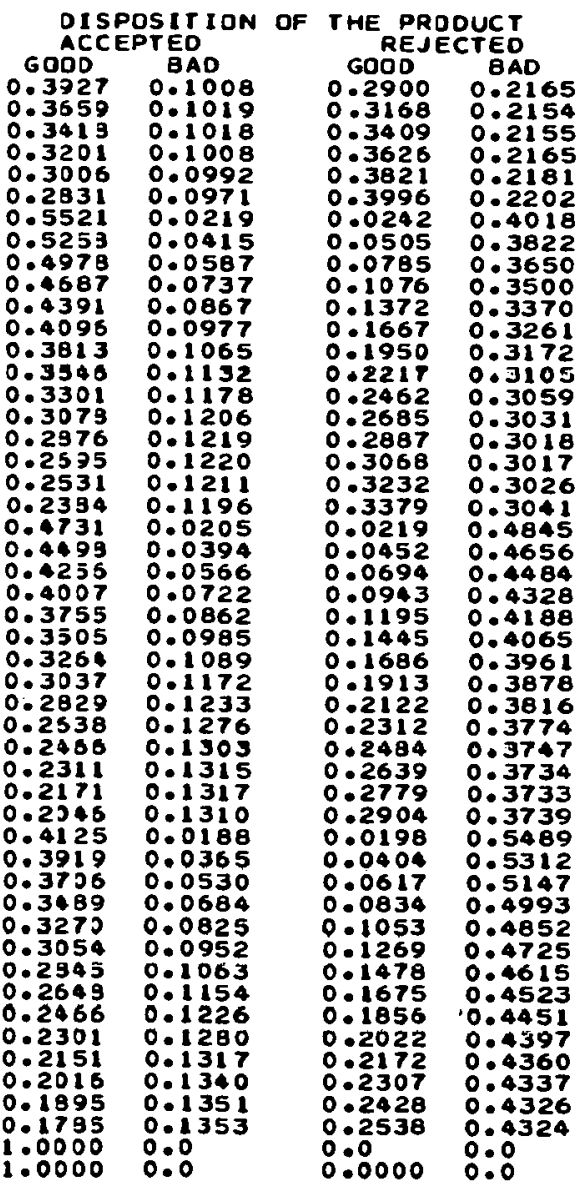

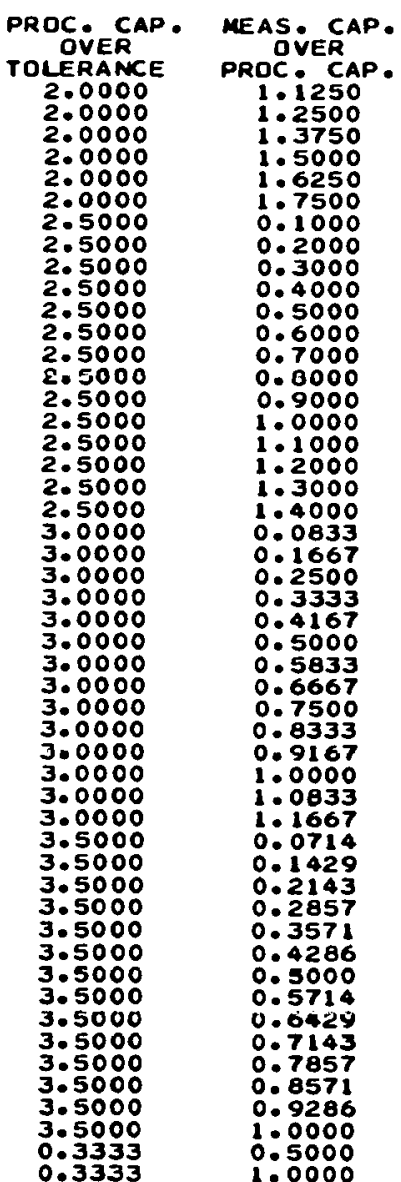




\begin{tabular}{|c|c|}
\hline $\begin{array}{l}\text { LERANCE } \\
:: 3 \\
0: 3 \\
0: 3 \\
:: 3 \\
0: 3 \\
0: 3 \\
0: 3 \\
0: 3 \\
0: 3 \\
0: 3 \\
0: 3 \\
0: 3 \\
0: 3 \\
0: 3 \\
0: 3 \\
0: 3 \\
0: 3 \\
0: 3 \\
0: 3 \\
0: 3 \\
0: 3 \\
0: 3 \\
0: 3 \\
0: 3 \\
0: 3 \\
0: 3 \\
0: 3 \\
0: 3 \\
0: 3 \\
0: 3 \\
0: 3 \\
0: 3 \\
0: 3 \\
0: 3 \\
0: 3 \\
0: 3 \\
0: 3 \\
0: 3 \\
0: 3 \\
0: 3 \\
0: 3 \\
0: 3 \\
0: 3 \\
0: 3 \\
0: 3 \\
0: 3 \\
0: 3 \\
0: 3 \\
03 \\
0: 3\end{array}$ & $\begin{array}{c}\text { CAPA } \\
\text { PROC. } \\
0: 1 \\
0: 1 \\
0: 1 \\
0: 1 \\
0: 1 \\
0: 1 \\
0: 1 \\
0: 1 \\
0: 1 \\
0: 1 \\
0: 1 \\
0: 1 \\
0: 2 \\
0: 2 \\
0: 2 \\
0: 2 \\
0: 2 \\
0: 2 \\
0: 2 \\
0: 2 \\
0: 2 \\
0: 2 \\
0: 2 \\
0: 2 \\
0: 2 \\
0: 2 \\
0: 2 \\
0: 3 \\
0: 3 \\
0: 3 \\
0: 3 \\
0: 3 \\
0: 3 \\
0: 3 \\
0: 3 \\
0: 3 \\
0: 3 \\
0: 3 \\
0: 3 \\
0: 3 \\
0: 3 \\
0: 4 \\
0: 4 \\
0: 4 \\
0: 4 \\
0: 4 \\
0: 4 \\
0: 4 \\
0: 4 \\
0: 4 \\
0: 4\end{array}$ \\
\hline
\end{tabular}

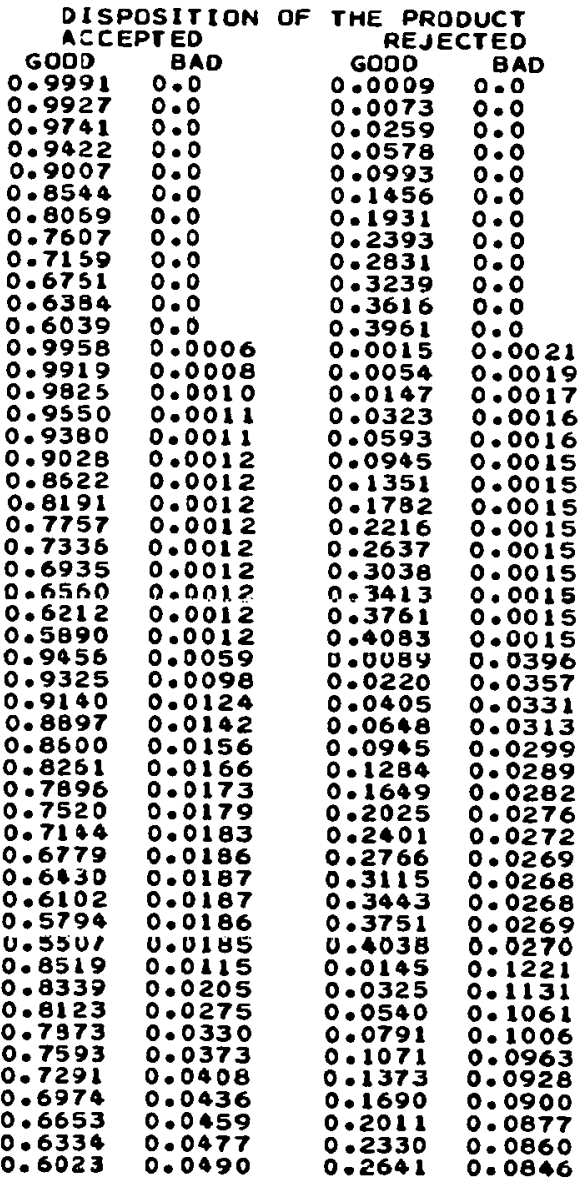

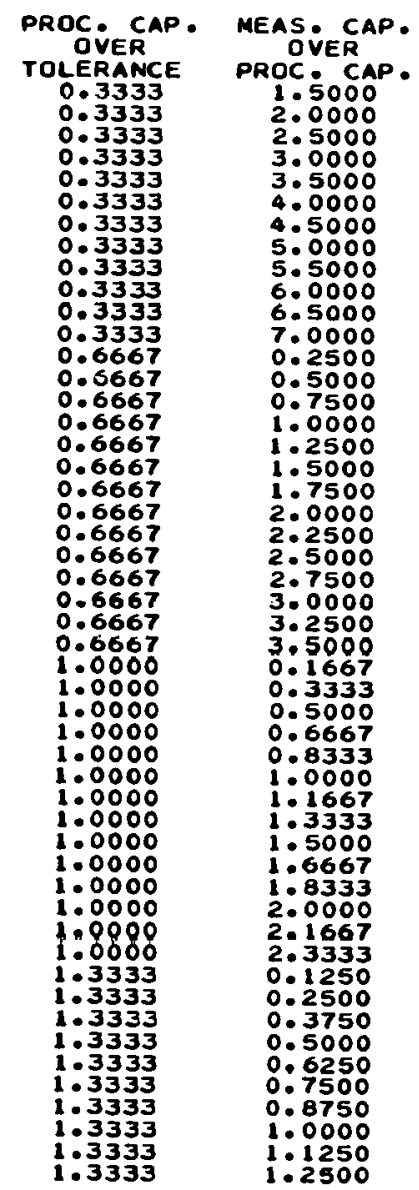

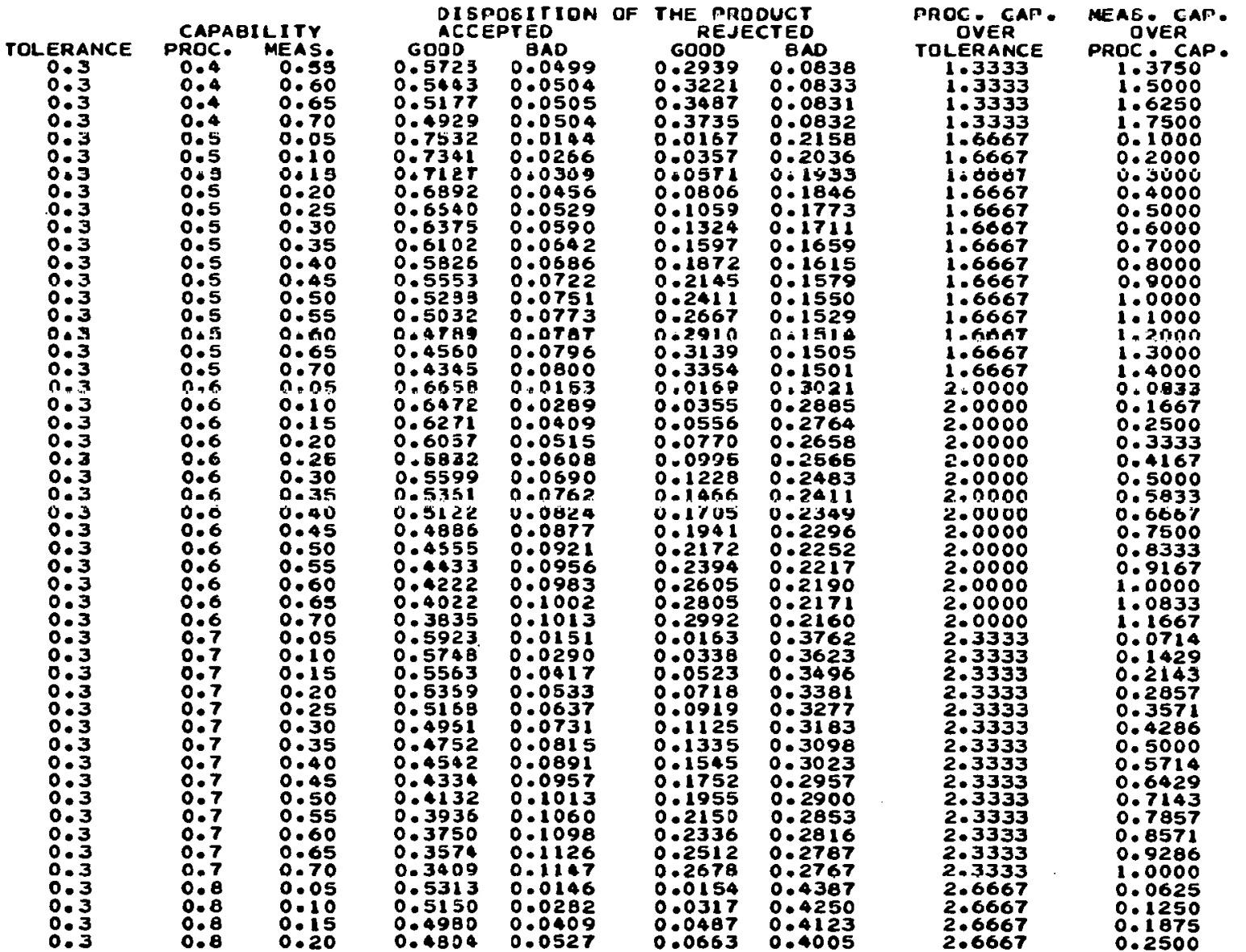



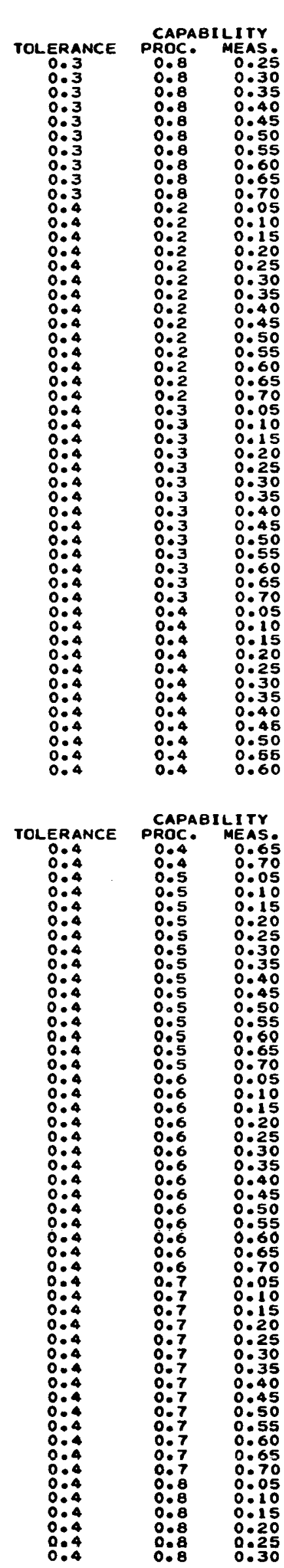

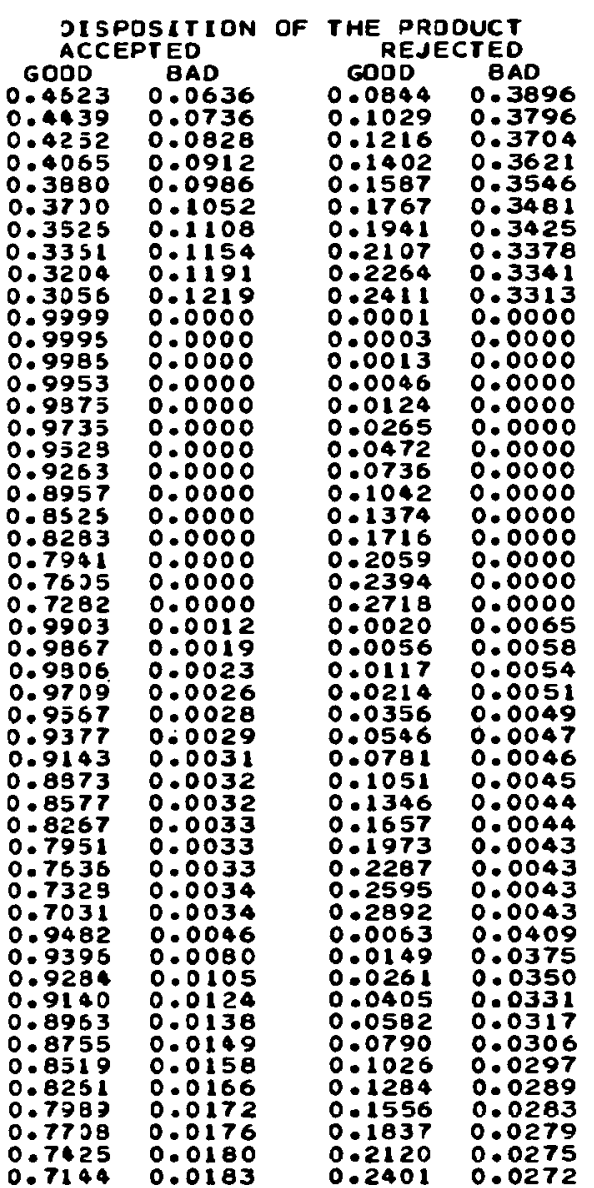

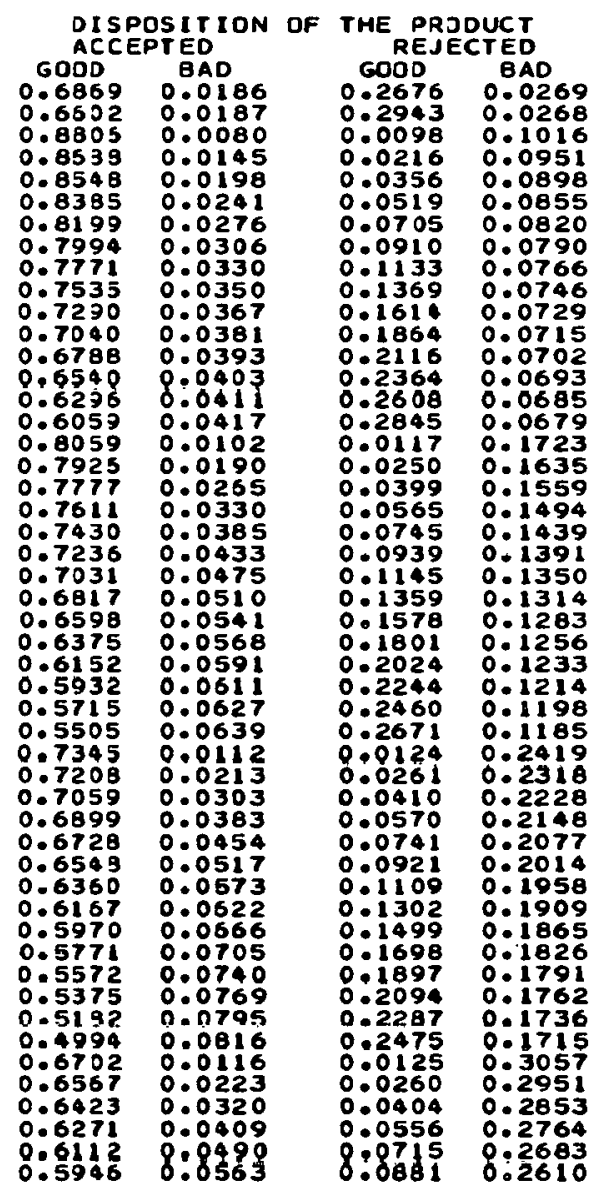

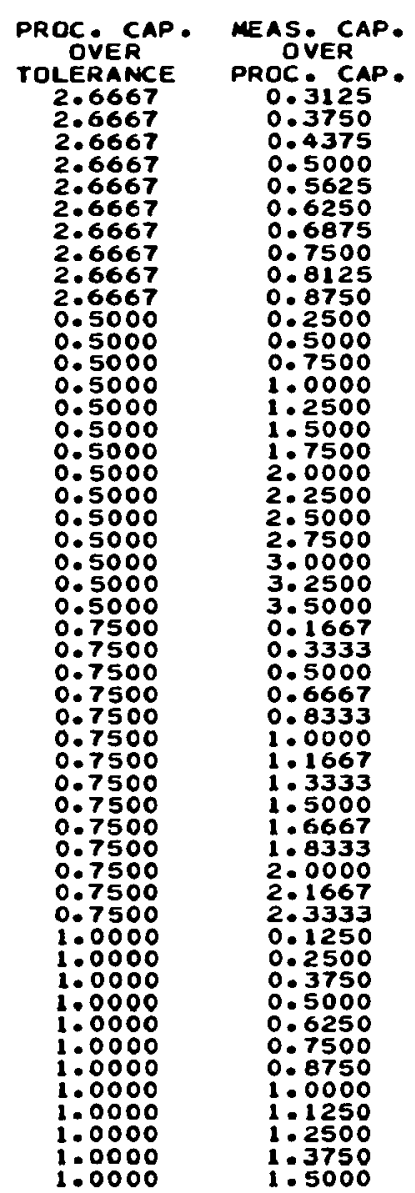

\begin{tabular}{|c|c|}
\hline 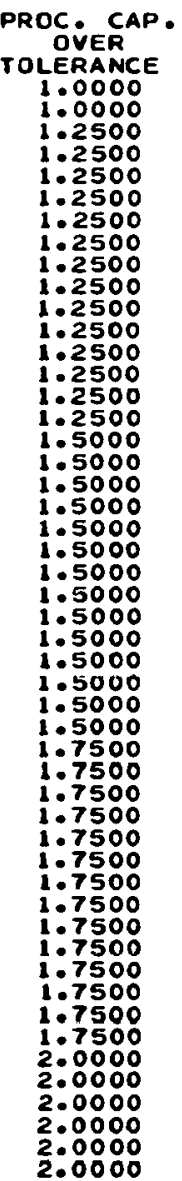 & 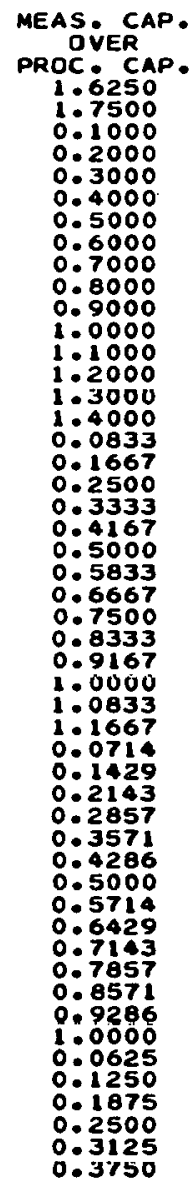 \\
\hline
\end{tabular}




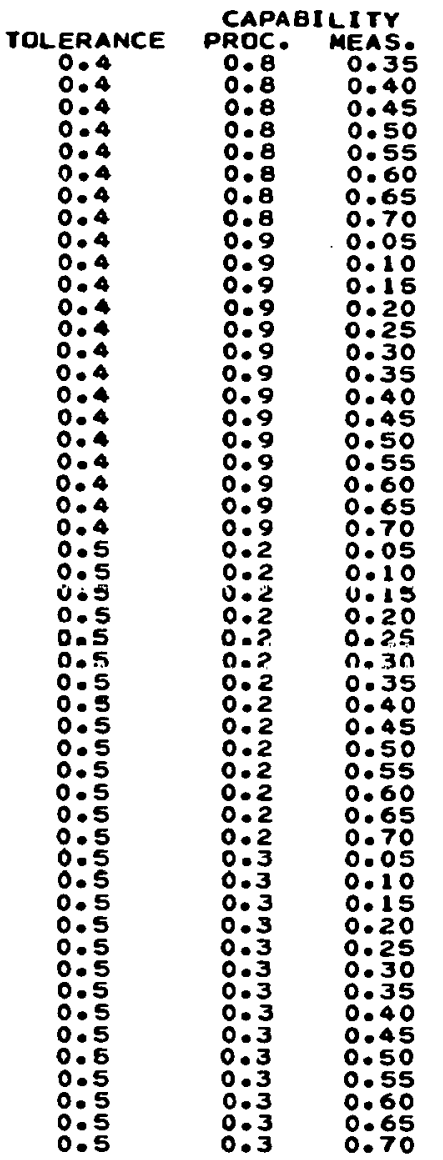

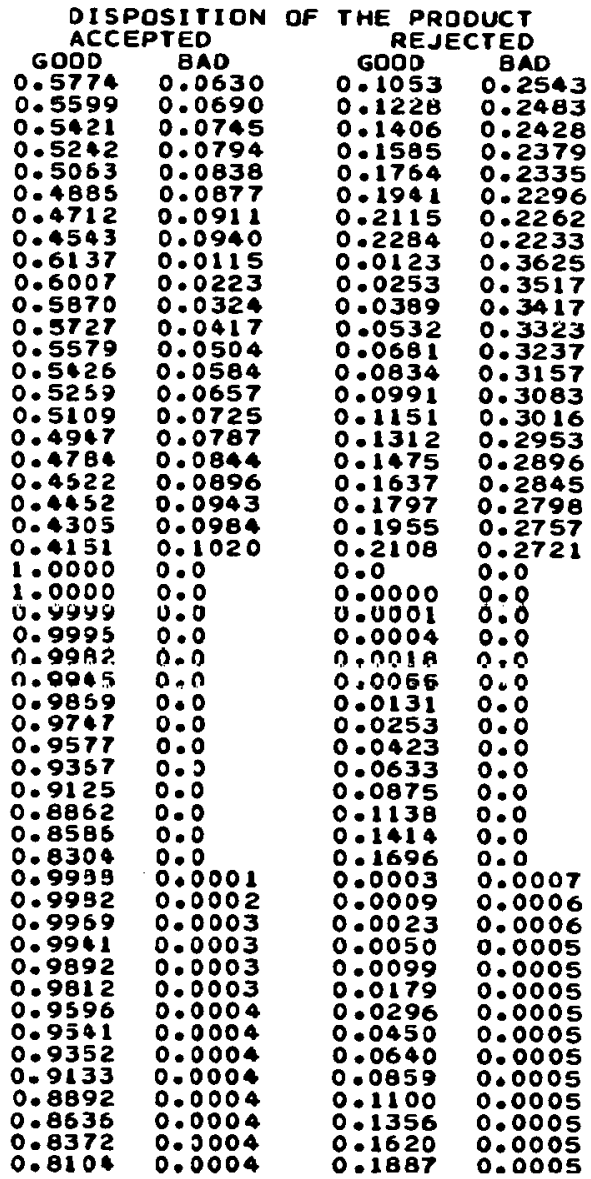

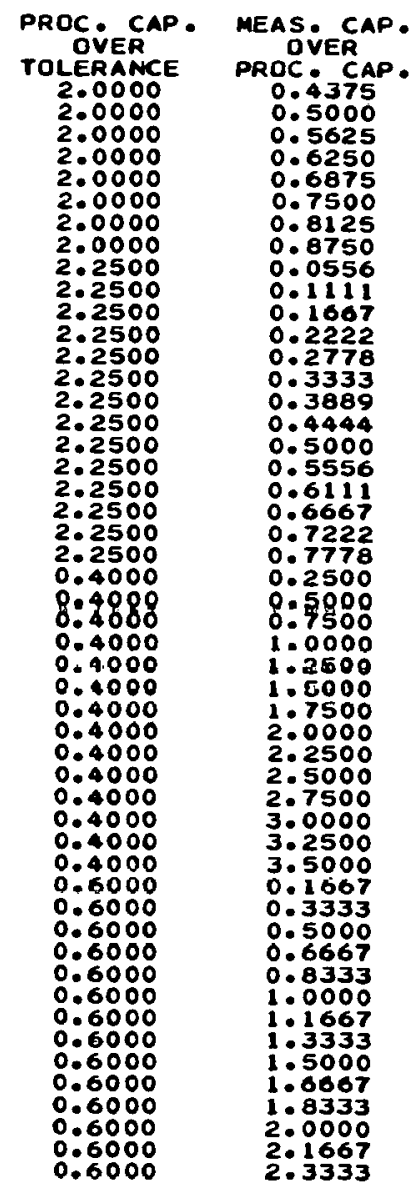

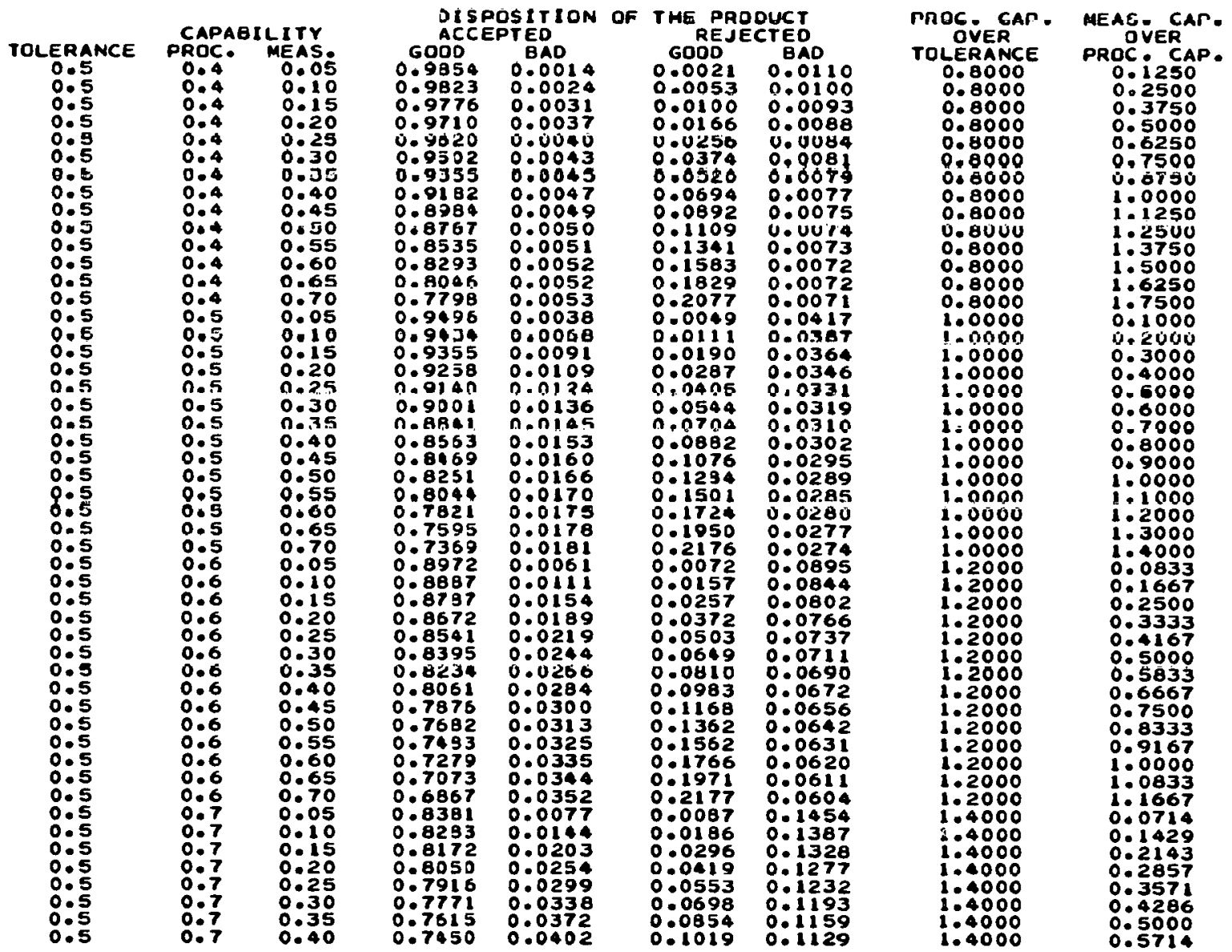




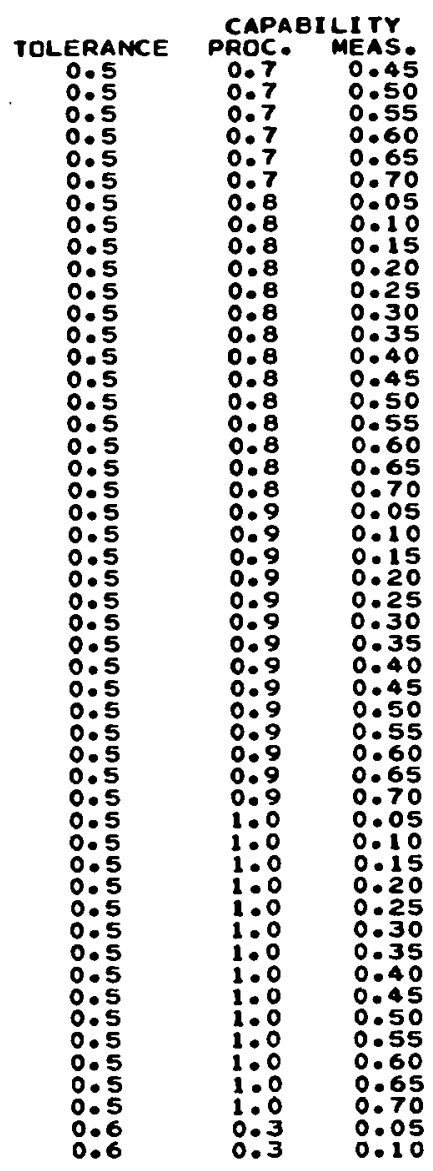

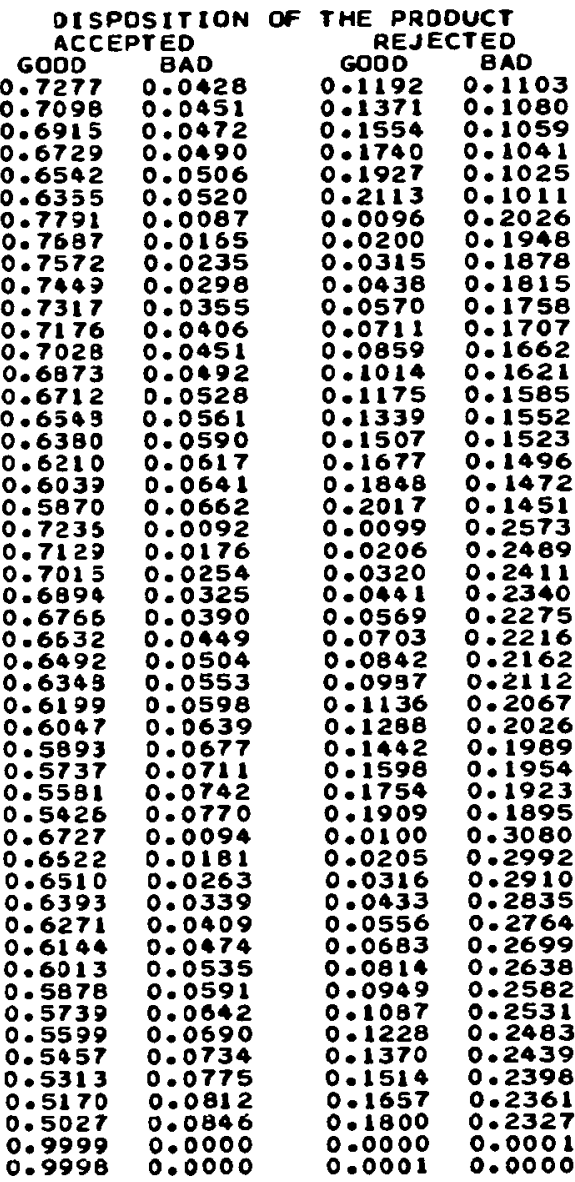

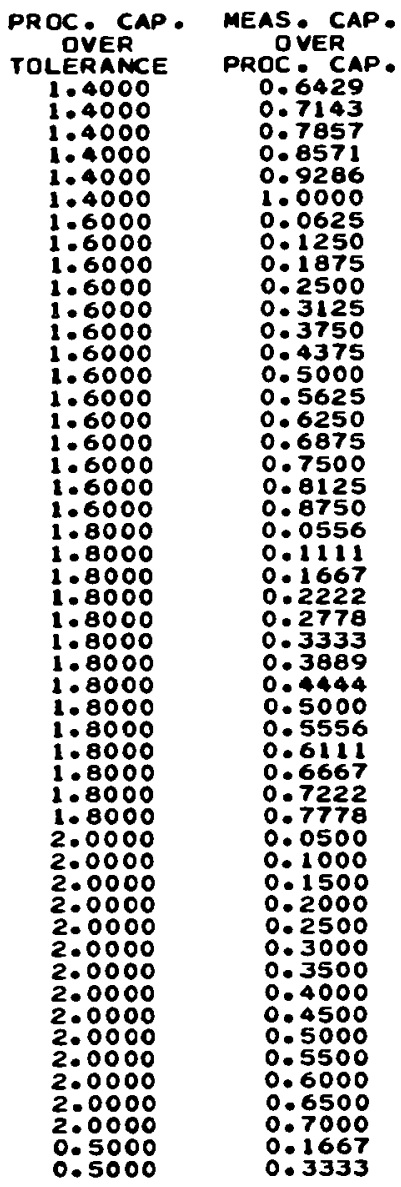

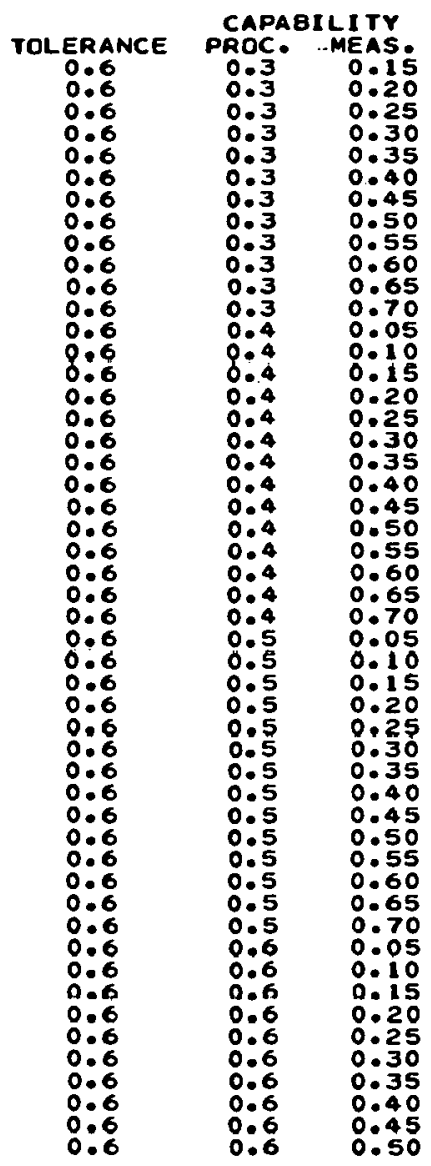

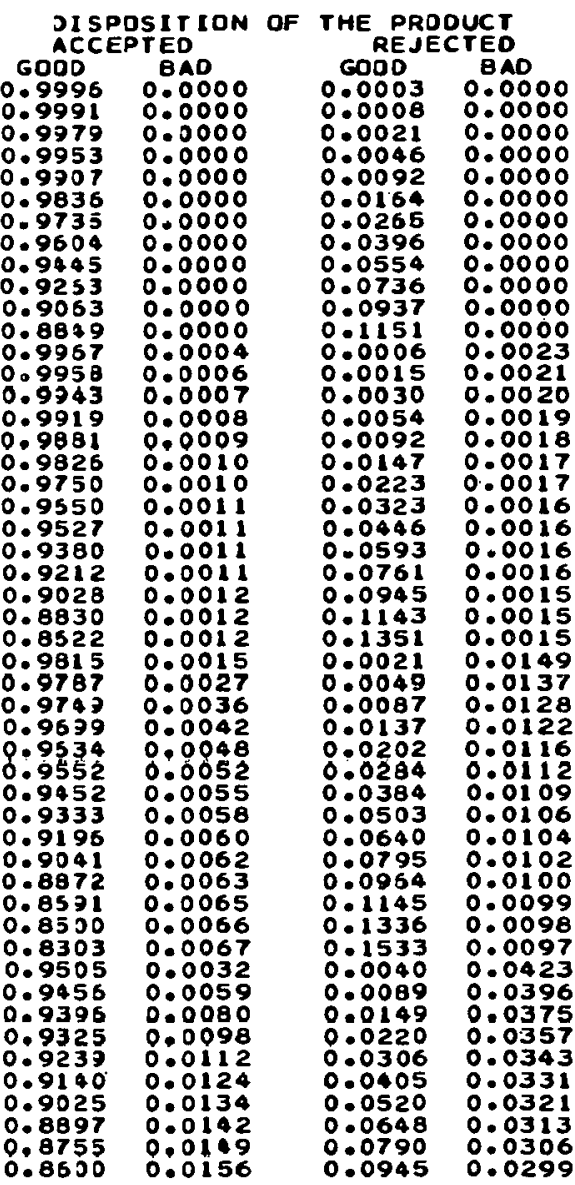

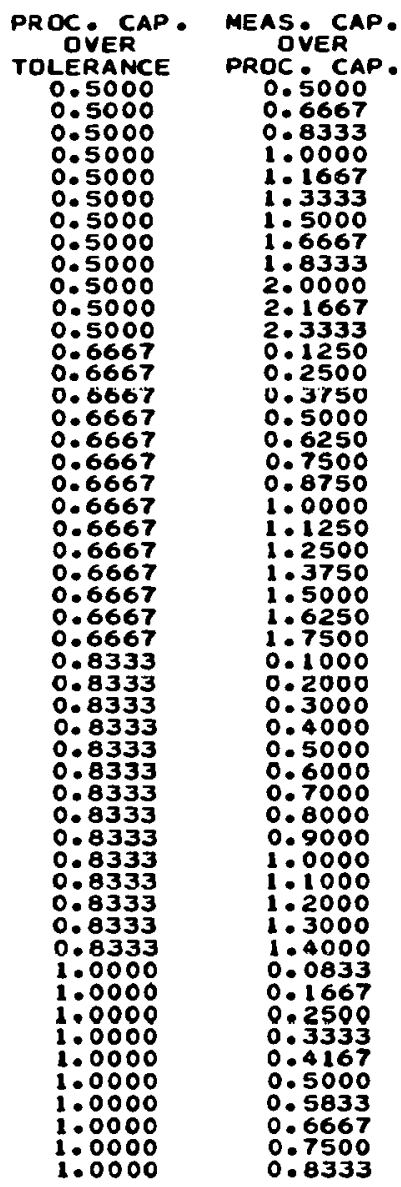




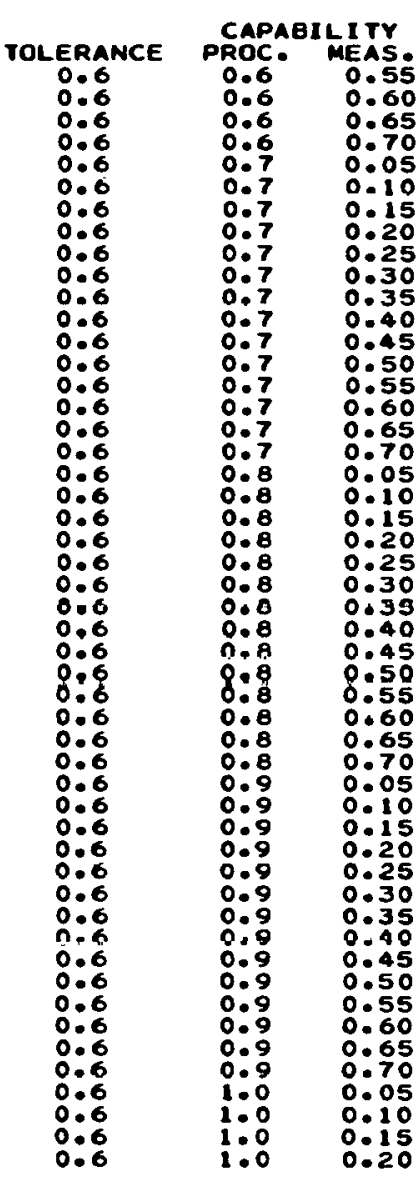

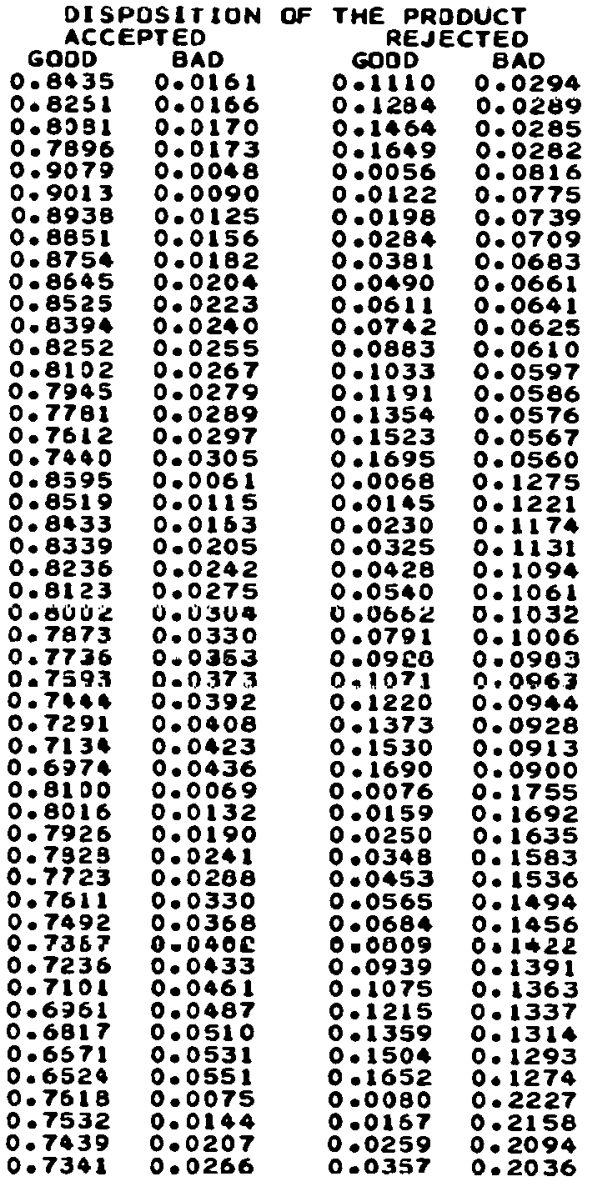

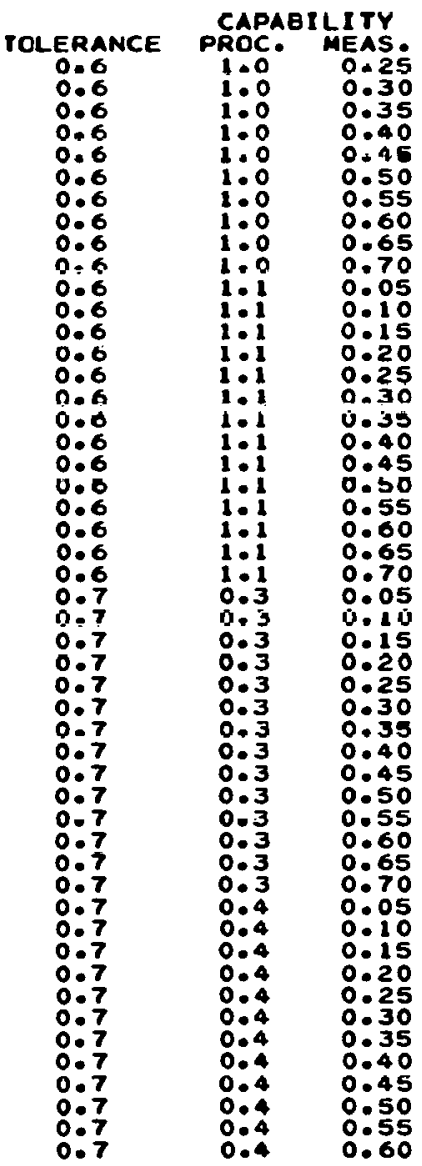

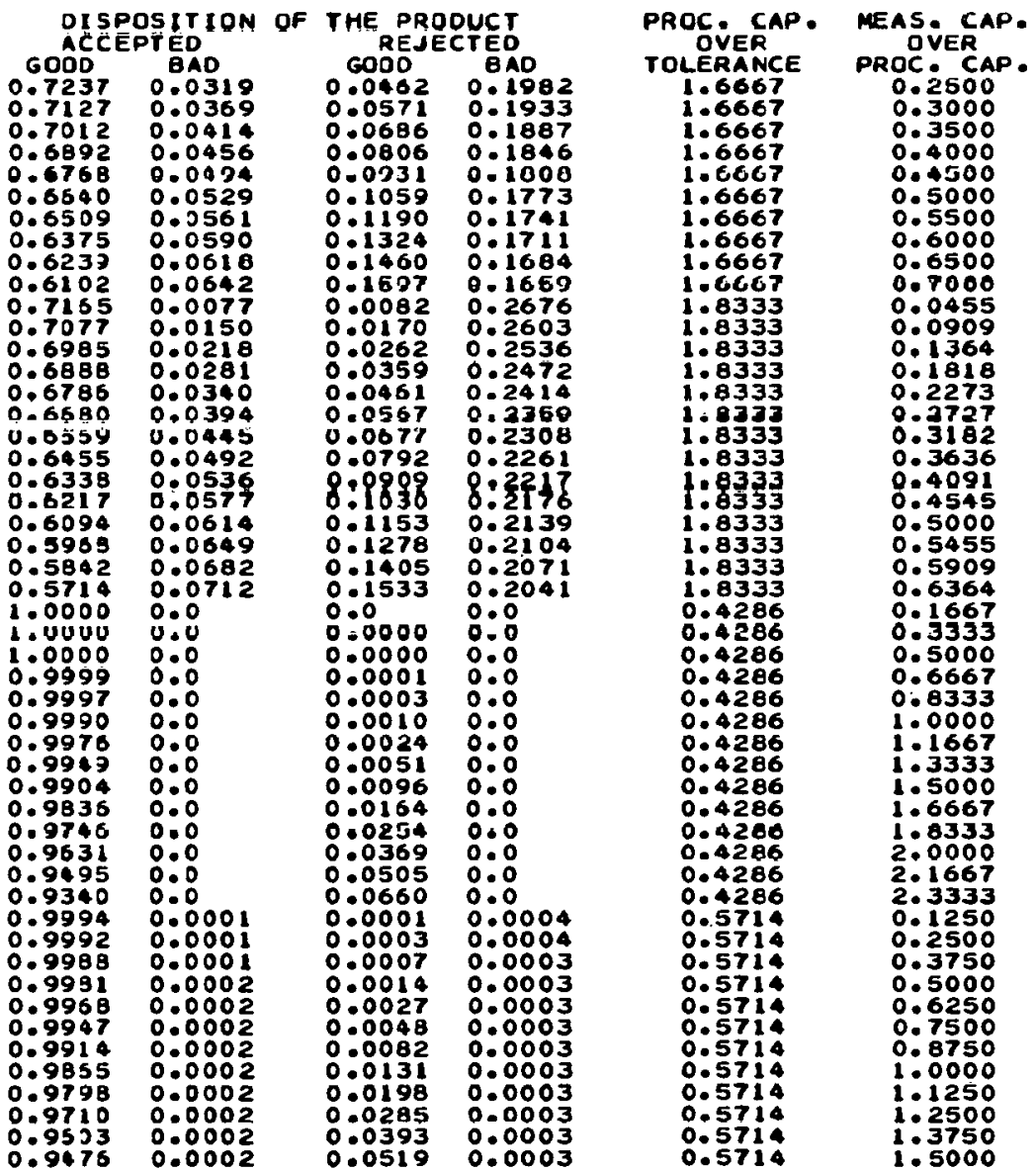

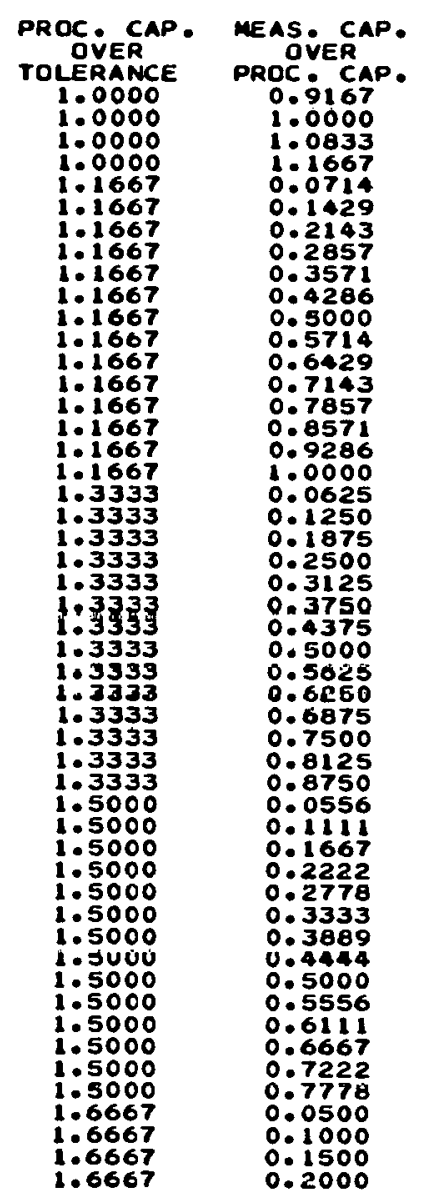

PROC CAP. 


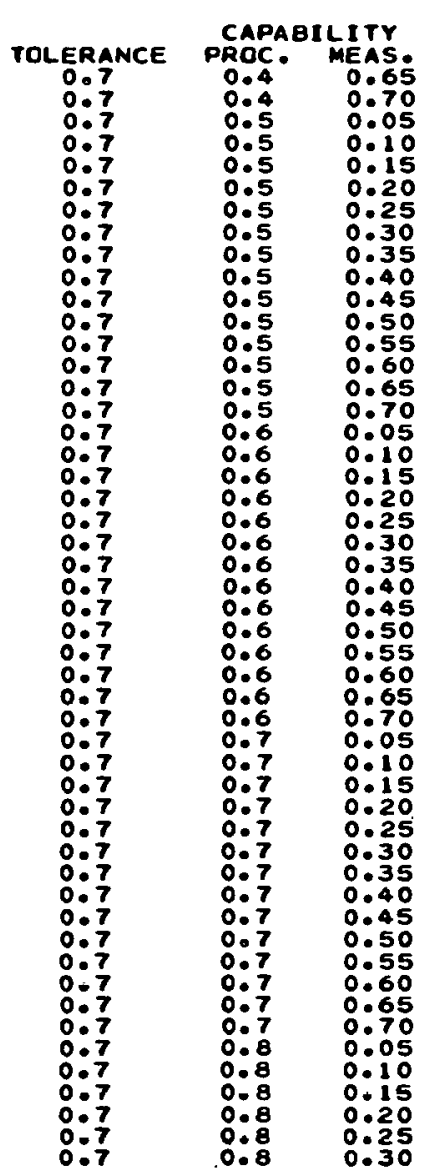

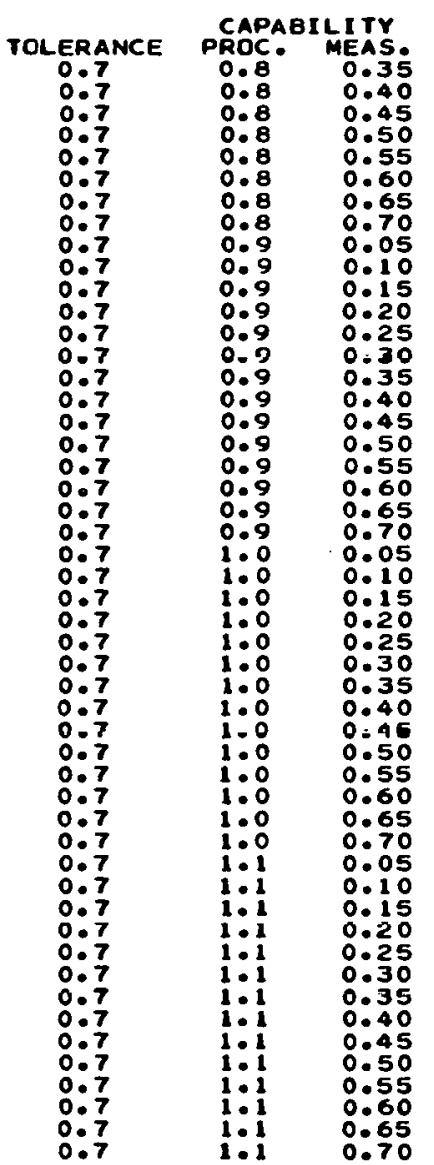

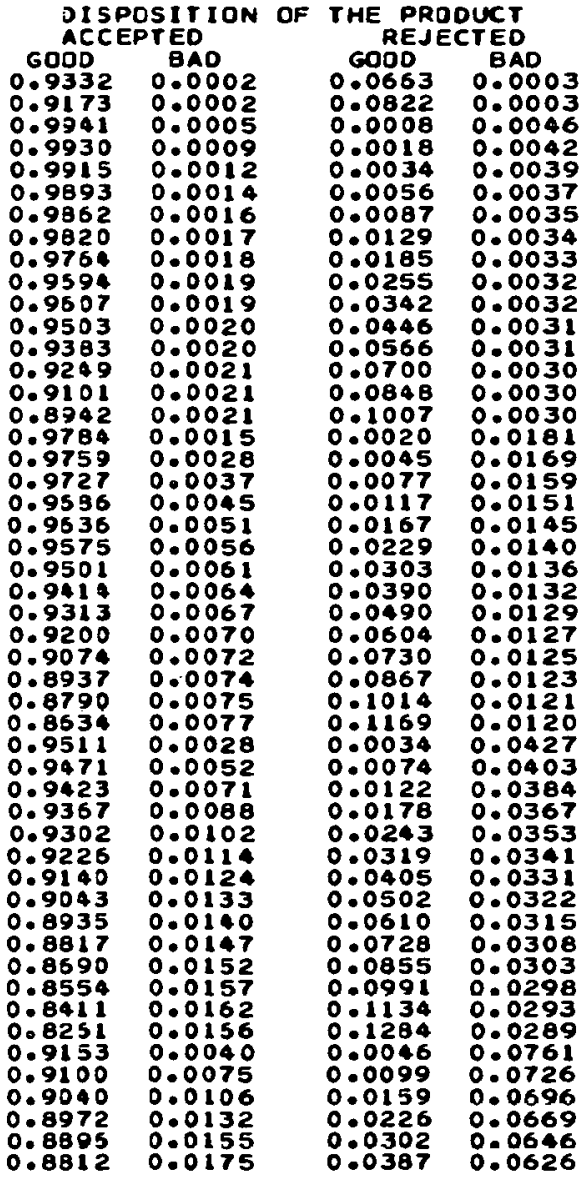

DISPOSITION OF THE PRODUCT GOÁDCEPTED

0.8718 O.0193

0.86150 .0208

$0.8339 \quad 0.0234$

$0.8252 \quad 0.0245$

$0.8130 \quad 0.0254$

0.78510 .0271

$\begin{array}{ll}0.8745 & 0.0050 \\ 0.8534 & 0.0095\end{array}$

0.86150 .0135

0.85410 .0170

0.85590 .0202

$0.8273 \quad 0.0256$

$0.8159 \quad 0.0279$

0.8059 0.

$\begin{array}{ll}0.7943 & 0.0318 \\ 0.7922 & 0.0334\end{array}$

$\begin{array}{ll}0.7922 & 0.0334 \\ 0.7695 & 0.0349\end{array}$

$0.7564 \quad 0.0363$

$\begin{array}{ll}0.7430 & 0.0375 \\ 0.8322 & 0.0057\end{array}$

0.83250 .01009

0.8255 0.0157

0.81020 .0200

$0.8015 \quad 0.0240$

$0.7925 \quad 0.0276$

$\begin{array}{ll}0.7928 & 0.0308 \\ 0.7725 & 0.0338\end{array}$

$0.7625 \quad 0.0338$

$0.7505 \quad 0.0390$

$\begin{array}{ll}0.7339 & 0.0412 \\ 0.7268 & 0.0433\end{array}$

$\begin{array}{ll}0.7268 & 0.0433 \\ 0.7114 & 0.0452\end{array}$

$0.7017 \quad 0.0469$

$\begin{array}{ll}0.7902 & 0.0062 \\ 0.7831 & 0.0120\end{array}$

$0.7754 \quad 0.0173$

$0.7873 \quad 0.0222$

$0.7495 \quad 0.0310$

$0.7400 \quad 0.0340$

0.72790 .0384

$0.7195 \quad 0.0417$

$0.6975 \quad 0.0475$

$0.6850 \quad 0.0501$

$\begin{array}{ll}0.6743 & 0.0525 \\ 0.6523 & 0.0547\end{array}$

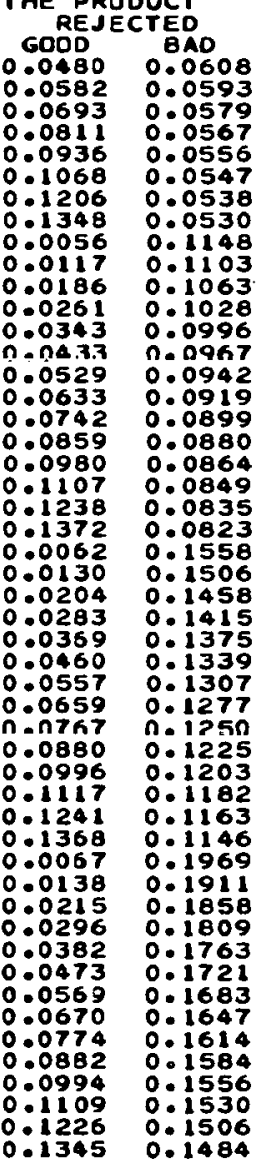

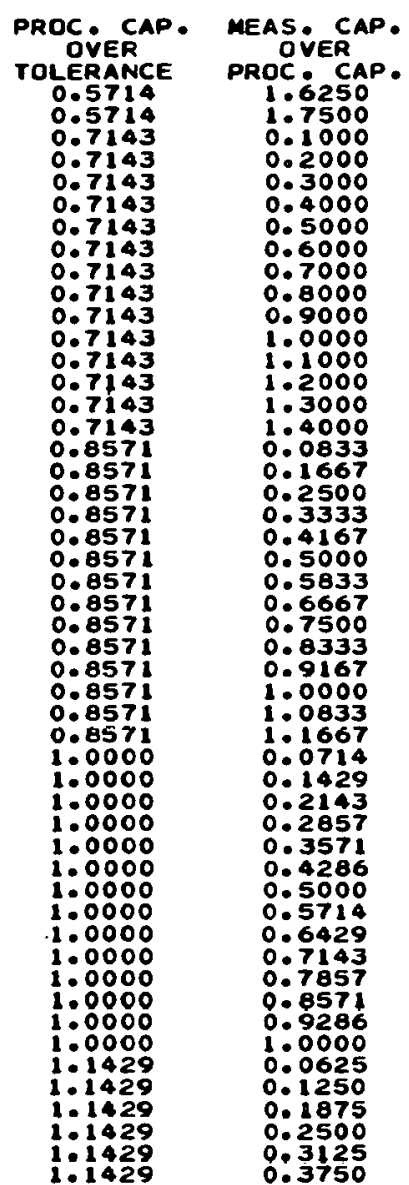

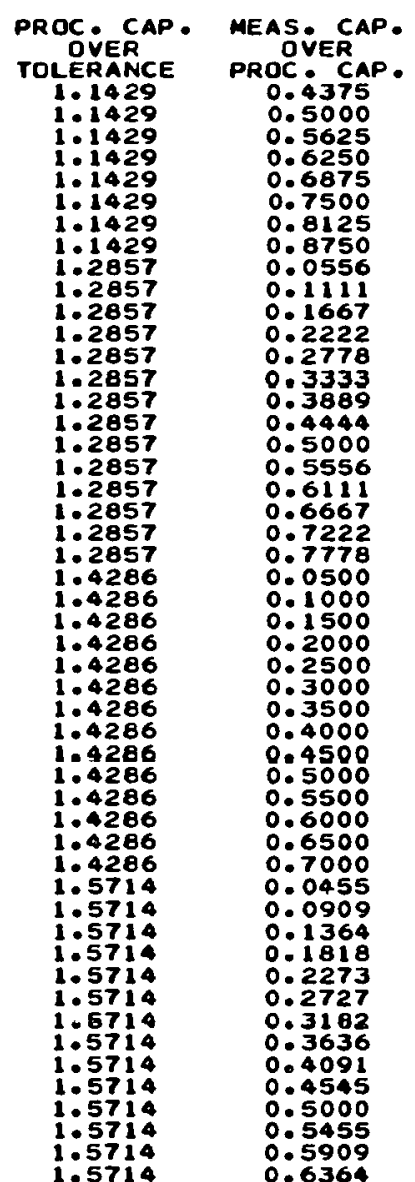




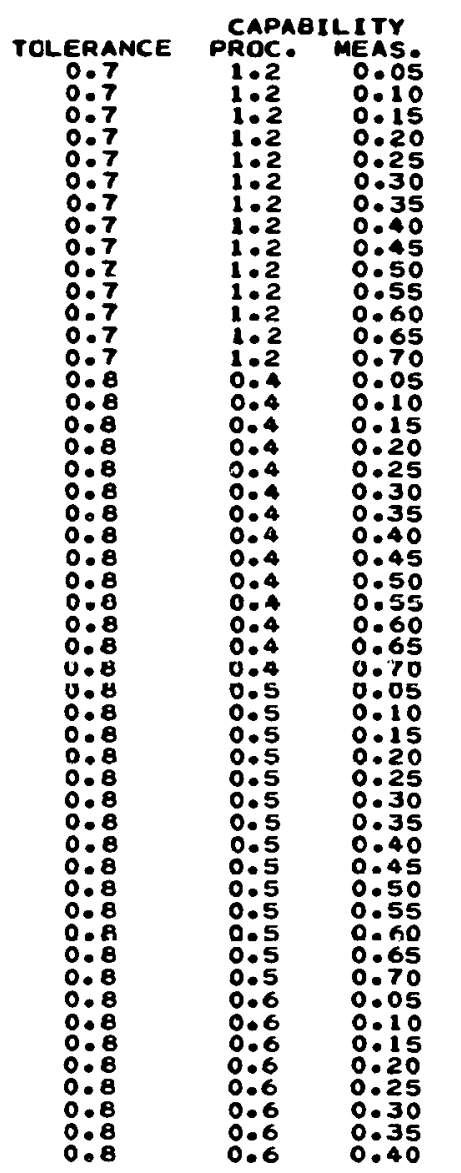

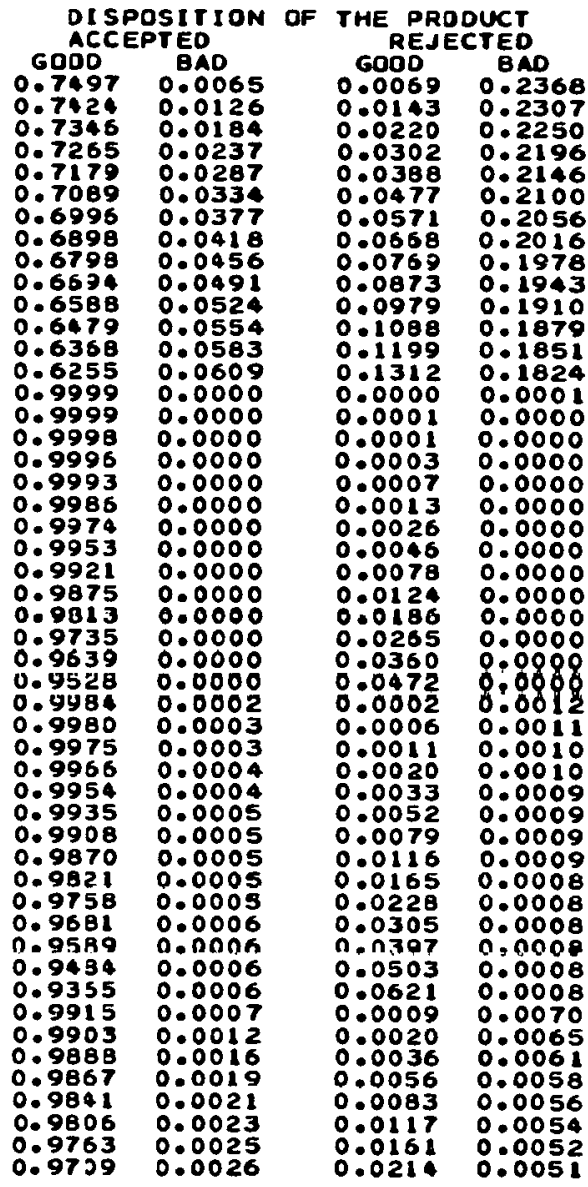

\begin{tabular}{|c|c|}
\hline 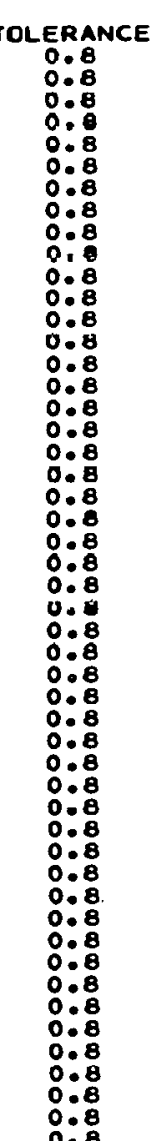 & $\begin{array}{l}\text { CAPA } \\
\text { PROC. } \\
0: 6 \\
0: 6 \\
0: 6 \\
0: 6 \\
0: 6 \\
0: 6 \\
0: 7 \\
0: 7 \\
0: 7 \\
0: 7 \\
0: 7 \\
0: 7 \\
0: 7 \\
0: 7 \\
0: 7 \\
0: 7 \\
0: 7 \\
0: 7 \\
0: 7 \\
0: 7 \\
0: 8 \\
0: 8 \\
0: 8 \\
0: 8 \\
0: 8 \\
0: 8 \\
0: 8 \\
0: 8 \\
0: 8 \\
0: 8 \\
0: 8 \\
0: 8 \\
0: 8 \\
0: 8 \\
0: 9 \\
0: 9 \\
0: 9 \\
0: 9 \\
0: 9 \\
0: 9 \\
0: 9 \\
0: 9 \\
0: 9 \\
0: 9 \\
0: 9 \\
0: 9 \\
0: 9 \\
0: 9 \\
1: 0 \\
1: 0\end{array}$ \\
\hline
\end{tabular}

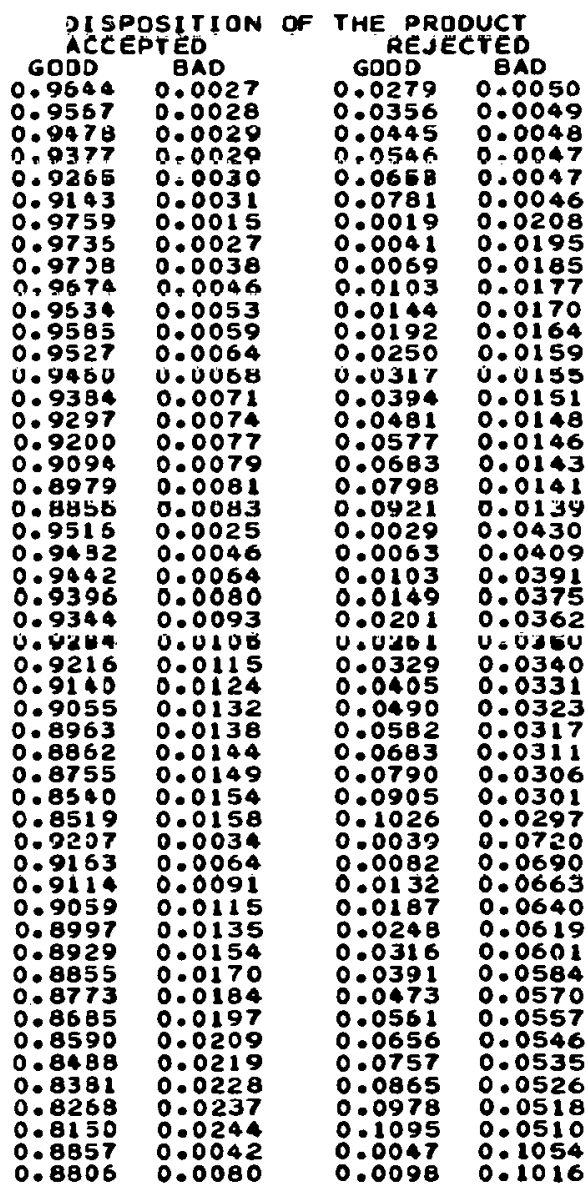

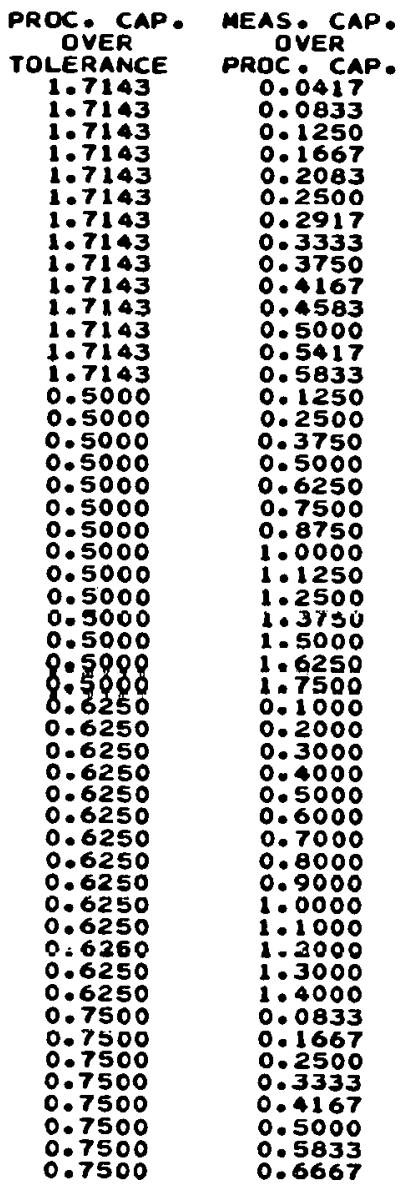

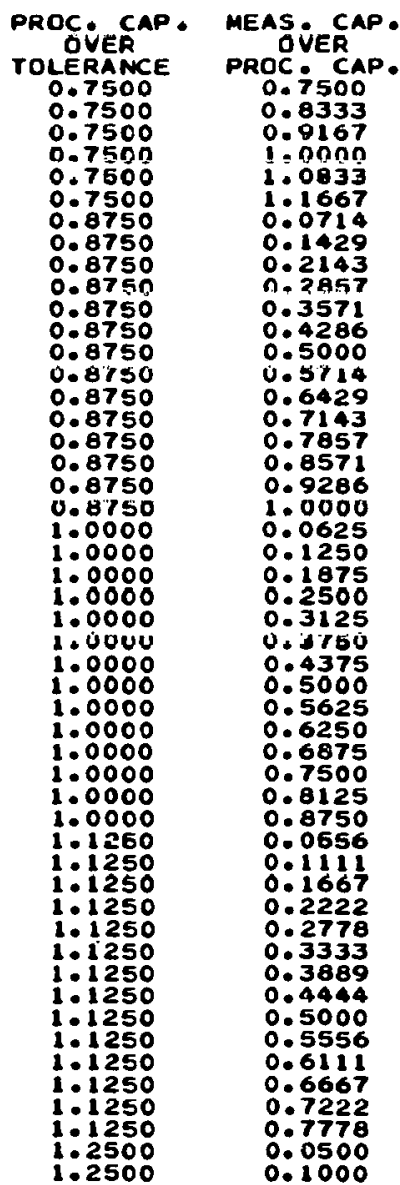




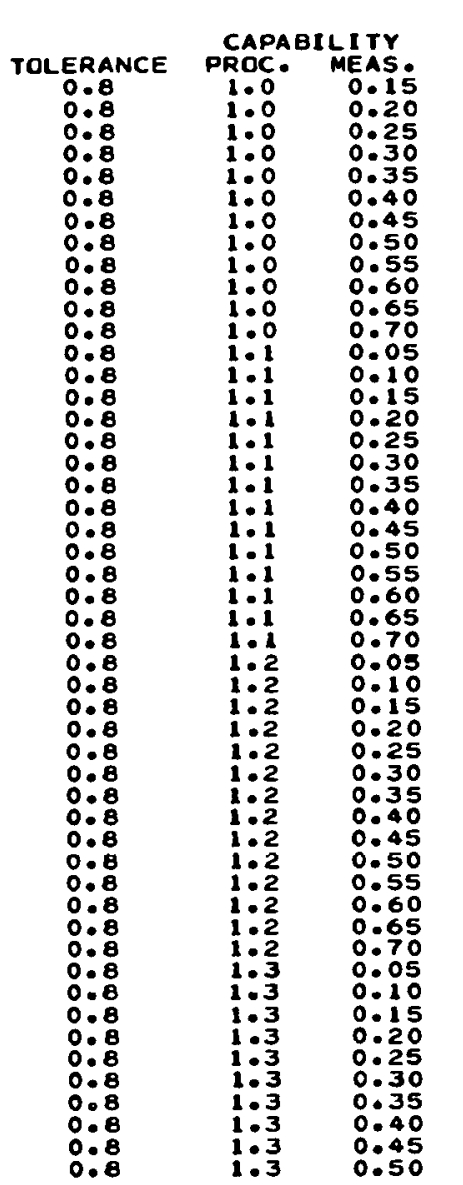

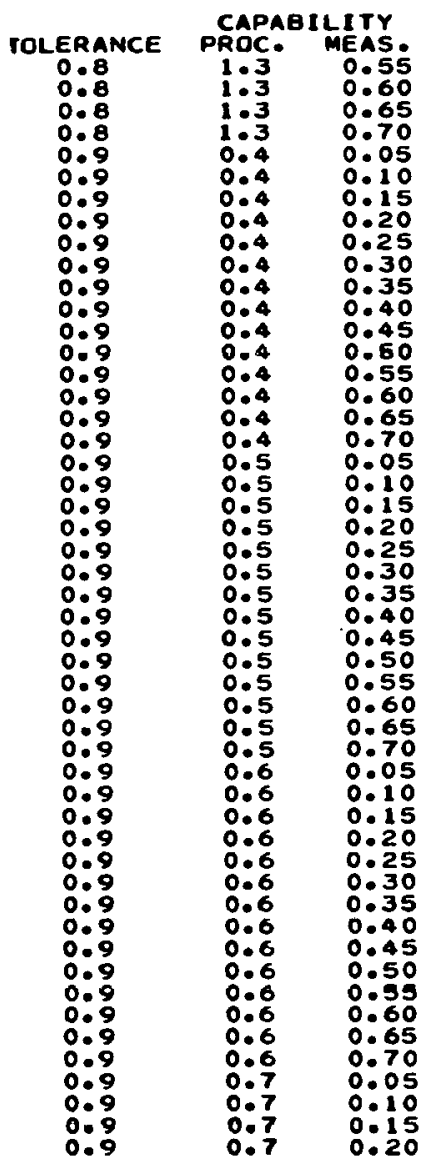

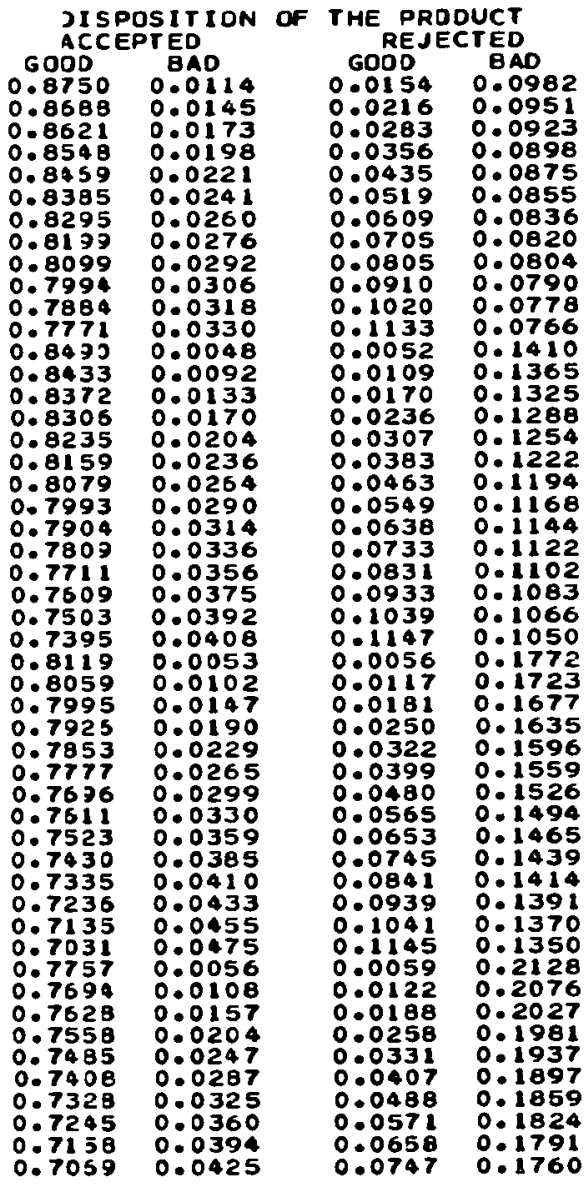

DISPOSITION OF ACCEPTEO GOJ DEPTEO

$0.6977 \quad 0.0453$

0.68820 .0480

$\begin{array}{ll}0.6785 & 0.0506 \\ 0.6685 & 0.0529\end{array}$

$1.0000 \quad 0.0000$

$1.0000 \quad 0.0000$

$1.0000 \quad 0.0000$

$0.9999 \quad 0.0000$

$0.9997 \quad 0.0000$

$0.9993 \quad 0.0000$

$0.9985 \quad 0.0000$

$\begin{array}{ll}0.9951 & 0.0000 \\ 0.9919 & 0.0000\end{array}$

$0.9874 \quad 0.0000$

$0.9816 \quad 0.0000$

$0.9744 \quad 0.0000$

0.0995 0.000

$0.9994 \quad 0.0001$

0.09850 .0001

0.9979

0.9967

0.9947

0.9890

0.9844

0.9717

0.9635

0.9955

0.9958

0.9930

0.9919

0.9865

0.9825

0.9720

0.9650

0.9430

0.9889

0.9863

0.0001

0.0001

0.0001

0.0001

0.0001

0.0001

0.0003

0.0004

0.0006

0.0008

0.0008

0.0009

0.0010

0.0010

0.0011

0.0021

0.0011

0.0013

0.0018 GOOD BAD

0.08390 .1731

$\begin{array}{ll}0.0934 & 0.1704 \\ 0.1031 & 0.1678\end{array}$

0.1131 0.1655

$0.0000 \quad 0.0000$

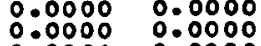

$0.0001 \quad 0.0000$

$0.0001 \quad 0.0000$

$0.0003 \quad 0.0000$

$0.0007 \quad 0.0000$

$0.0028 \quad 0.0000$

0.00490 .0000

$\begin{array}{ll}0.0081 & 0.0000 \\ 0.0126 & 0.0000\end{array}$

$\begin{array}{ll}0.0126 & 0.0000 \\ 0.0183 & 0.0000\end{array}$

$0.0001 \quad 0.0003$

$0: 0003 \quad 0.0002$

0.00110 .0002

$0.0018 \quad 0.0002$

$0.0030 \quad 0.0002$

$0.0073 \quad 0.0002$

$0.0107 \quad 0.0002$

$0.0153 \quad 0.0002$

$0.0210 \quad 0.0002$

$0.0280 \quad 0.0002$

0.00030 .0024

$0.0008 \quad 0.0023$

$0.0015 \quad 0.0021$

$0.0024 \quad 0.0020$

$0.0054 \quad 0.019$

0.0078 8.0019

0.0018

0.01470 .0017

$0.0195 \quad 0.0017$

$0.0253 \quad 0.0017$

0.0430 .0016

0.04930 .0016

$0.0000 \quad 0.0094$

0.00210 .0088

$0.0036 \quad 0.0083$
THE PRDDUCT

$0.0256 \quad 0.0000$

$0.0006 \quad 0.0002$

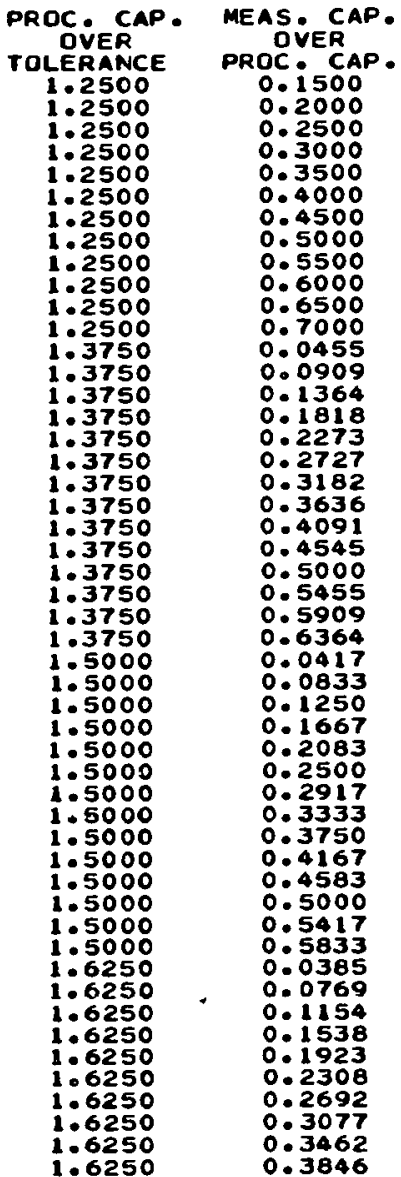

PROC CAP. MEAS CAP.

OVER

TOLERANC

1.6250

1.6250
1.6250

1.6250

0.4444

0.4444

0.4444

0.4449

0.4444

0.4444

0.4444

0.4444

0.4444

0.4444

0.5556

0.5556

. 5556

0.5556

0.5556

0.5556

0.5556

0.5556

0.5556

0.5556

0.5556

0.5556

0.6667

0.6667

0.6667

0.6667

0.6667

0.6667

0.6667

0.6667

0.6667

0.6667

0.6667

0.6667

0.7778

0.7778

0.7778
OVER

PROC CAP

0.4615

0.5000

0.5385

0.2500

0.3750

0.5000

0.7500

0.8750

1.0000

1.1250

1. 2500

1.5000

1.6250

. 7500

. 1000

0.2000

0.4000

0.5000

0.6000

0.7000

0.8000

1.0000

11000

1.2000

1.4000

0.1667

- 2500

0.3333

0.4167

0.5833

0.6667

0.7500

0.8333

1. 0000

1. 0833

1. 1667

0.0714

0.2143 


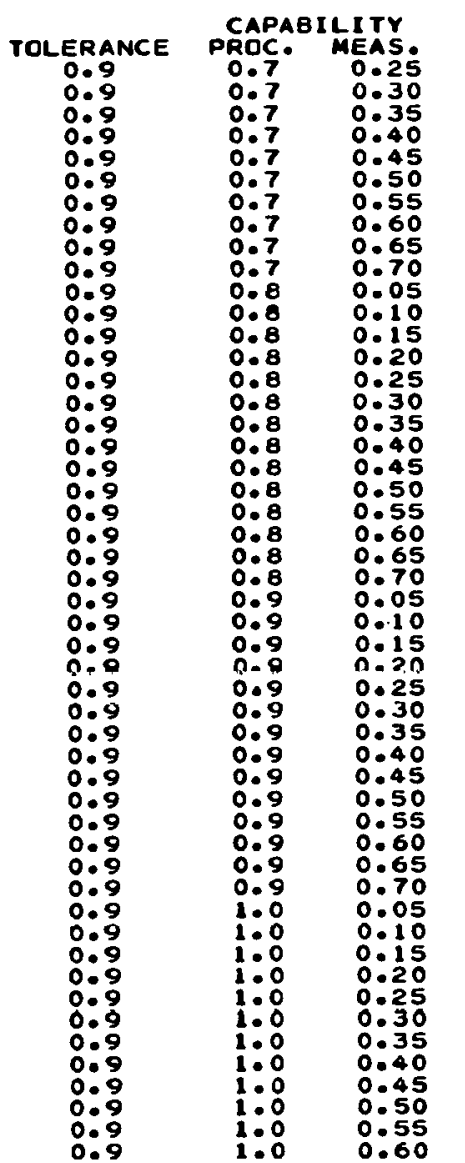

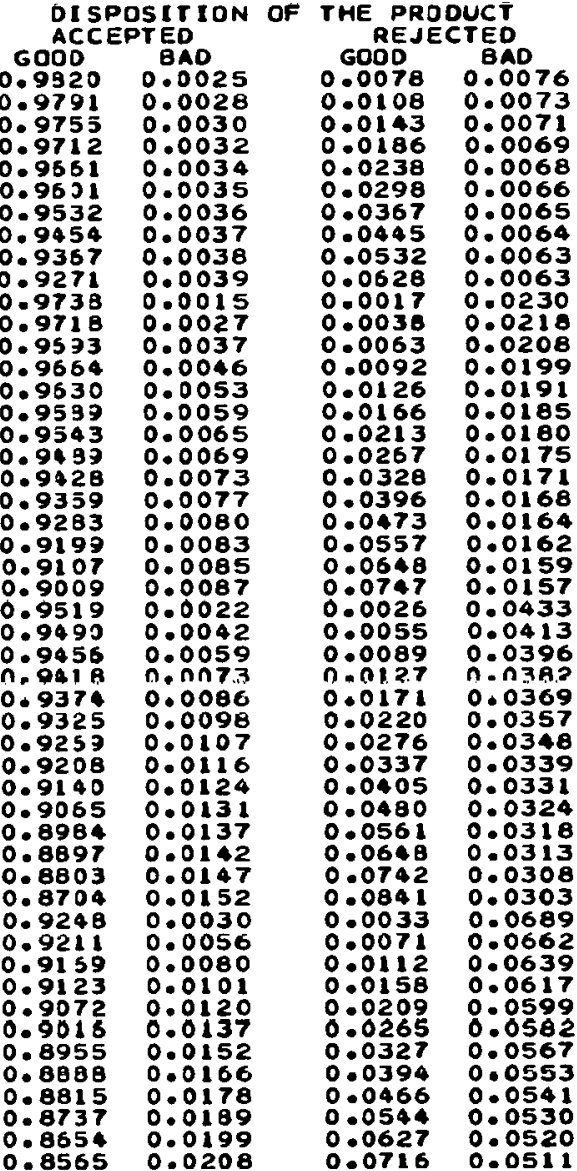

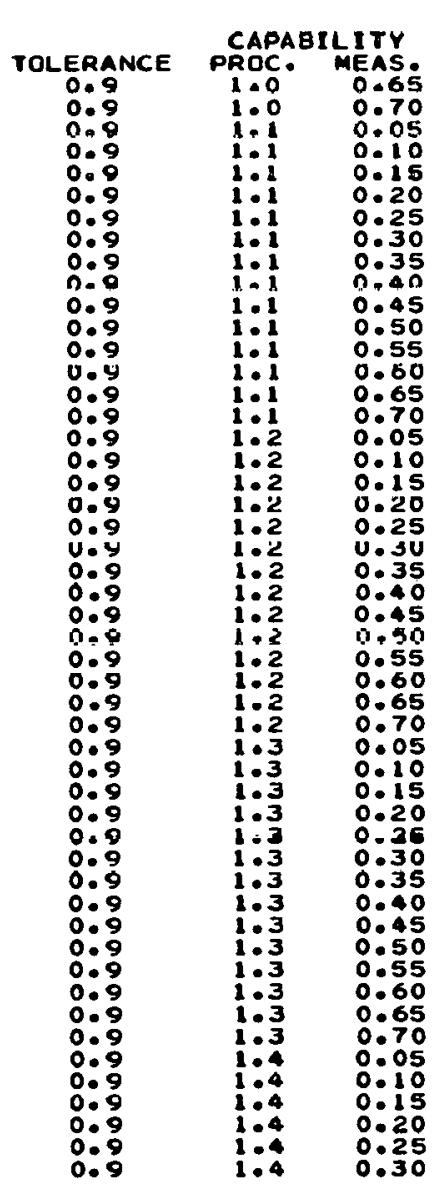

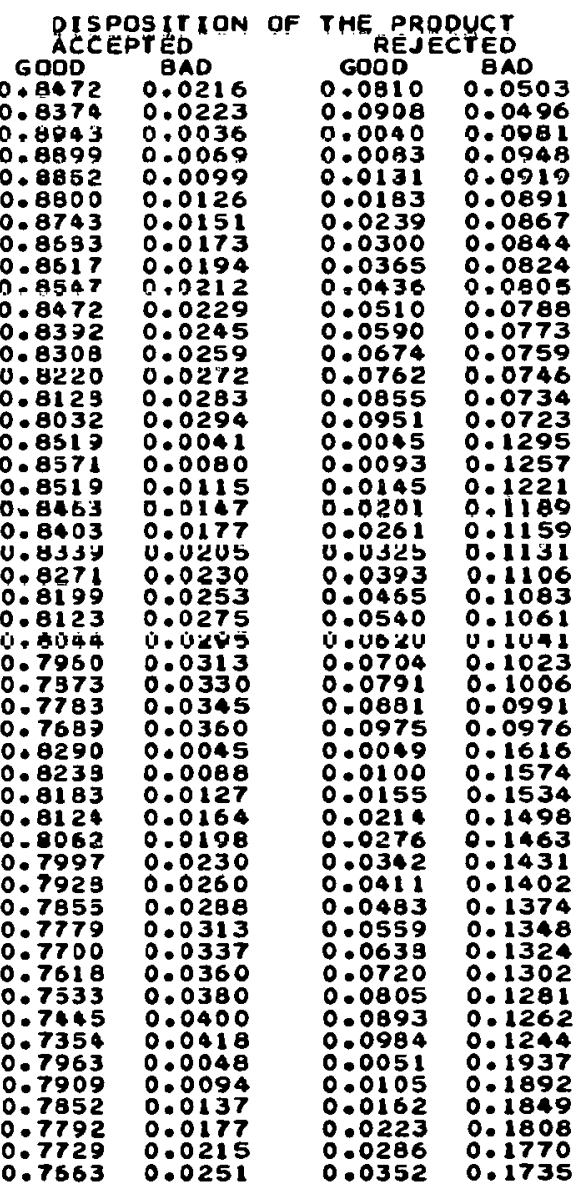

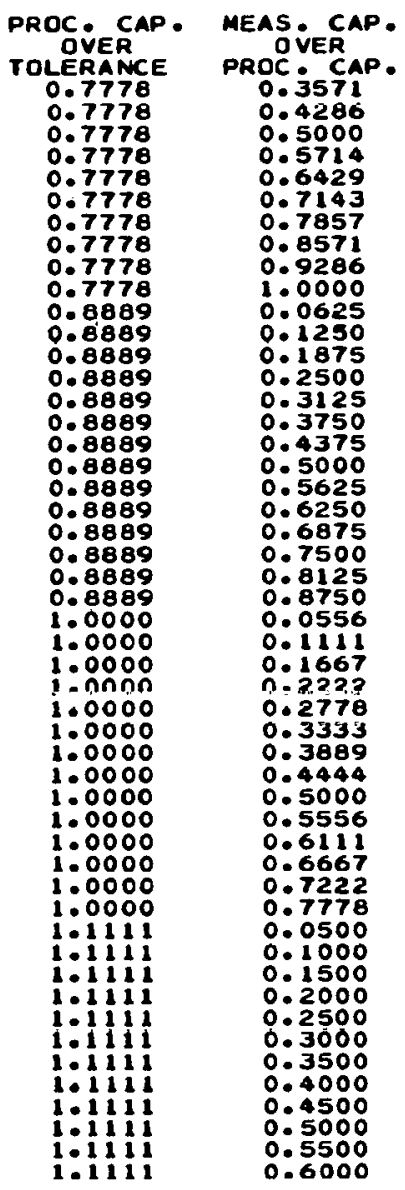

\begin{tabular}{|c|c|}
\hline 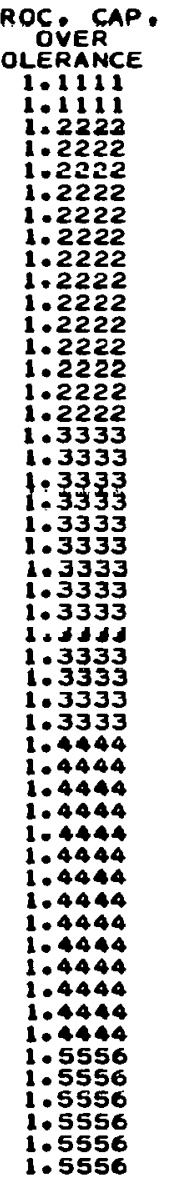 & 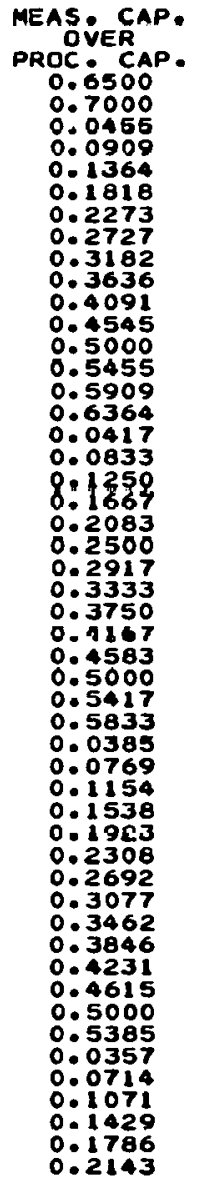 \\
\hline
\end{tabular}




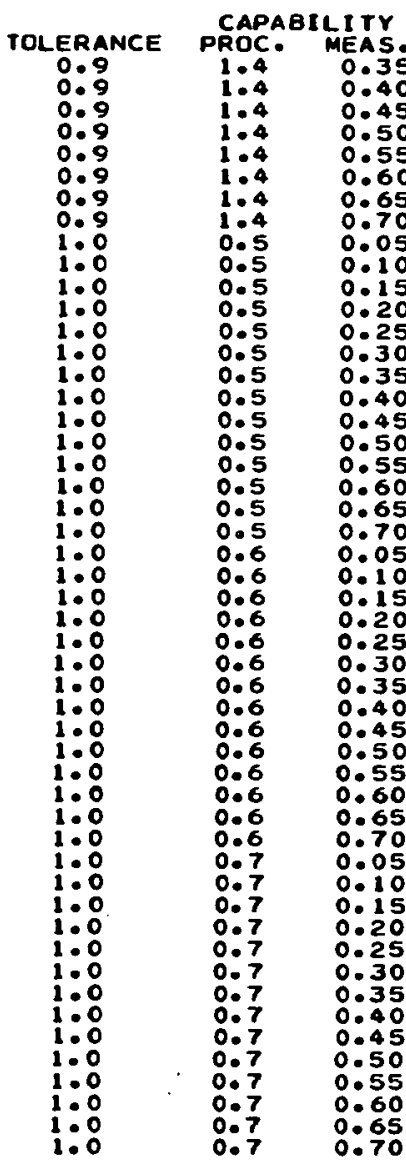

DISPOSITION OF THE PRDDUCT GOACCEPTED

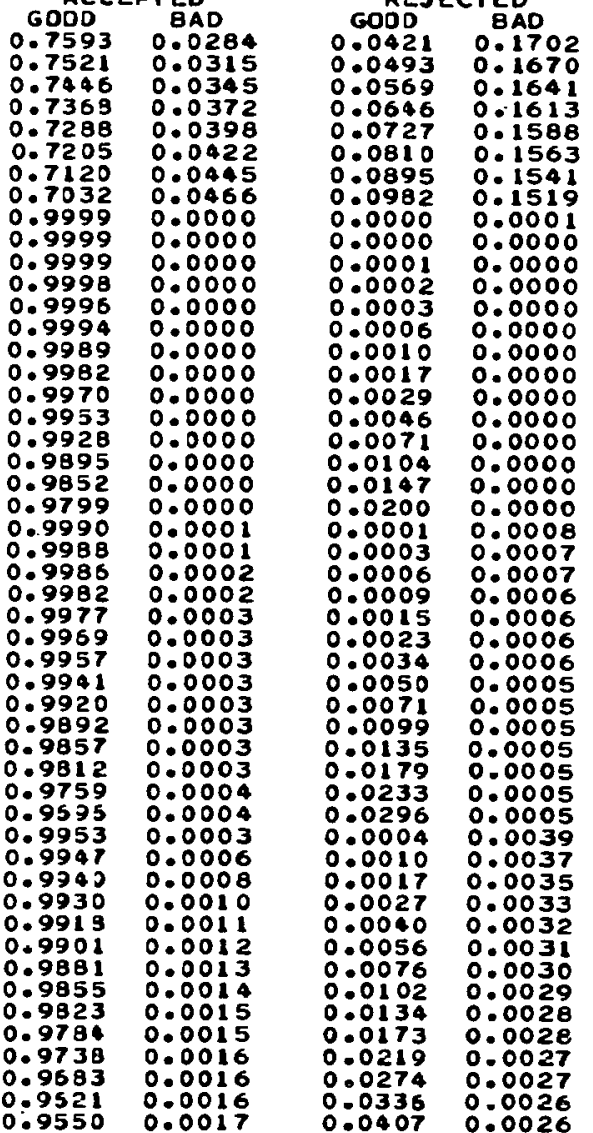

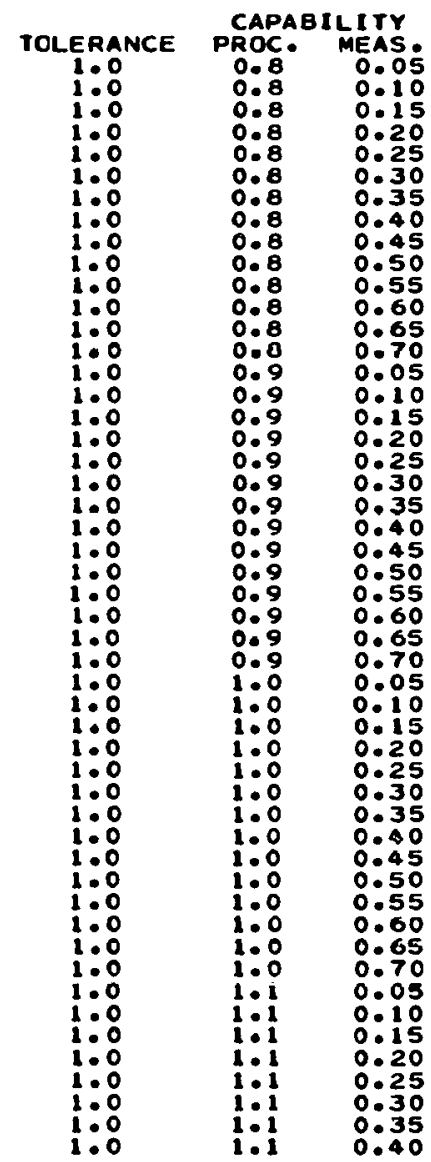

DISPOSITION OF THE PRODUCT

$\begin{array}{cc}\text { GOODD } & 8 A 0 \\ 0.9856 & 0.0008 \\ 0.985 & 0.0014\end{array}$

$0.9840 \quad 0.0014$

$0.9823 \quad 0.0024$

0.98020 .002

$0.9746 \quad 0.0034$

$0.9668 \quad 0.0039$

$0.9680 \quad 0.0039$

0.95640 .0042

$0.9502 \quad 0.0043$

$0.9432 \quad 0.0044$

$0.0355 \quad 0.004 .5$

0.97210 .0019

$0.9590 \quad 0.0036$

$0.9625 \quad 0.0052$

$0.9591 \quad 0.0059$

$0.9552 \quad 0.0065$

0.05070 .0070

$0.9457 \quad 0.0074$

$0.9401 \quad 0.0078$

$0.9339 \quad 0.0082$

$0.9195 \quad 0.0087$

$0.9522 \quad 0.0020$

0.94707038

0.94340 .0068

$0.9395 \quad 0.0080$

0.9355

0.9309 0.010

$0.9258 \quad 0.0109$

0.92010 .0117

0.91450 .0124

$0.9001 \quad 0.0136$

$0.9280 \quad 0.0026$

$0.9248 \quad 0.0050$

0.92120 .007

0.91730 .009

$0.9082 \quad 0.0124$

$0.9031 \quad 0.0138$
ACCEPTED

$0.9776 \quad 0.003$

$0.9702 \quad 0.0026$

$0.9116 \quad 0.0090$

0.90730 .013

0.89240 .0141
THE PRDDUCT
GODESECTED
GODD BAD

$0.0010 \quad 0.0116$

$0.0021 \quad 0.0110$

$0.0053 \quad 0.0100$

$0.0074 \quad 0.0096$

$0.0100 \quad 0.0093$

$0.0130 \quad 0.0090$

$0.0166 \quad 0.0088$

$0.0208 \quad 0.0086$

0.02560 .0084

$0.0312 \quad 0.0062$

$0.0374 \quad 0.0081$

0.04440 .0080

$0.0016 \quad 0.0249$

$0.0035 \quad 0.0237$

0.00570 .0227

$0.0083 \quad 0.0218$

0.01120 .0210

$0.0146 \quad 0.0204$

$0.0186 \quad 0.0198$

$0.0336 \quad 0.0185$

0.0398 0.0181

0.05410 .0175

$0.0621 \quad 0.0173$

$0.0078 \quad 0.0401$

0.01110 .0387

0.0149000375

$0.0190 \quad 0.0364$

$0.0287 \quad 0.0346$

$0.0344 \quad 0.0338$

$0.0405 \quad 0.0331$

0.05440 .0319

0.06210 .0314

0.07040 .0310

$0.0062 \quad 0.0640$

$0.0097 \quad 0.0619$

$0.0137 \quad 0.0600$

$0.0180 \quad 0.0582$

0.02270 .0567

0.02790 .0553
$0.0280 \quad 0.0189$

$0.0023 \quad 0.0435$
PROC . CAP -

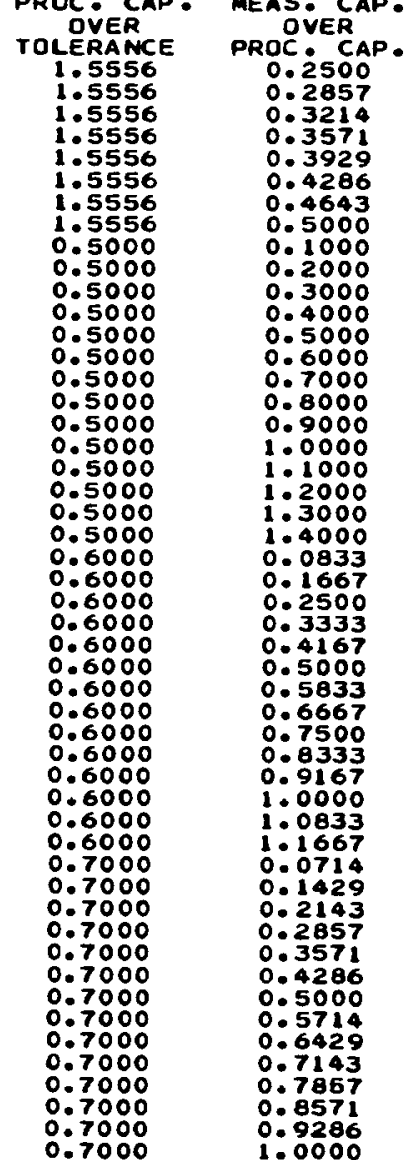

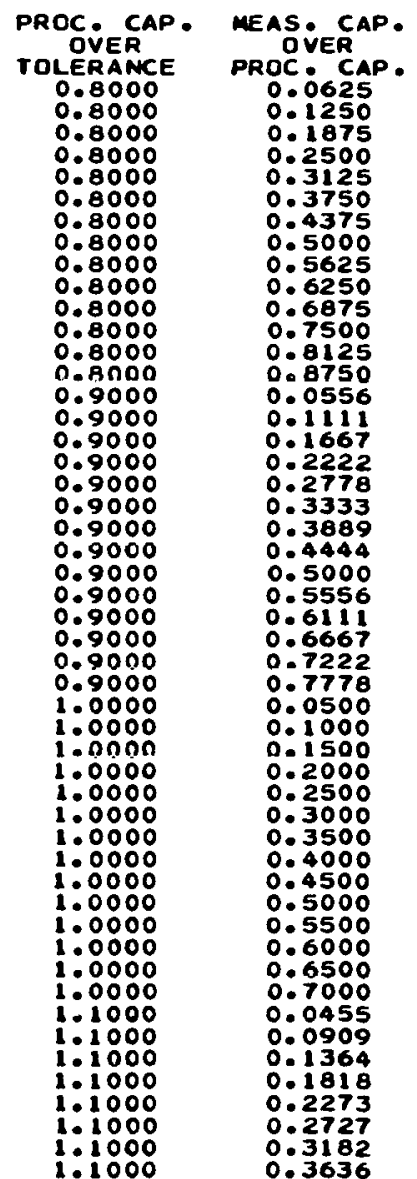




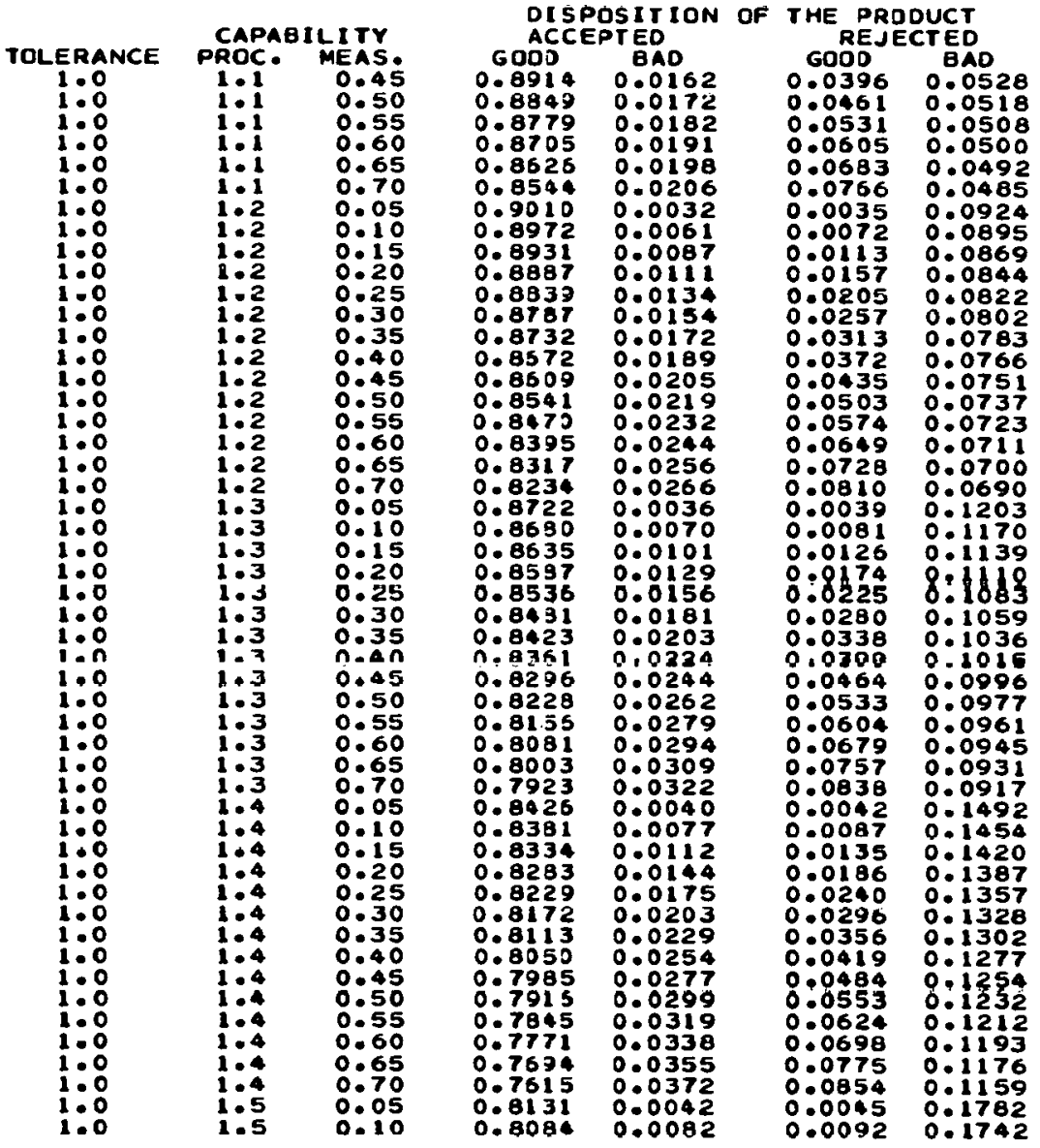

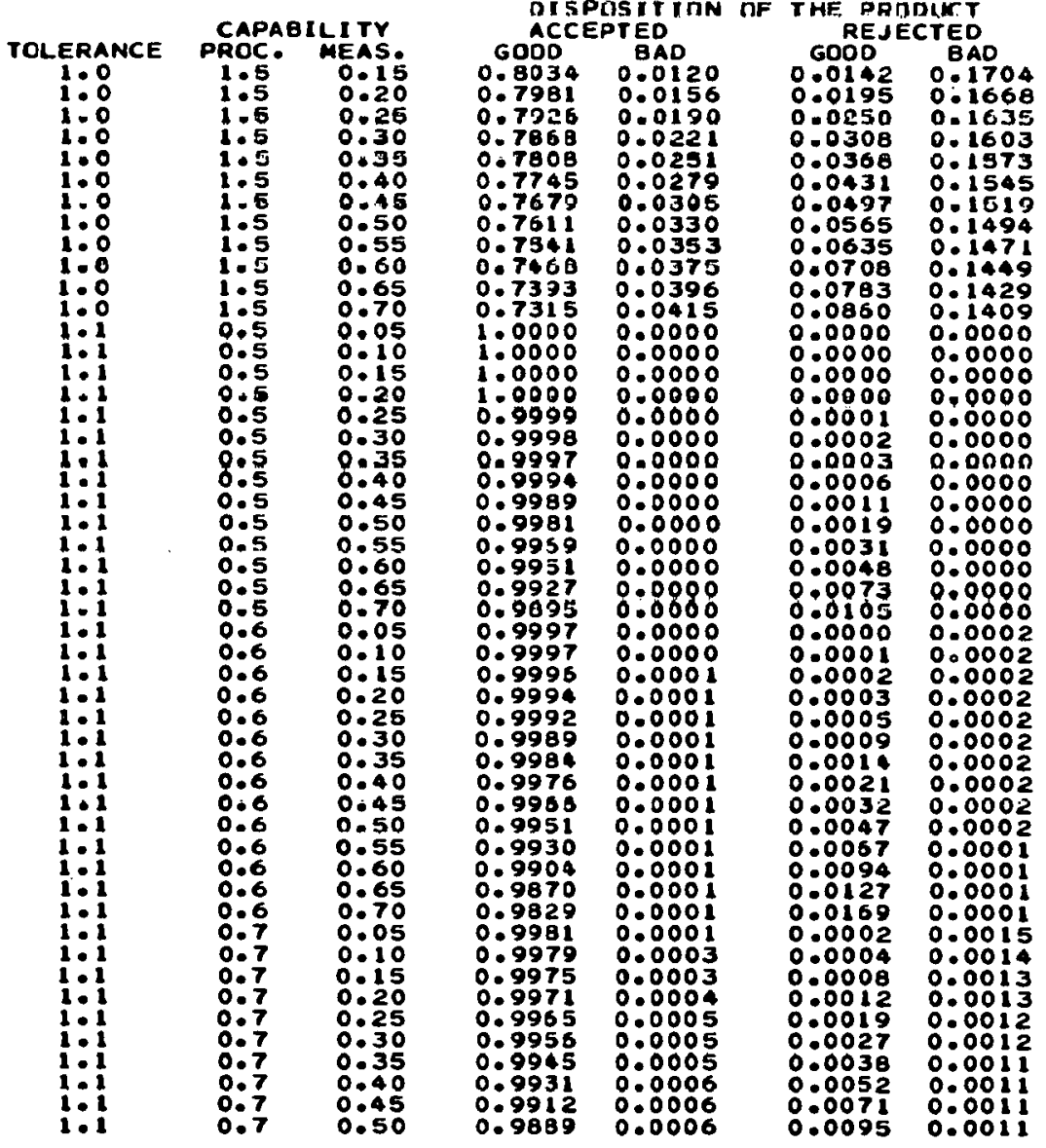

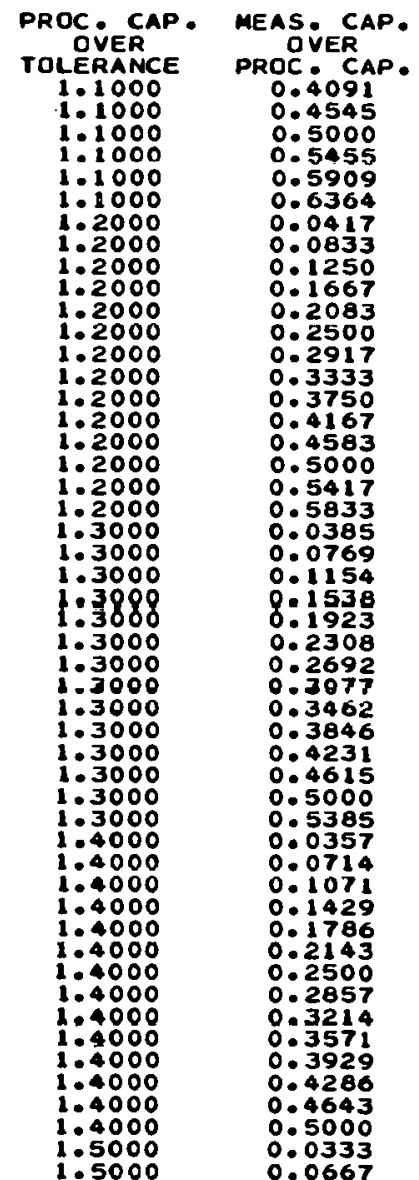

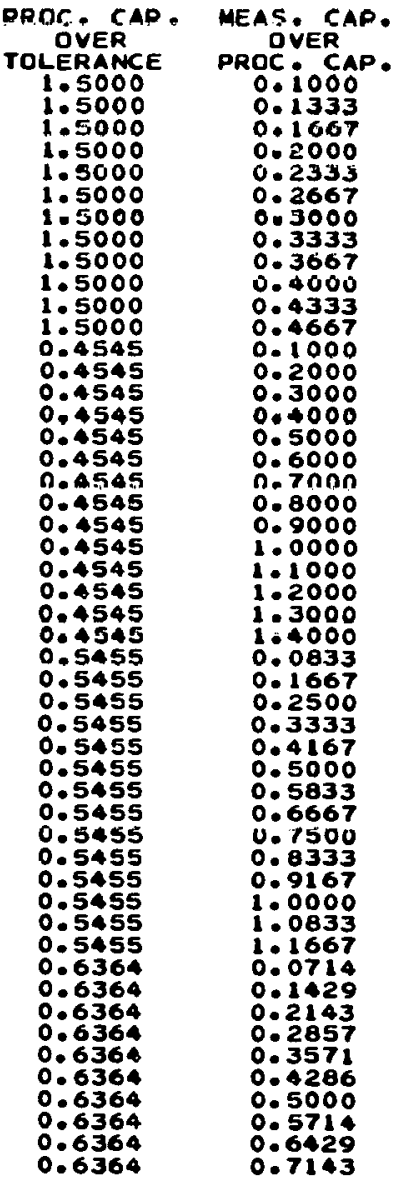




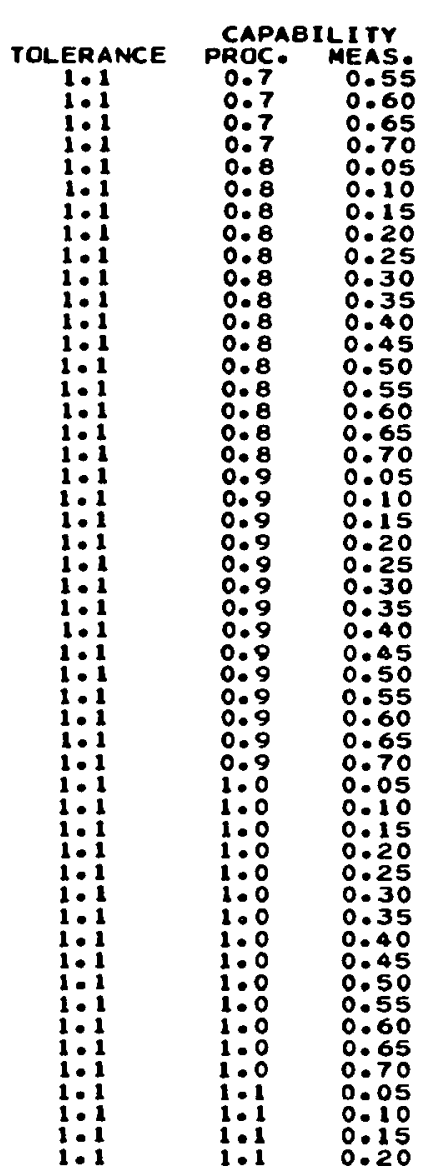

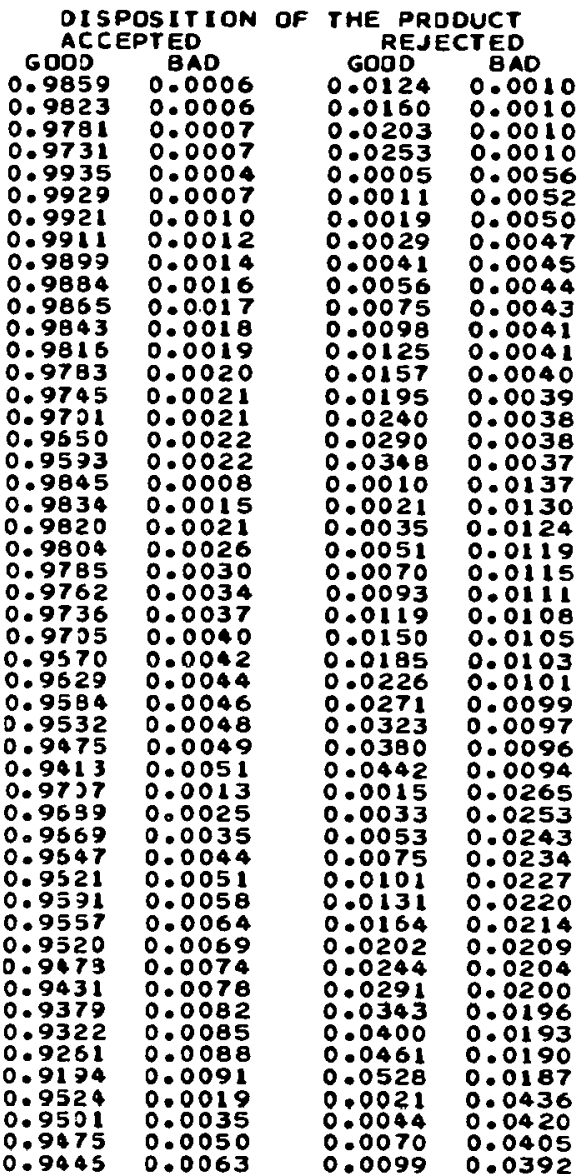

\begin{tabular}{ccc} 
& \multicolumn{2}{c}{ CAPABILITY } \\
TOLERANCE & PROC. MEAS \\
$1: 1$ & $1: 1$ & $0: 25$ \\
$1: 1$ & $1: 1$ & $0: 30$ \\
$1: 1$ & $1: 1$ & $0: 35$ \\
$1: 1$ & $1: 1$ & $0: 40$ \\
$1: 1$ & $1: 1$ & $0: 45$ \\
$1: 1$ & $1: 1$ & $0: 50$ \\
$1: 1$ & $1: 1$ & $0: 55$ \\
$1: 1$ & $1: 1$ & $0: 60$ \\
$1: 1$ & $1: 1$ & $0: 65$ \\
$1: 1$ & $1: 1$ & $0: 70$ \\
$1: 1$ & $1: 2$ & $0: 05$ \\
$1: 1$ & $1: 2$ & $0: 10$ \\
$1: 1$ & $1: 2$ & $0: 15$ \\
$1: 1$ & $1: 2$ & $0: 20$ \\
$1: 1$ & $1: 2$ & $0: 25$ \\
$1: 1$ & $1: 2$ & $0: 30$ \\
$1: 1$ & $1: 2$ & $0: 35$ \\
$1: 1$ & $1: 2$ & $0: 40$ \\
$1: 1$ & $1: 2$ & $0: 45$ \\
$1: 1$ & $1: 2$ & $0: 50$ \\
$1: 1$ & $1: 2$ & $0: 55$ \\
$1: 1$ & $1: 2$ & $0: 60$ \\
$1: 1$ & $1: 2$ & $0: 65$ \\
$1: 1$ & $1: 2$ & $0: 70$ \\
$1: 1$ & $1: 3$ & $0: 05$ \\
$1: 1$ & $1: 3$ & $0: 10$ \\
$1: 1$ & $1: 3$ & $0: 15$ \\
$1: 1$ & $1: 3$ & $0: 20$ \\
$1: 1$ & $1: 3$ & $0: 25$ \\
$1: 1$ & $1: 3$ & $0: 30$ \\
$1: 1$ & $1: 3$ & $0: 35$ \\
$1: 1$ & $1: 3$ & $0: 40$ \\
$1: 1$ & $1: 3$ & $0: 45$ \\
$1: 1$ & $1: 3$ & $0: 50$ \\
$1: 1$ & $1: 3$ & $0: 55$ \\
$1: 1$ & $1: 3$ & $0: 60$ \\
$1: 1$ & $1: 3$ & $0: 65$ \\
$1: 1$ & $1: 3$ & $0: 70$ \\
$1: 1$ & $1: 4$ & $0: 05$ \\
$1: 1$ & $1: 4$ & $0: 10$ \\
$1: 1$ & $1: 4$ & $0: 15$ \\
$1: 1$ & $1: 4$ & $0: 20$ \\
$1: 1$ & $1: 4$ & $0: 35$ \\
$1: 1$ & $1: 4$ & $0: 30$ \\
$1: 1$ & $1: 4$ & $0: 35$ \\
$1: 1$ & $1: 4$ & $0: 45$ \\
$1: 1$ & $1: 4$ & $0: 50$ \\
$1: 1$ & $1: 4$ & $0: 55$ \\
$1: 1$ & $1: 4$ & 0.60 \\
& &
\end{tabular}

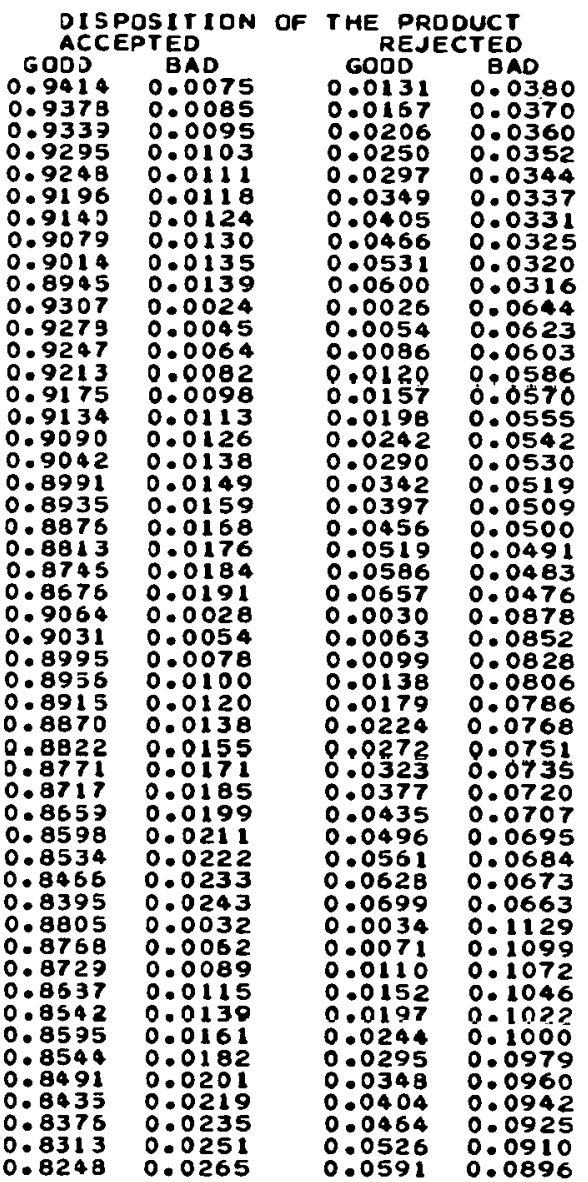

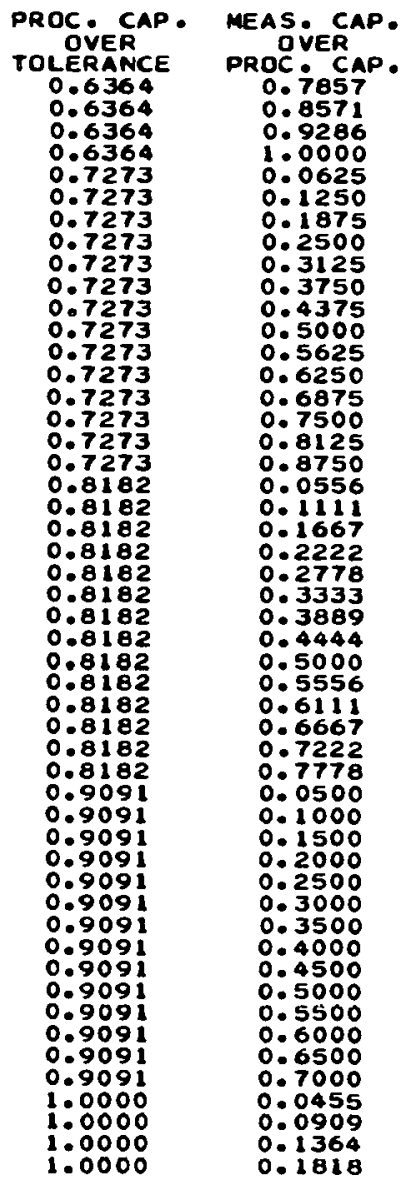

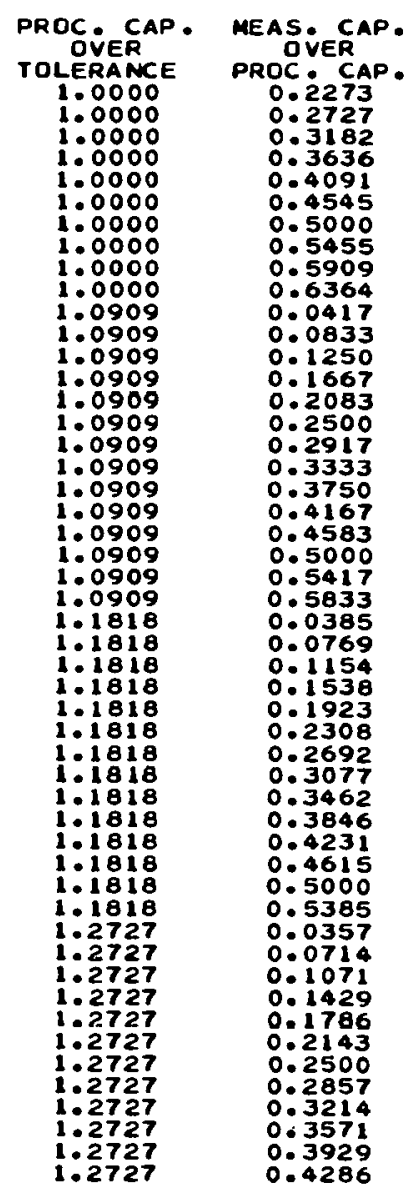




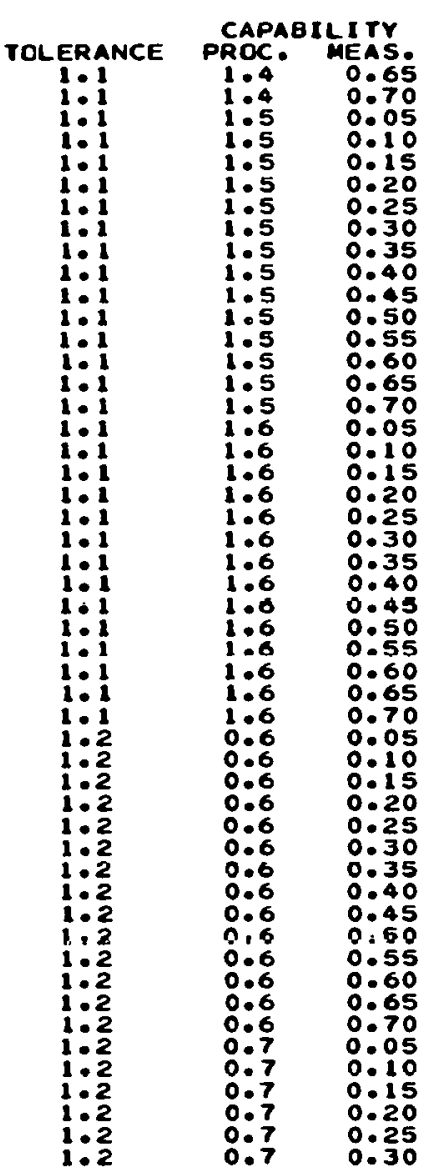

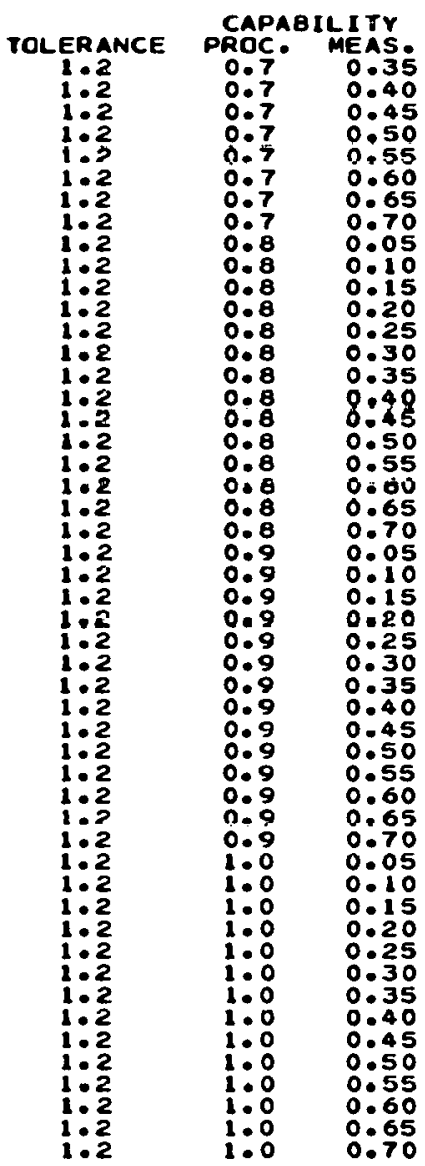

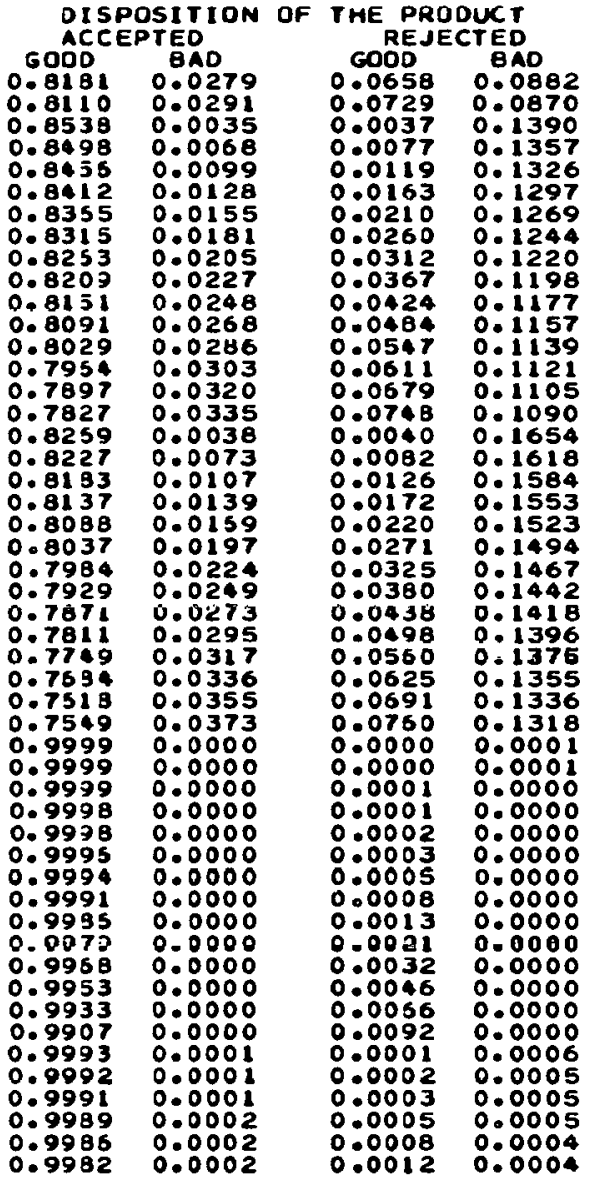

OISPDSITION OF THE PROOUCT GOOCCEPTED

$0.9976 \quad 0.0002$

$0.9969 \quad 0.0002$

$0.9959 \quad 0.0002$

$0: 9945 \quad 0: 0002$

$0: 9905 \quad 0: 0002$

0.9878 :0:0002

0.99710 .0002

$0.9967 \quad 0: 0004$

$0: 9963 \quad 0: 0005$

$0: 9958 \quad 0: 0006$

$0: 9943 \quad 0: 0007$

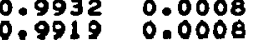

$0: 990$ D $0: 0009$

$0.9881 \quad 0.0009$

$0.9856 \quad 0.0010$

0.9020 y.untu

$0: 9750$ 0:0010

0.99180 .0005

$0.9903 \quad 0.0012$

0.9993 0.0.012

$0.9881 \quad 0.0017$

0.985000020

0.9830

0.9806

0.9746

0.9709

0.9667

8.9620

0.9815

0.9815

0.9787

0.9769

0.9726

0.9669

0.9669

0.9595

8.9552

0.0022

0.0023

0.0025

0.0026

$0: 0027$

0.0008

0.0022

0.0027

0.0036

0.0039

0.0045

0.0048

0.0050

0.0052

$0.9452 \quad 0.0055$

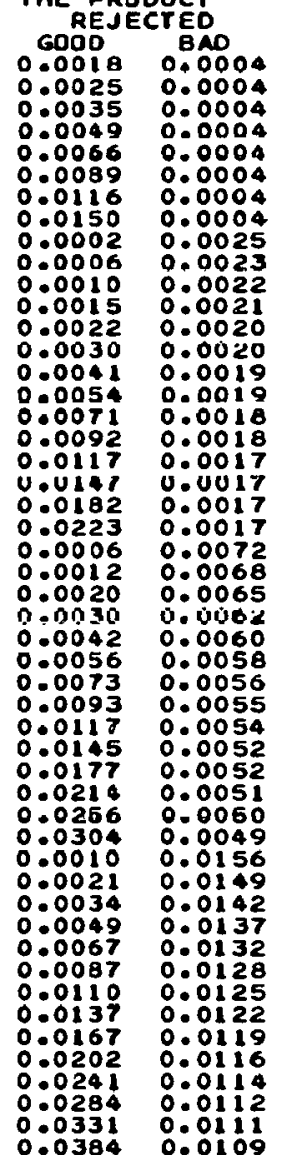

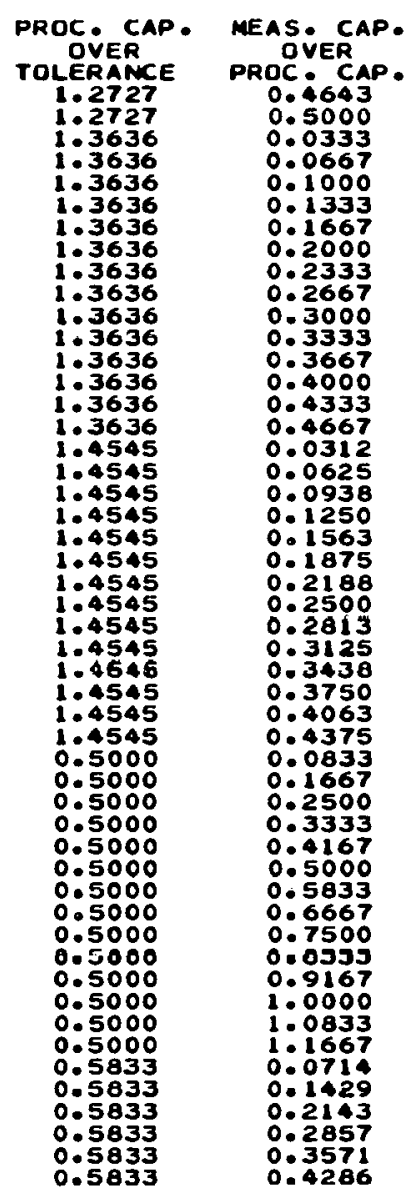

PROC CAP. MEAS

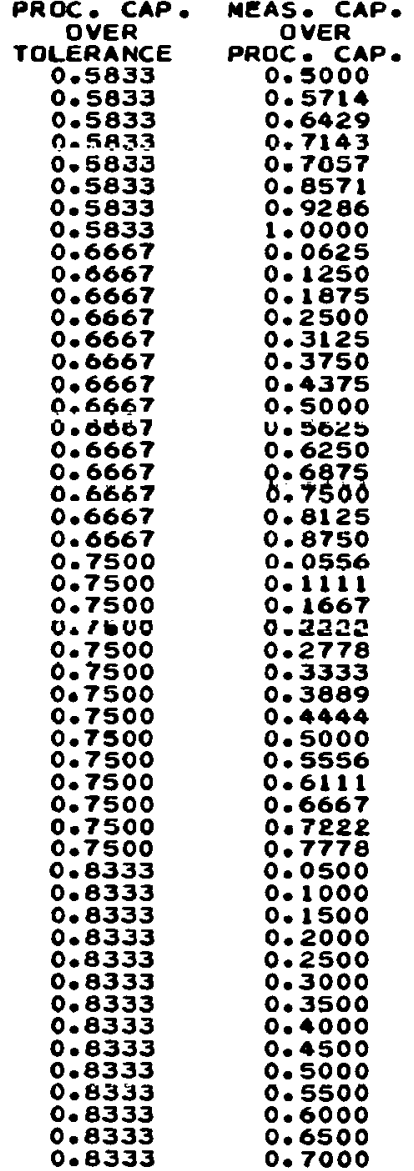




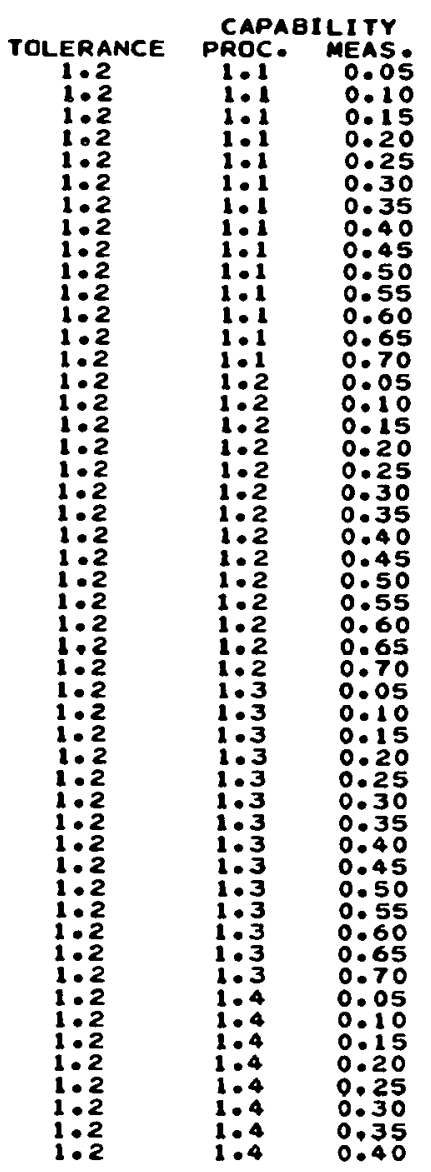

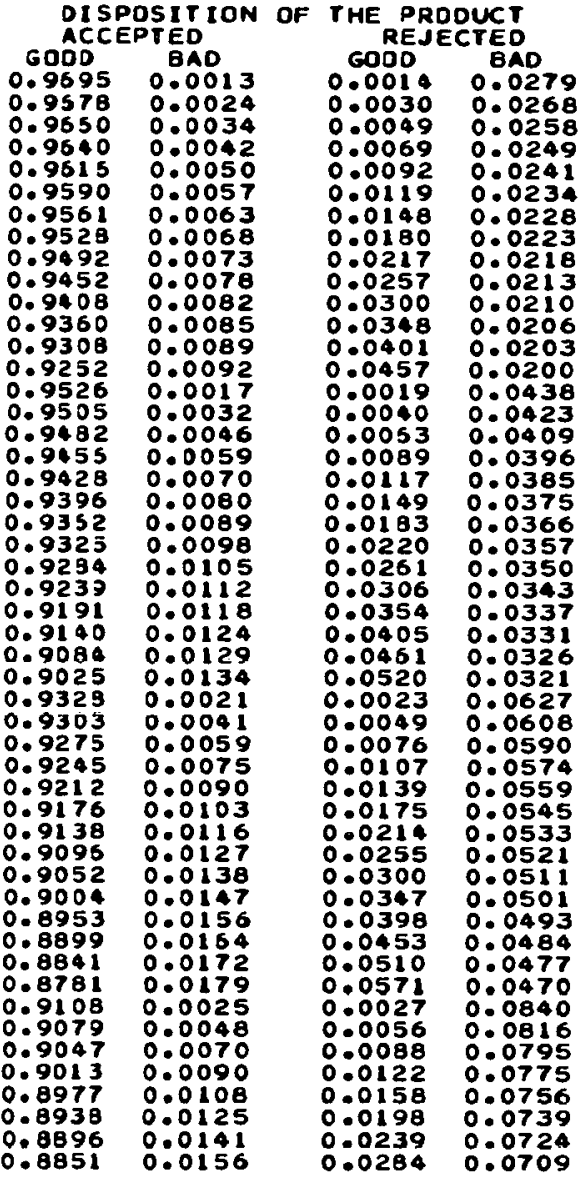

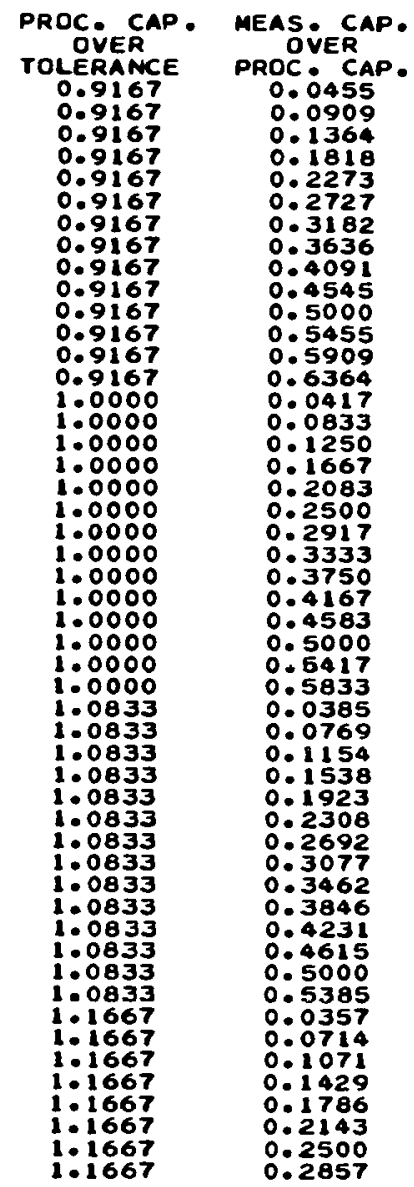

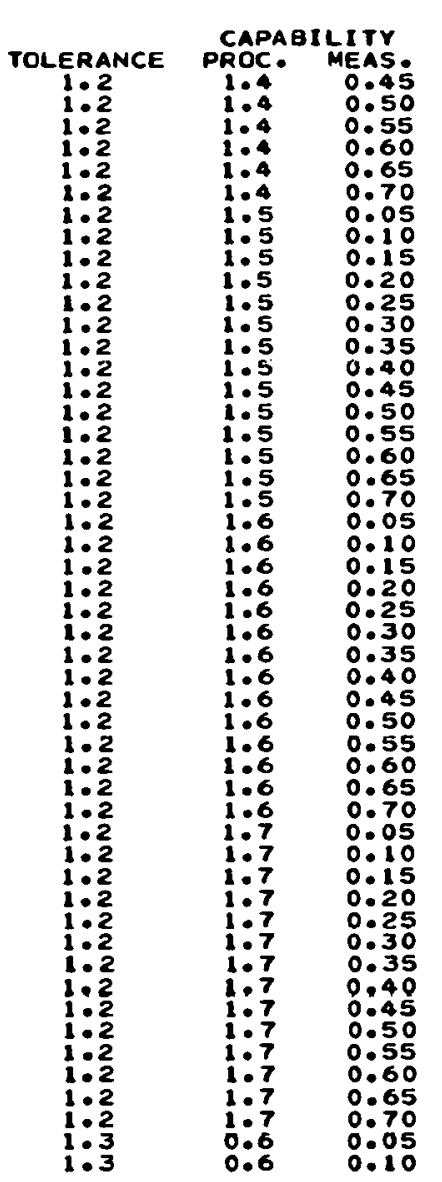

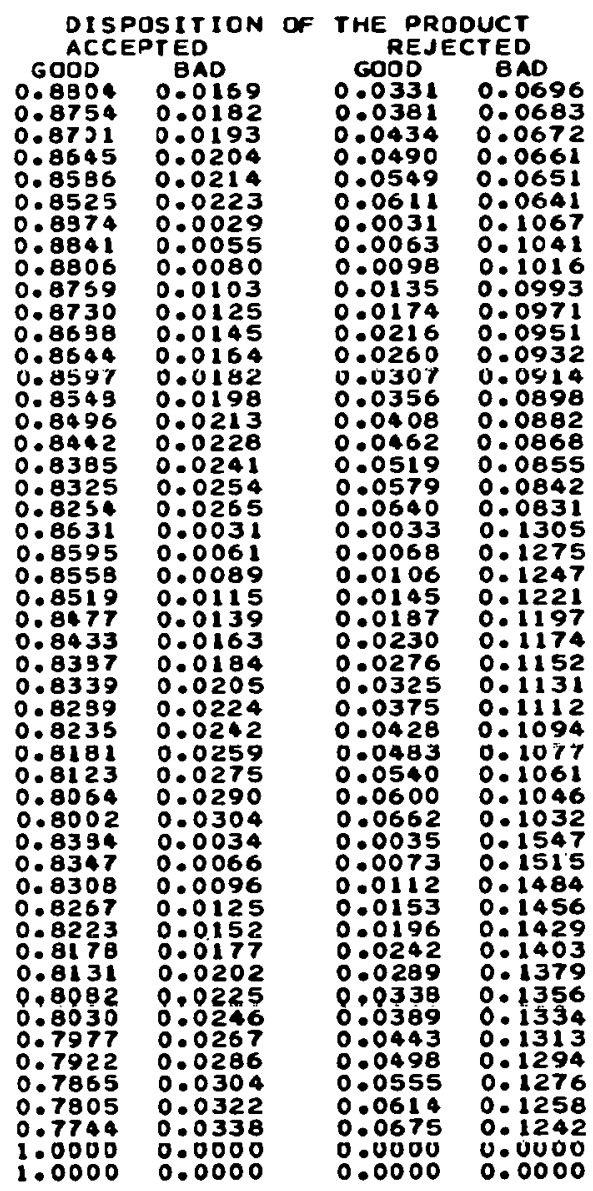

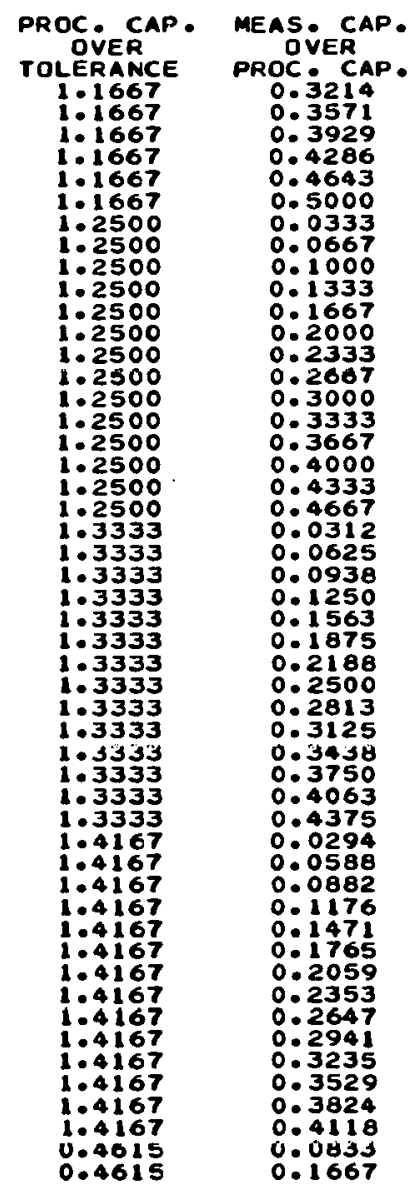




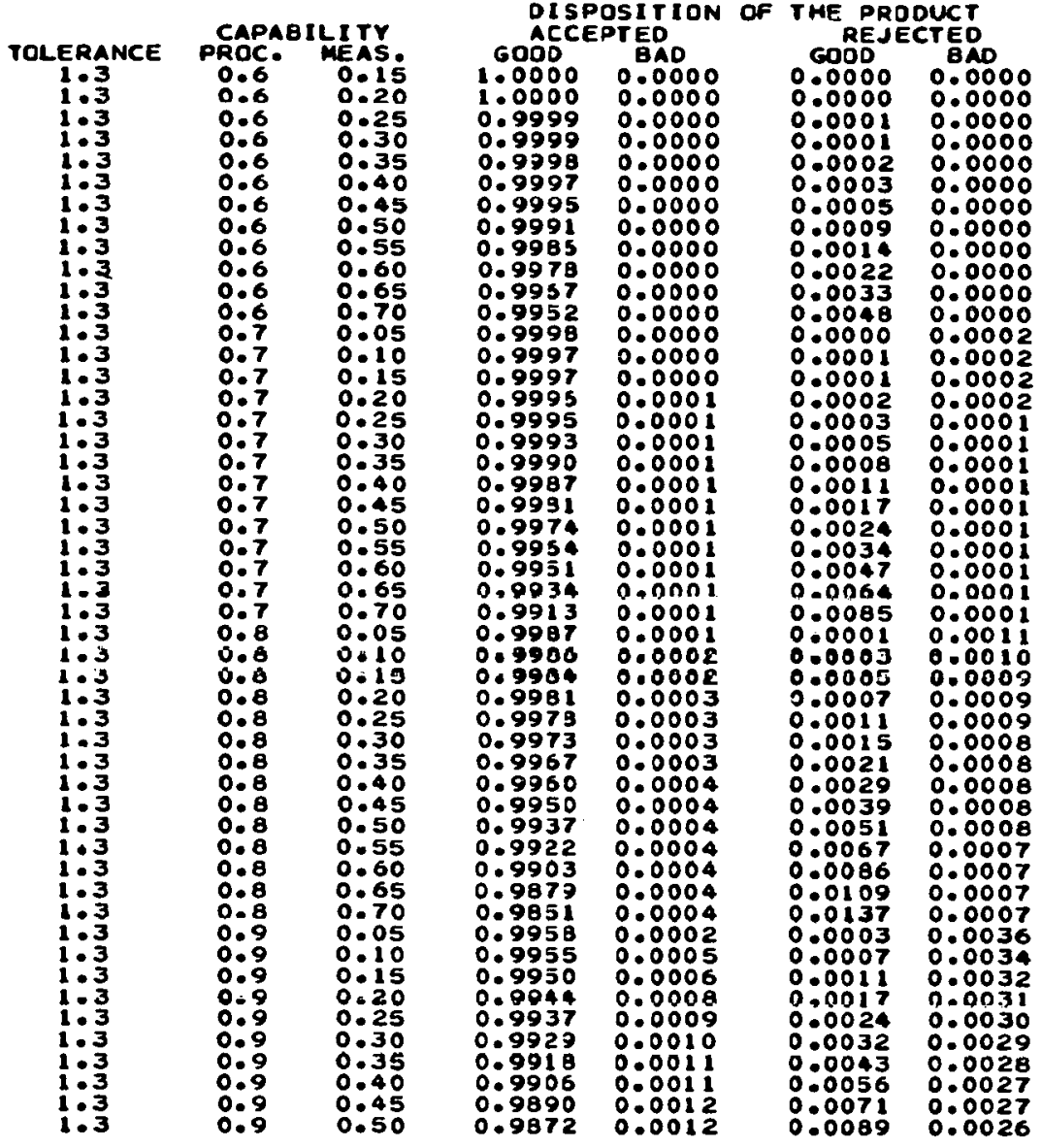

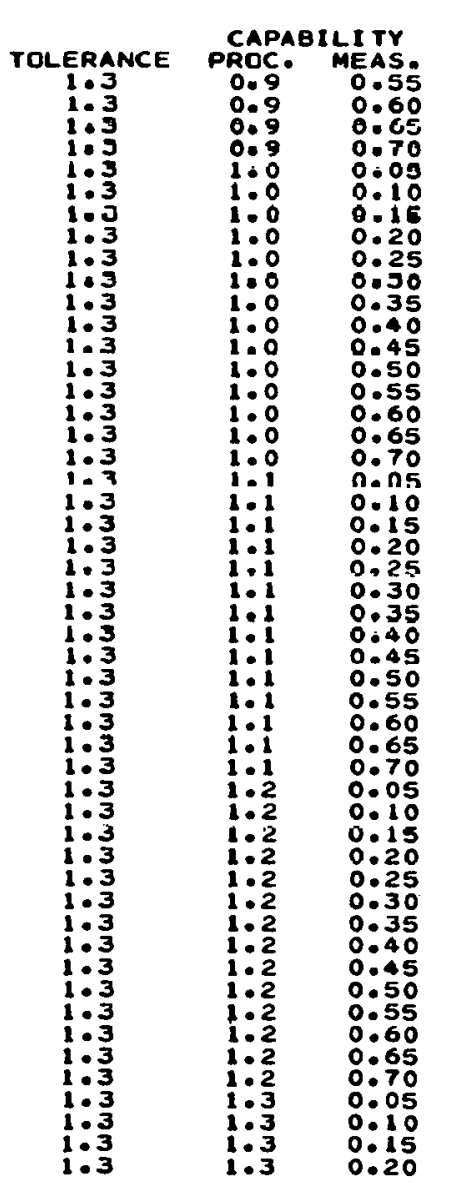

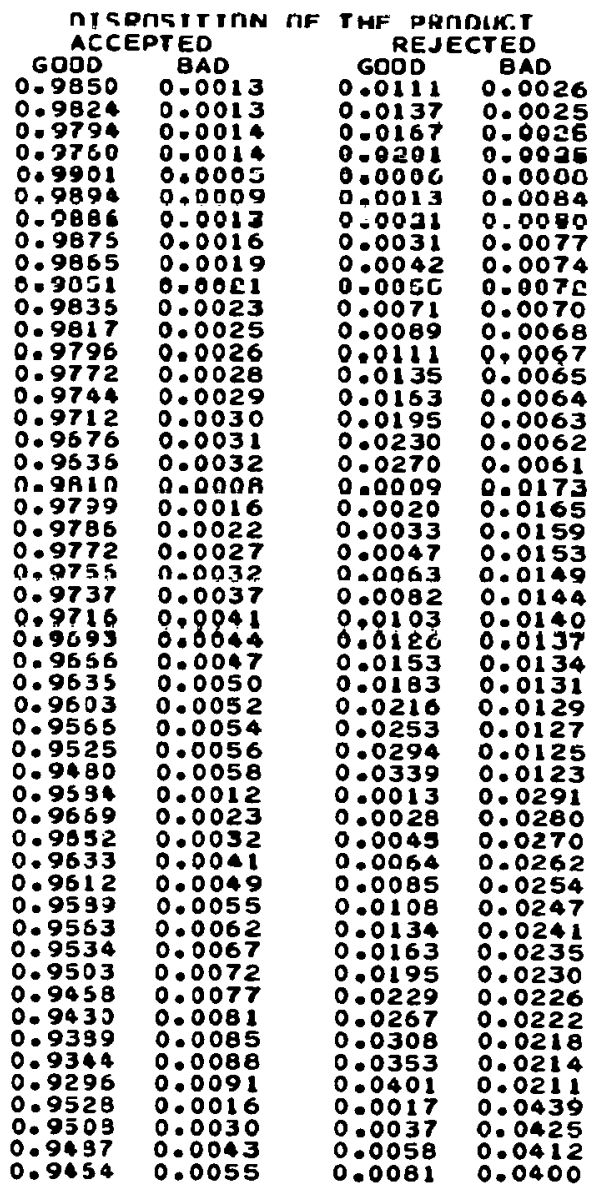

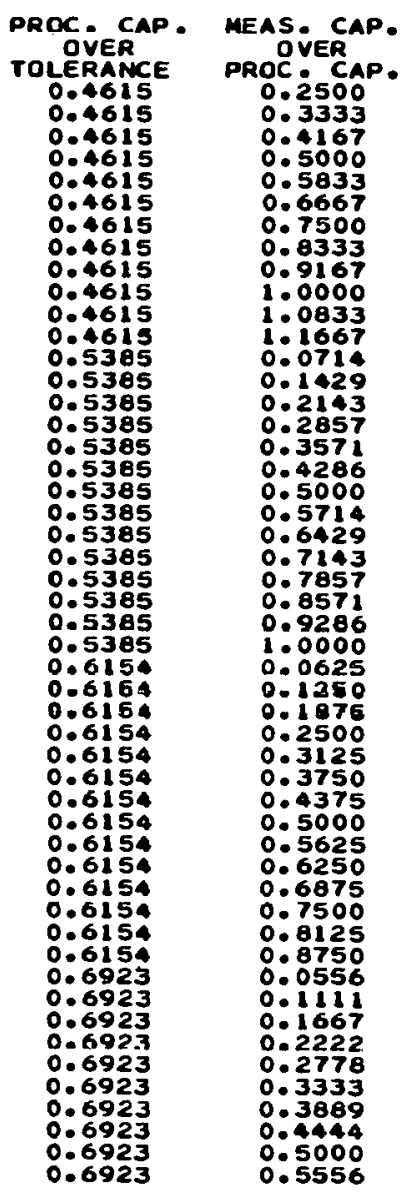

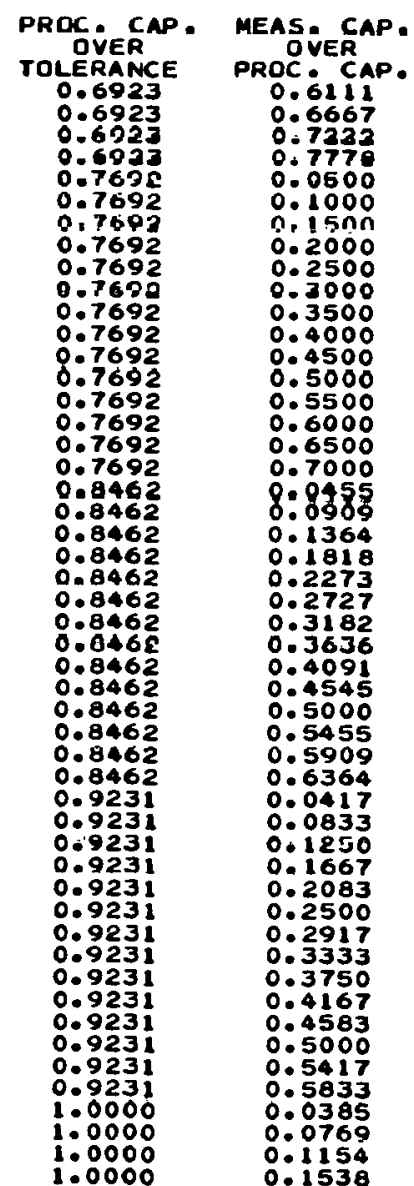




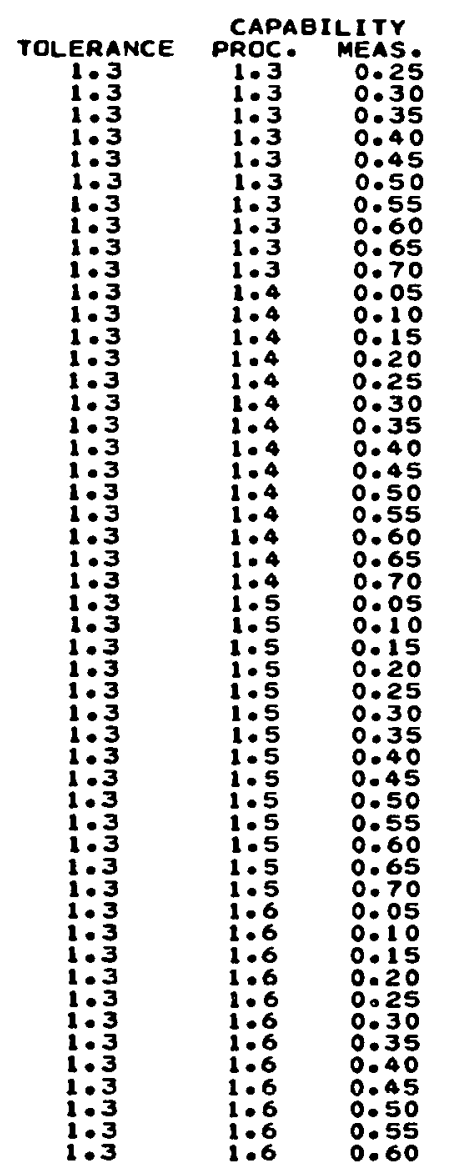

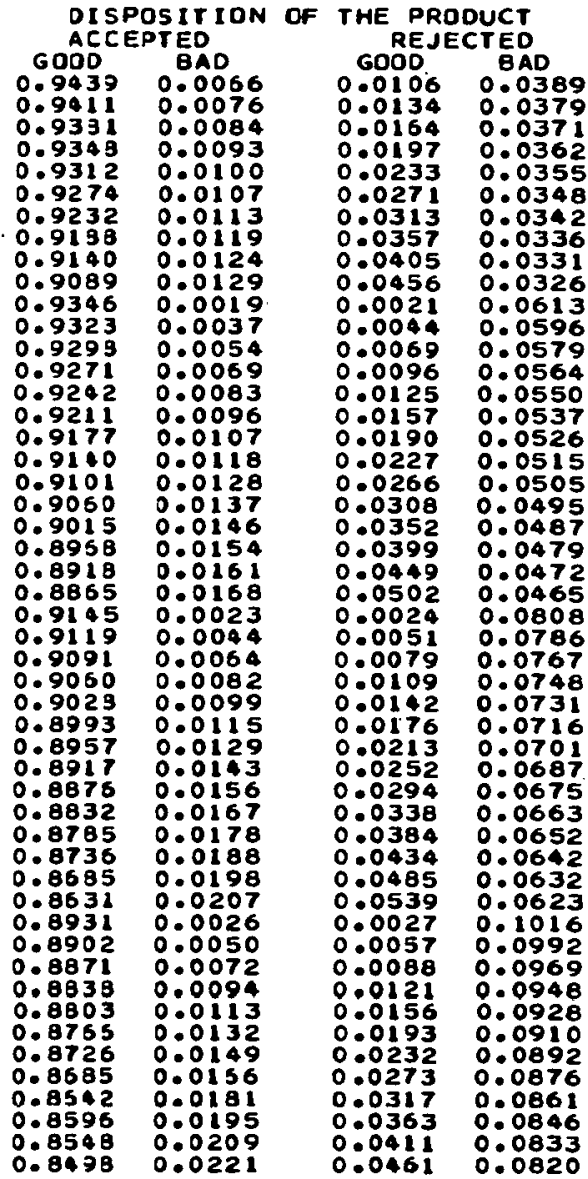

\begin{tabular}{|c|c|}
\hline 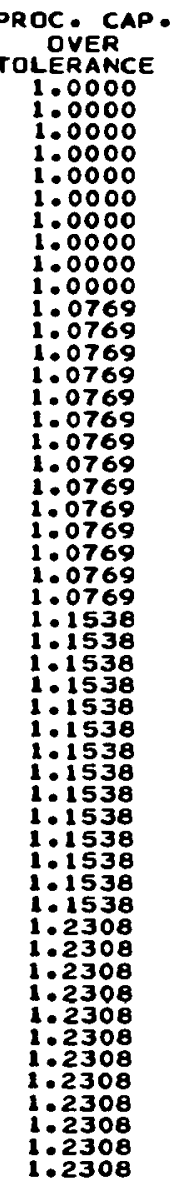 & 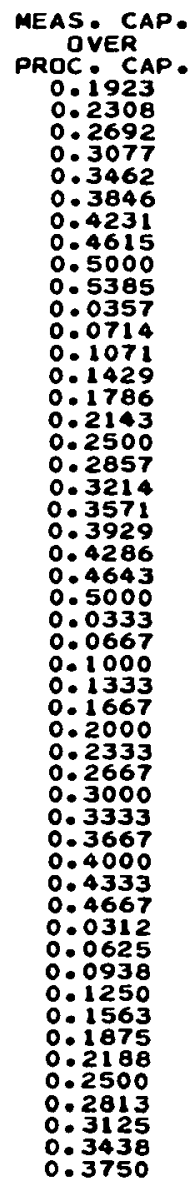 \\
\hline
\end{tabular}

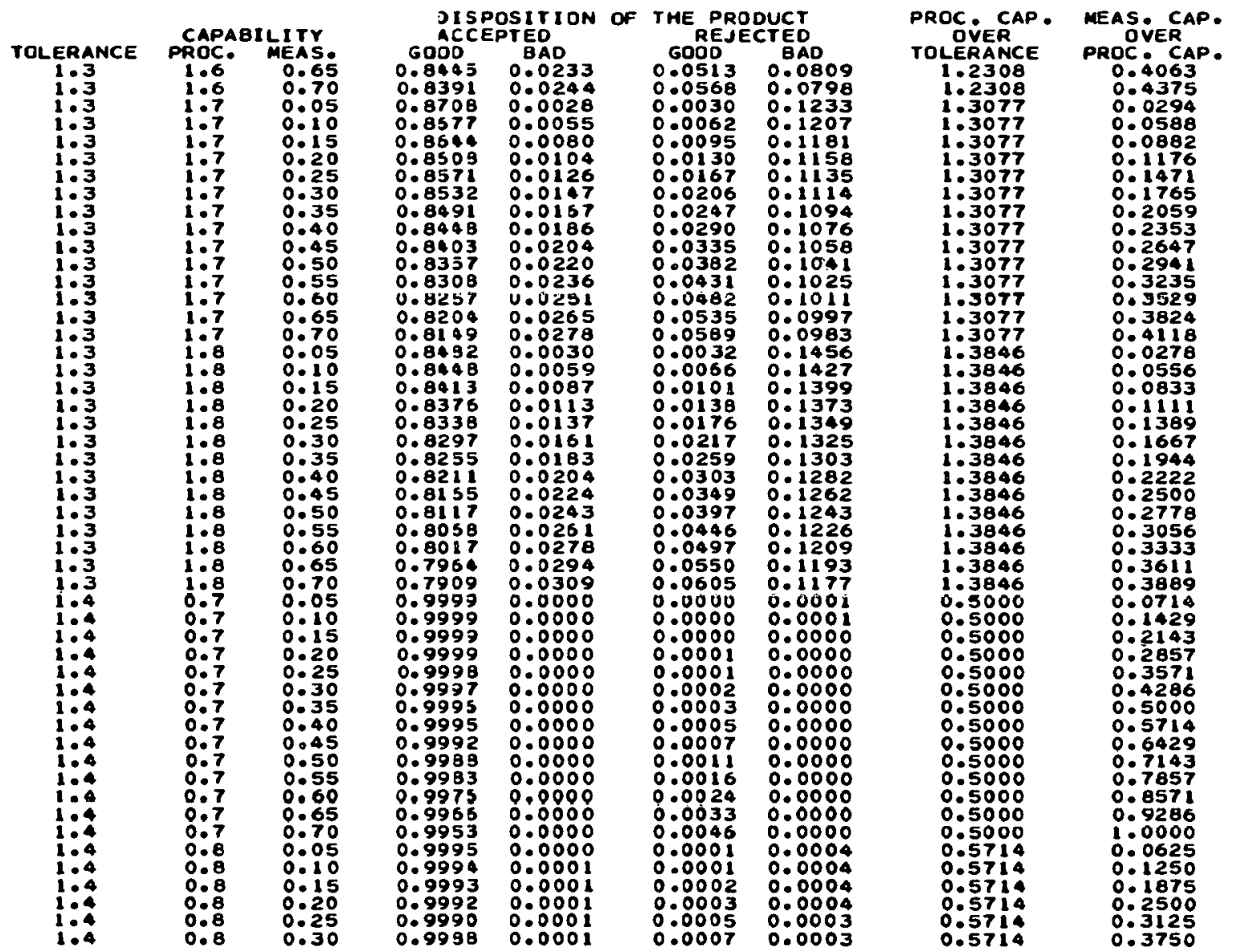




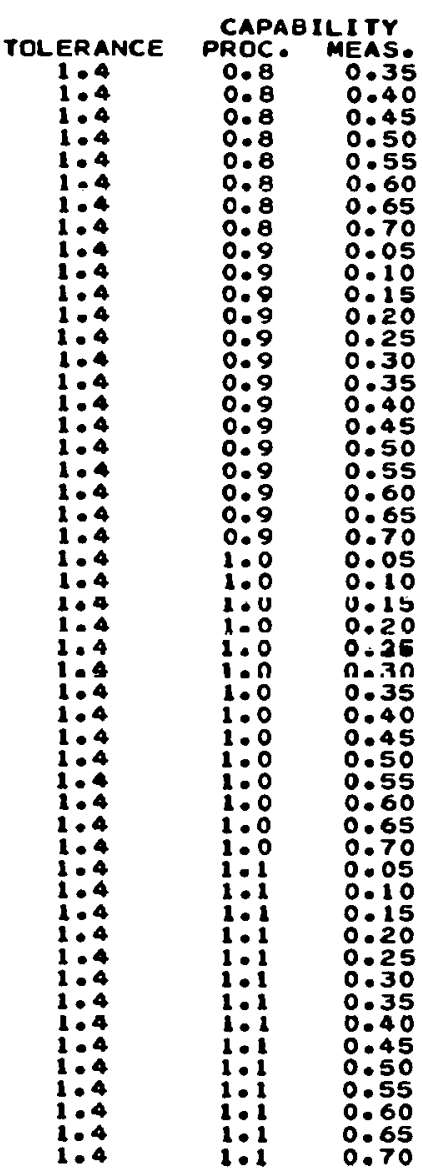

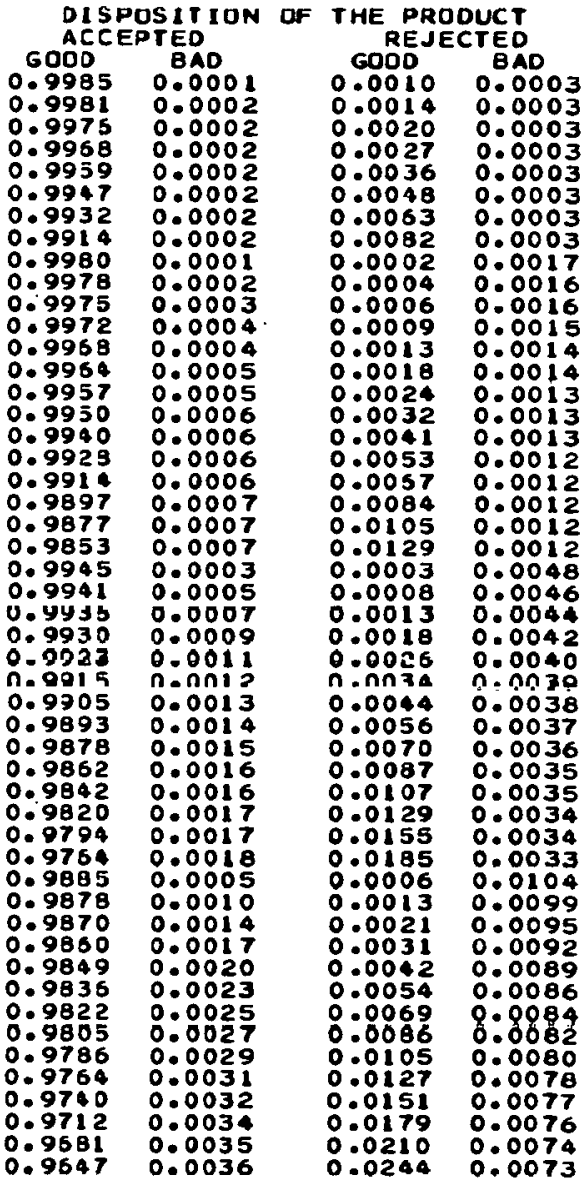

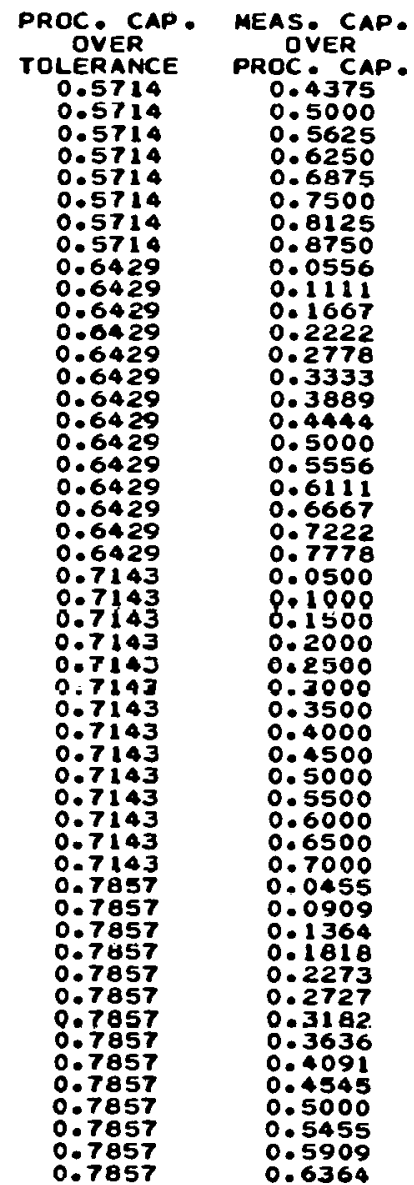

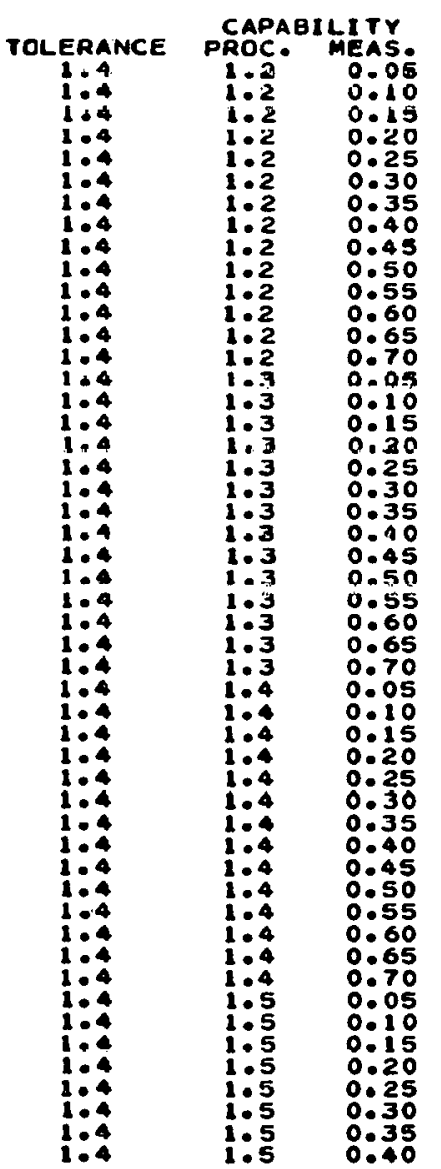

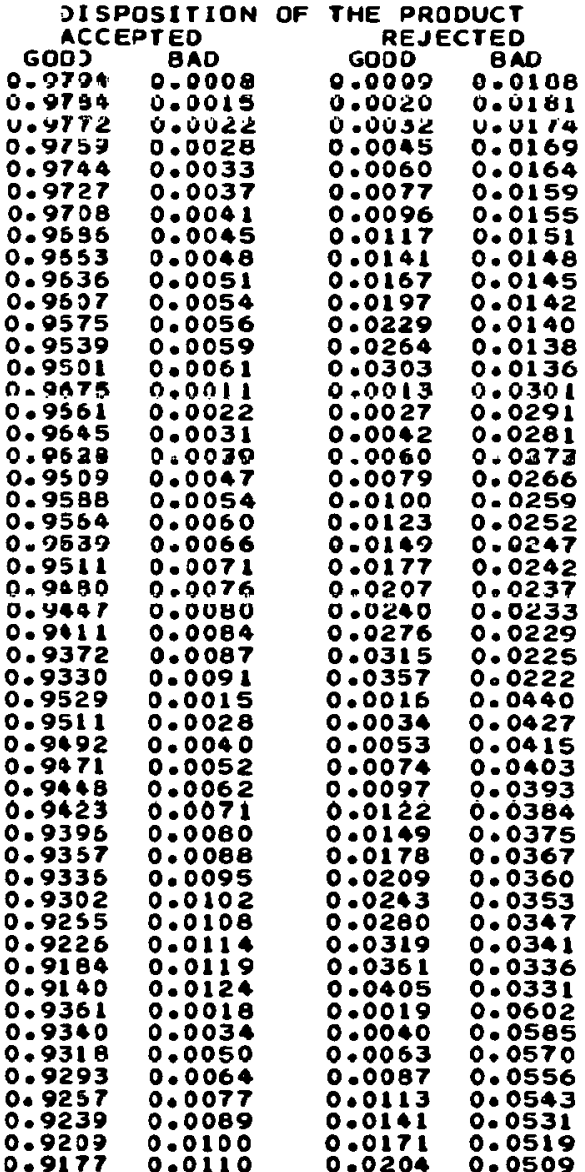

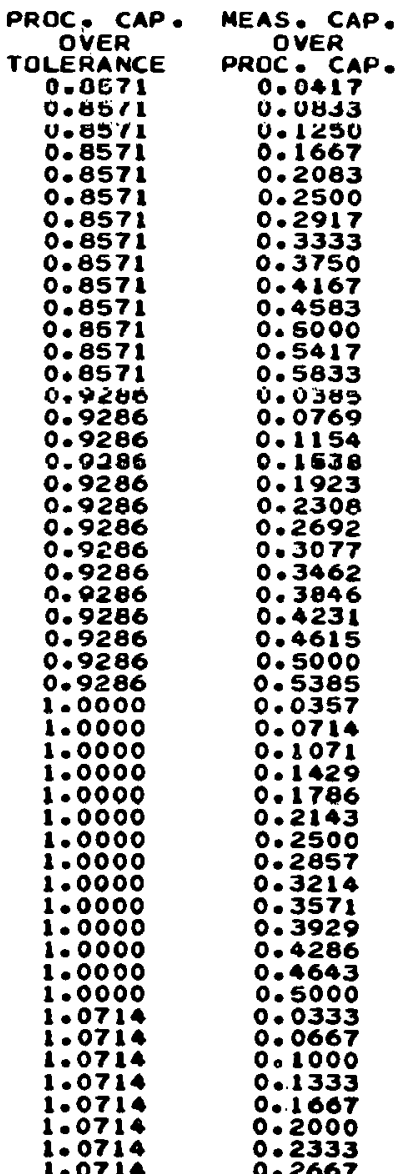




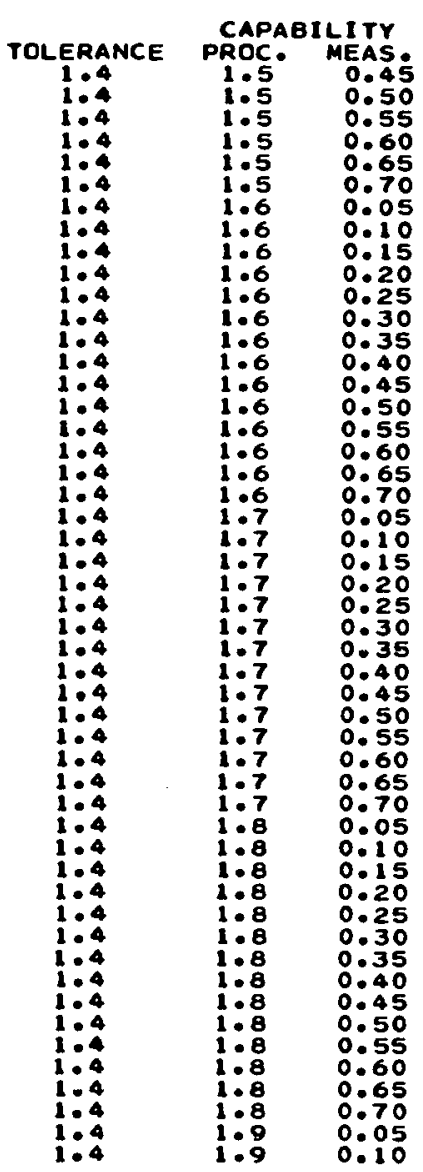

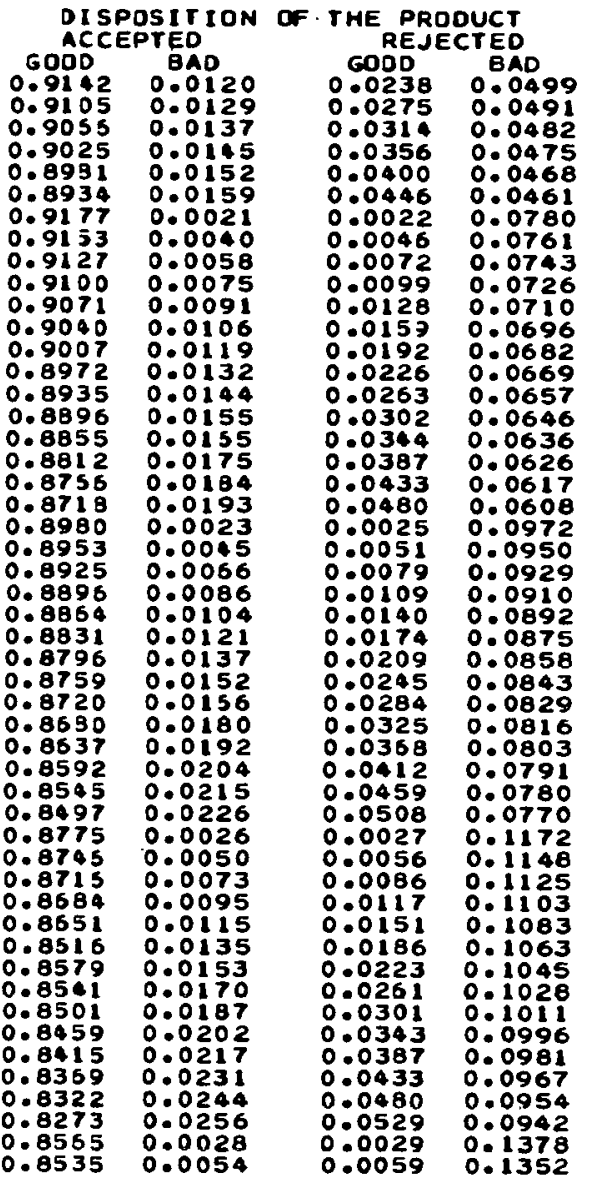

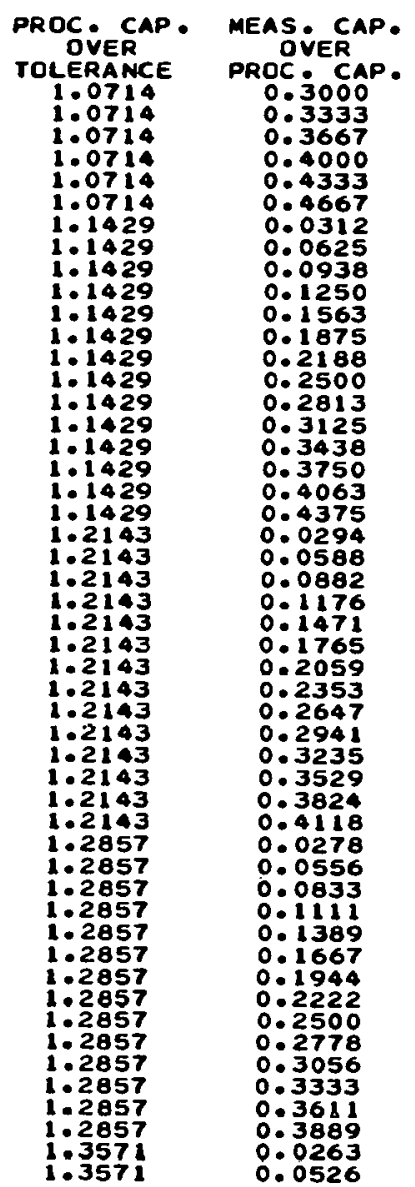

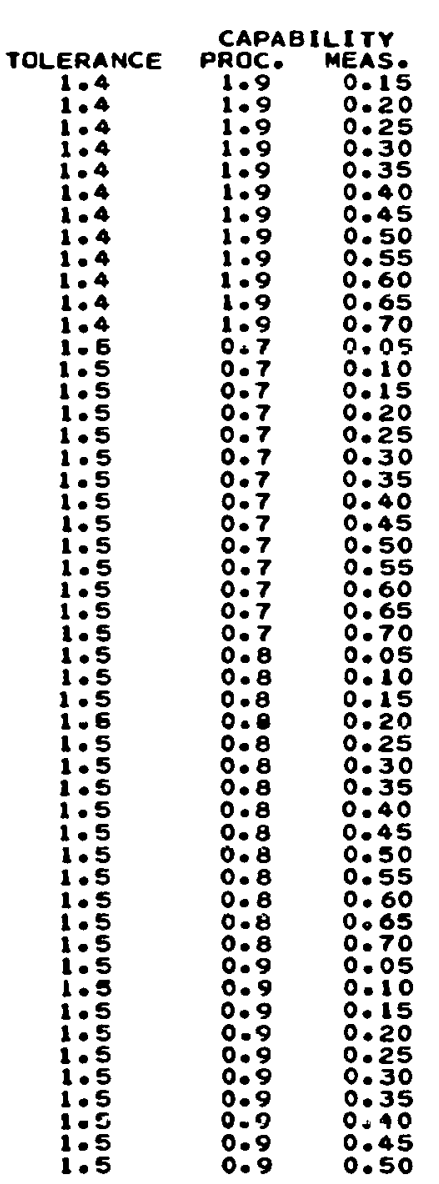

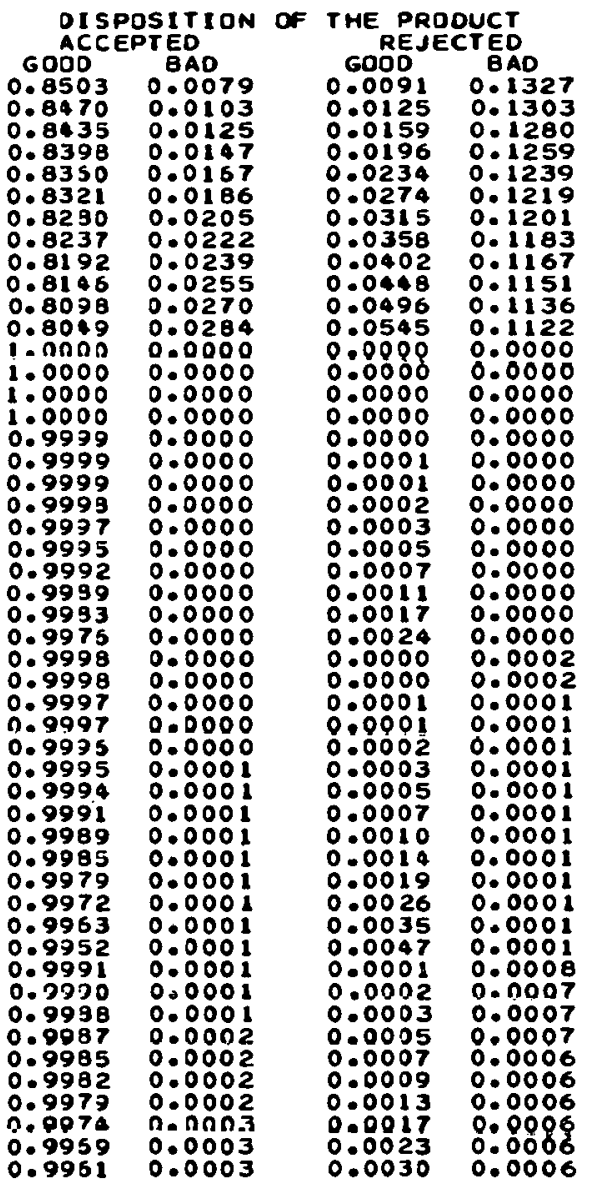

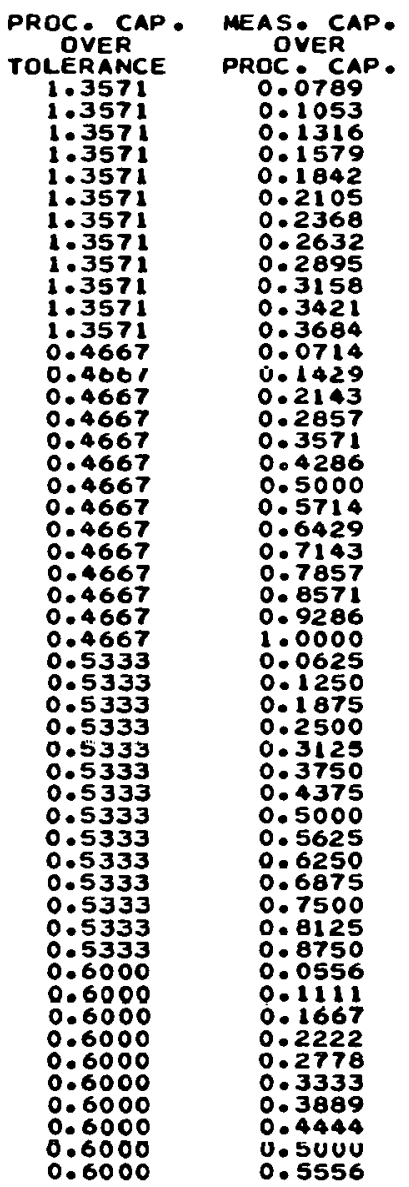




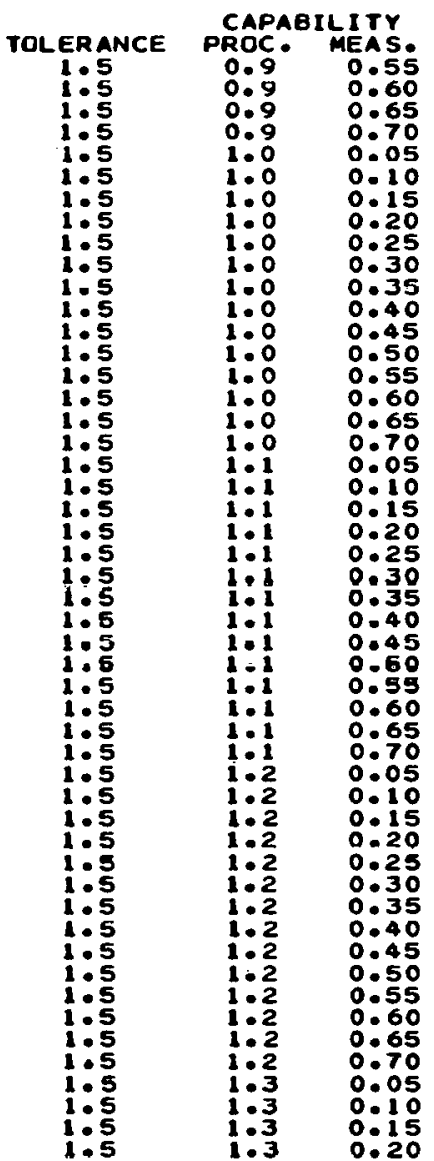

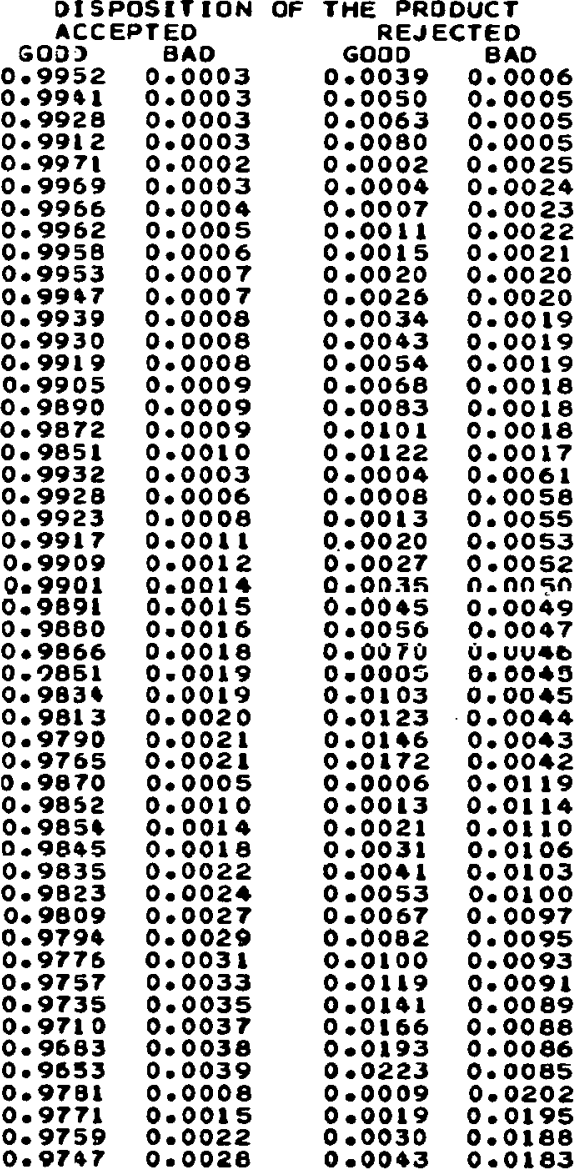

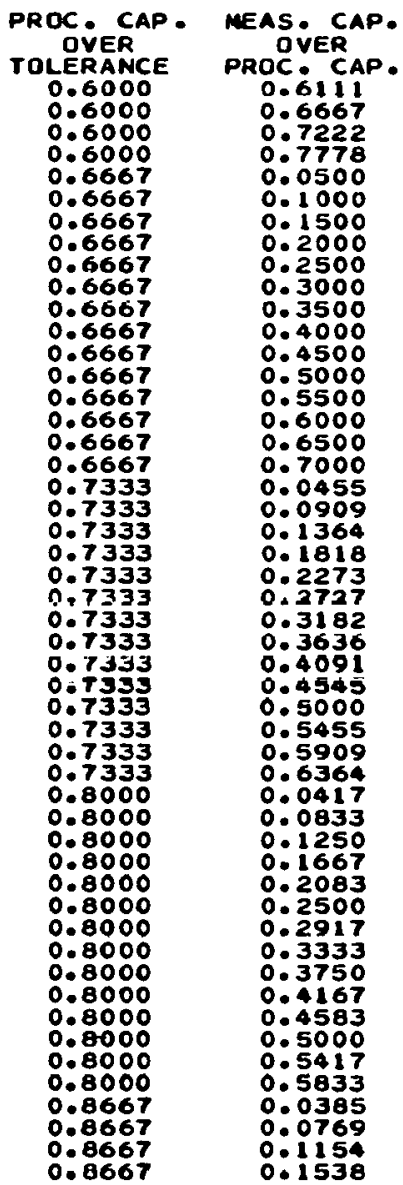

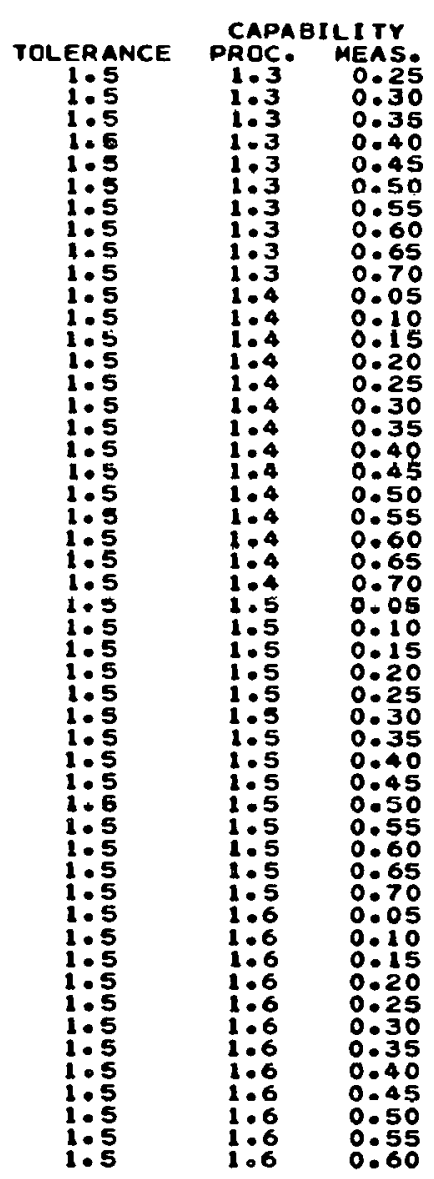

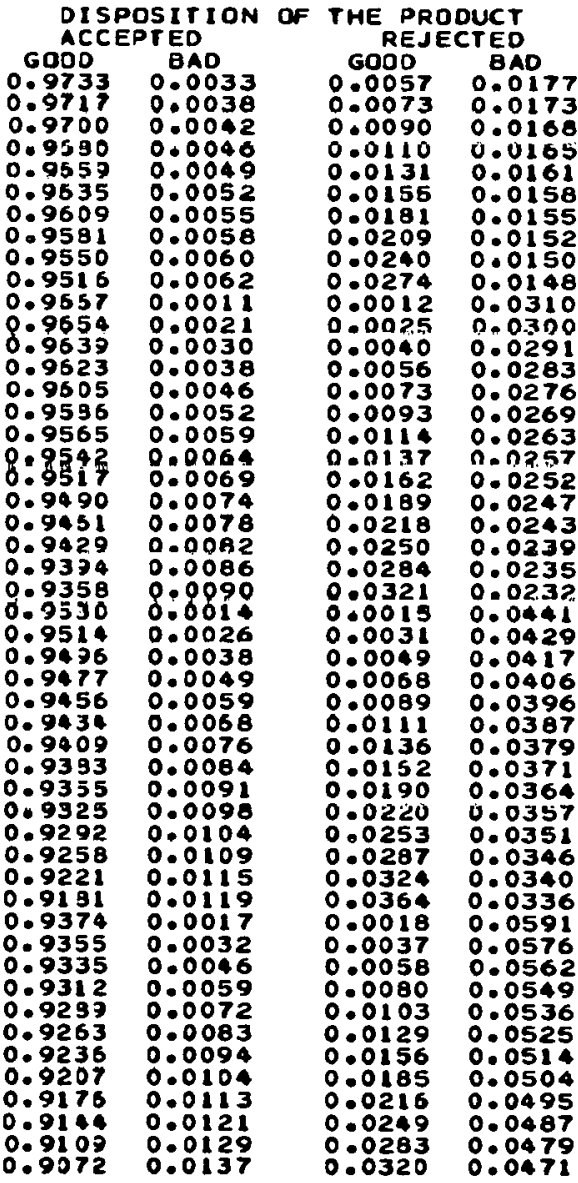

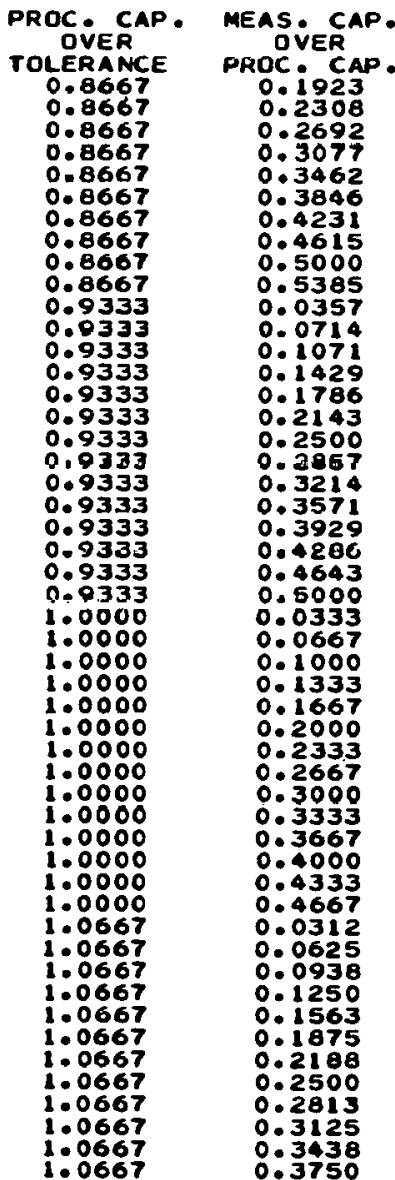




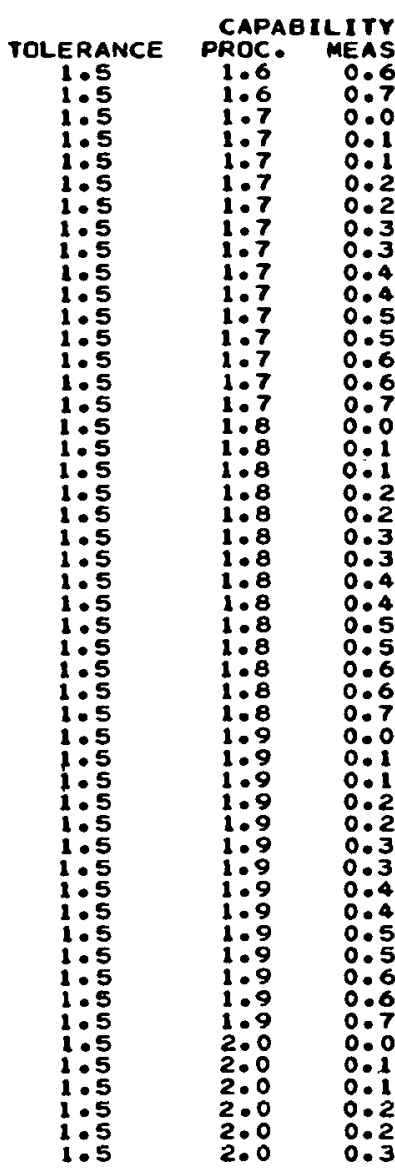

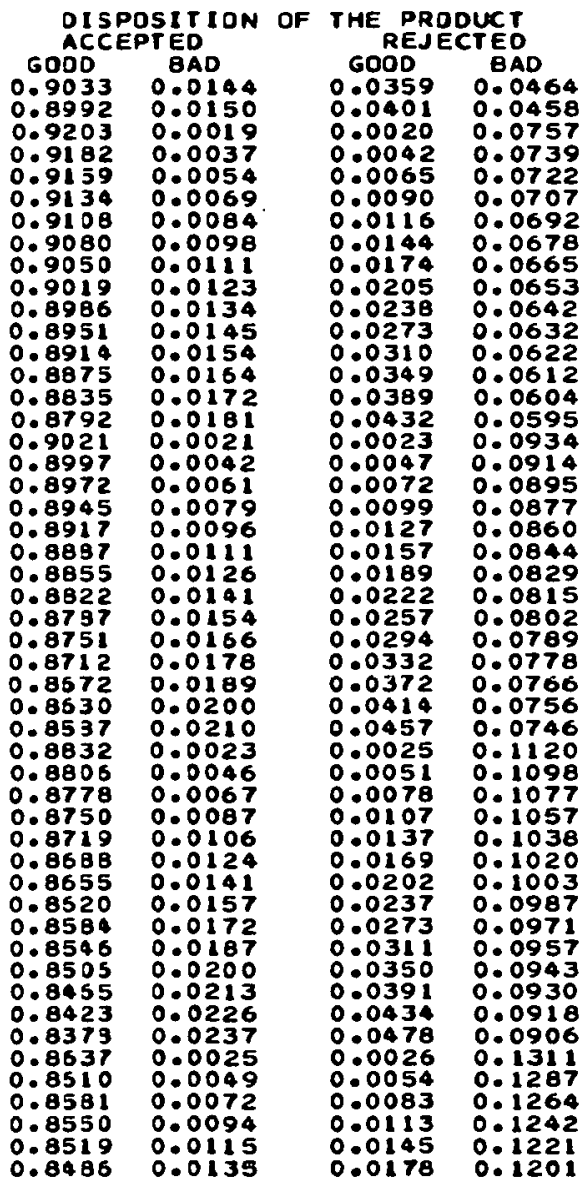

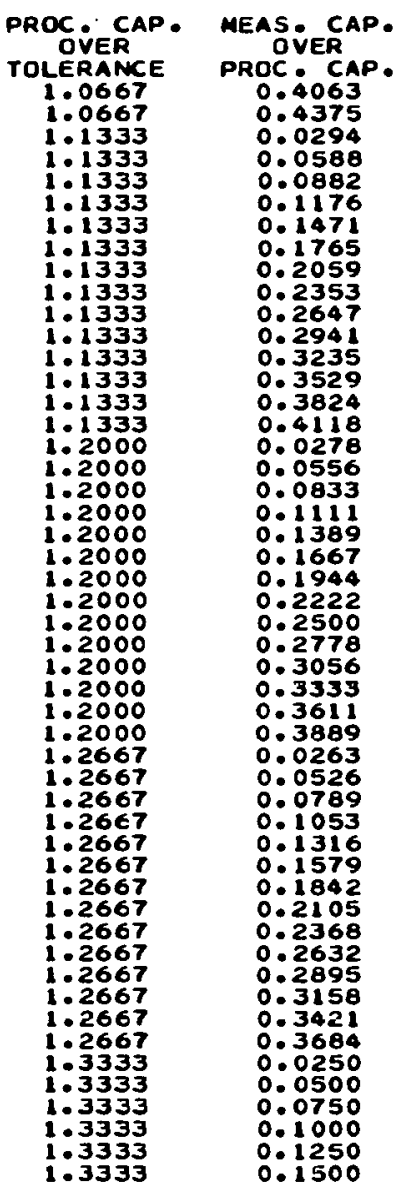

\begin{tabular}{ccc} 
& \multicolumn{2}{c}{ CAPABILITY } \\
TOLERANCE & $\begin{array}{c}\text { PROC. } \\
\text { MEAS. } \\
1.5\end{array}$ & MEA \\
$1: 5$ & $2: 0$ & 0.35 \\
$1: 5$ & $2: 0$ & 0.40 \\
$1: 5$ & $2: 0$ & $0: 45$ \\
$1: 5$ & $2: 0$ & $0: 50$ \\
$1: 5$ & $2: 0$ & 0.55 \\
$1: 5$ & $2: 0$ & $0: 60$ \\
$1: 5$ & $2: 0$ & 0.65 \\
$1: 5$ & 2.0 & 0.70
\end{tabular}

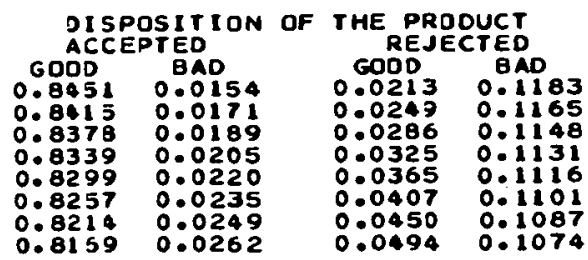

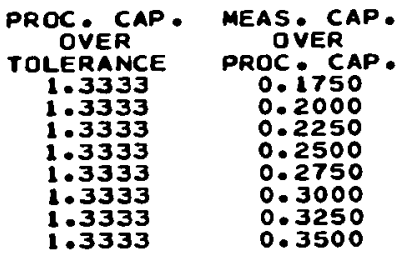




\section{ACKNOWLEDGEMENTS}

The study was motivated by discussions with T. W. Robinson who helped in the structure and formulation of the problem. R. C. Meacham wrote the computer programs that generated the tables and graphs. 


\section{Distribution}

Energy Research and Development Administration - Oak Ridge

Hickman, H. D.

Leed, R. E.

Zachry, D. S.,Jr

\section{Lawrence Livermore Laboratory}

Cervelli, J.

Nelms, W. S.

Los Alamos Scientific Laboratory

Aragon, J.

Gauler, R. S.

Sandford, T. A.

Waugh, H. G.

Wechsler, J. J.

Oak Ridge Gaseous Diffusion Plant

Levin, R. W.

Wilcox, W. J., Jr

Oak Ridge National Laboratory

Gardiner, D. A.

Lever, W. E. (3)

Oak Ridge Y-12 Plant

Bernander, N. K.

Bostock, D. J.

Briscoe, O.W.

Davis, R. L.

Fraser, R. J.

Holland, C. W.

Jackson, V. C.

Kahl, K. G.

Keith, A.

Kite, H. T. (25)

Leete, R. S., Jr (3)

Long, P. J.

Martin, W. R./Googin, J. M.
McConnell, O. K., Jr

Pearson, K. O.

Perry, A. E.

Phillips, L. R.

Robinson, T. W. (6)

Rose, R. P.

Schwartz, H. S.

Smith, H. F., Jr

Smith, R. D.

Thompson, W. H., Jr

Tilson, F. V.

White, J. C.

Whitten, L. G., Jr

Williams, R. D.

$Y$-12 Central Files (master copy)

$Y-12$ Central Files (route copy)

$Y-12$ Central Files ( $Y-12 R C$ )

$Y-12$ Central Files (5)

Paducah Gaseous Diffusion Plant

Millican, R. M.

\section{Sandia - Livermore}

Bohrer, D. J.

Madsen, V.P.

Vieira, J. R.

In addition, this report is distributed in accordance with the category UC-32, Mathematics and Computers, as given in the USERDA Standard Distribution Lists for Unclassified Scientific and Technical Reports, TID.4500. 